\title{
Identification of Conserved Protein Kinase CK2 and 14-3-3 Target Sites In Neurogenic Transcriptional Regulators
}

\author{
Lucas Matthew Jozwick
}

Follow this and additional works at: https://researchrepository.wvu.edu/etd

\section{Recommended Citation \\ Jozwick, Lucas Matthew, "Identification of Conserved Protein Kinase CK2 and 14-3-3 Target Sites In Neurogenic Transcriptional Regulators" (2013). Graduate Theses, Dissertations, and Problem Reports. 7318. \\ https://researchrepository.wvu.edu/etd/7318}

This Thesis is protected by copyright and/or related rights. It has been brought to you by the The Research Repository @WVU with permission from the rights-holder(s). You are free to use this Thesis in any way that is permitted by the copyright and related rights legislation that applies to your use. For other uses you must obtain permission from the rights-holder(s) directly, unless additional rights are indicated by a Creative Commons license in the record and/ or on the work itself. This Thesis has been accepted for inclusion in WVU Graduate Theses, Dissertations, and Problem Reports collection by an authorized administrator of The Research Repository @ WVU. For more information, please contact researchrepository@mail.wvu.edu. 
Identification of Conserved Protein Kinase CK2 and 14-3-3 Target Sites In Neurogenic Transcriptional Regulators

\title{
Lucas Matthew Jozwick
}

\author{
Thesis submitted \\ to the Eberly College of Arts and Sciences \\ at West Virginia University \\ in partial fulfillment of the requirements for the degree of \\ Master of Science in \\ Biology
}

\author{
Ashok P. Bidwai, Ph. D., Chair \\ Clifton P. Bishop, Ph. D. \\ Philip E. Keeting, Ph. D. \\ Department of Biology
}

\section{Morgantown, West Virginia \\ 2013}

Keywords: protein kinase CK2, 14-3-3, Sine Oculis, Extramacrochaetae, E(spl), Enhancer of Split, Drosophila eye, neurogenesis

Copyright 2013 Lucas Matthew Jozwick 


\begin{abstract}
All rights reserved
INFORMATION TO ALL USERS

The quality of this reproduction is dependent upon the quality of the copy submitted.

In the unlikely event that the author did not send a complete manuscript and there are missing pages, these will be noted. Also, if material had to be removed, a note will indicate the deletion.
\end{abstract}

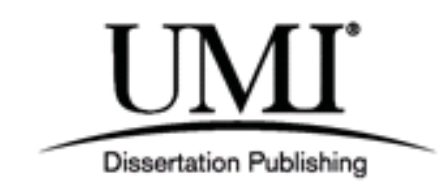

UMI 1549756

Published by ProQuest LLC (2013). Copyright in the Dissertation held by the Author.

Microform Edition (c) ProQuest LLC.

All rights reserved. This work is protected against unauthorized copying under Title 17, United States Code

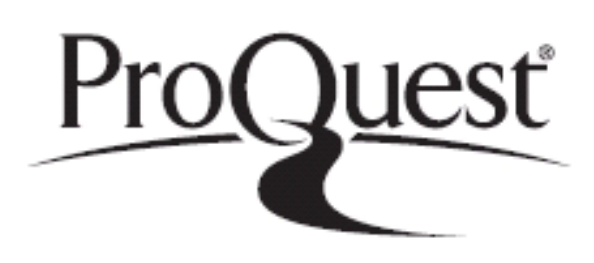

ProQuest LLC.

789 East Eisenhower Parkway

P.O. Box 1346

Ann Arbor, MI 48106 - 1346 


\section{ABSTRACT \\ Identification of Conserved Protein Kinase CK2 and 14-3-3 Target Sites In Neurogenic Transcriptional Regulators}

\section{Lucas Matthew Jozwick}

In the decades following the identification of CK2 as the first 'phosphotransferase', a great deal has been learned regarding its biological importance. In one developmental context, CK2 regulates cell fate decisions during Drosophila neurogenesis by activating the $\mathrm{E}(\mathrm{spl}) \mathrm{M} 8$ repressor, a terminal effector of the Notch pathway. The finding that CK2 is intimately involved in retinal cell determination propelled a search for additional neurogenic factors regulated by CK2. Here, using bioinformatics and biochemical assays, the transcription factors $\mathrm{E}(\mathrm{spl}) \mathrm{My}$, Extramacrochaetae, and Sine Oculis were identified and characterized as targets of CK2. Significantly, each of these factors is expressed at distinct time points of eye development and thereby adds to the participation of CK2 in neurogenesis. Furthermore, E(spl)M8, -M5, and -M7 phosphorylation studies revealed that specific residues in the C-terminal domain regulate these repressors. However, the sequence motifs present in the aforementioned are variable and not present in all $\mathrm{E}(\mathrm{spl})$ members, raising the possibility of divergent regulation. Interestingly, previous experiments suggested that the cofactor 14-3-3 formed complexes with most $\mathrm{E}(\mathrm{spl})$ proteins. Bioinformatics and genetic analyses revealed a conserved 14-3-3 interaction motif in $\mathrm{E}(\mathrm{spl}) \mathrm{M} \delta$ and its mammalian homologs HES1 and HES4. These findings demonstrate a functional diversification among $\mathrm{E}(\mathrm{spl})$ repressors through disparate kinases and protein cofactors. 


\section{Table of Contents}

$\begin{array}{ll}\text { ABSTRACT } & 2\end{array}$

\begin{tabular}{lr} 
CHAPTER 1 & $\mathbf{7}$ \\
\hline
\end{tabular}

PREFACE

BIOCHEMISTRY OF PROTEIN KINASE CK2 10

BIOLOGY OF CK2 12

Signalling THROUGH THE NOTCH RECEPTOR

Notch Signaling and Activation of Enhancer of Split Complex Genes 16

$\begin{array}{lr}\text { The ENHANCER OF SPLIT COMPLEX } & 17\end{array}$

REPRESSION BY ENHANCER OF SPLIT $\quad 20$

MAKING A DROSOPHILA EYE

Retinal Determination Factor Sine Oculis

MAKING THE MACROCHAETAE $\quad 27$

EXTRAMACROCHAETAE REGULATES bHLH ACTIVITY 28

THE 14-3-3 FAMILY OF PROTEINS

GSK3 AND NeUROnal DeVelopment

$\begin{array}{lr}\text { CONCLUSION } & 34\end{array}$

CHAPTER 2: IDENTIFICATION AND CHARACTERIZATION OF E(SPL)MY, EXTRAMACROCHAETAE AND SINE OCULIS AS TARGETS FOR CK2

ABSTRACT

INTRODUCTION $\quad 45$

MATERIALS AND METHODS

IDENTIFICATION OF CONSERVED CK2 SITES 48

ISOLATION OF THE E(SPL)MY OPEN READING FRAME $\quad 48$

MUTAGENESIS OF E(SPL)MY CK2 SITES $\quad 49$

PURIFICATION OF GST-FUSION PROTEINS $\quad 49$

PURIFICATION OF MBP-SINE OCULIS $\quad 50$

PROTEIN KINASE CK2 PHOSPHORYLATION ASSAY

STRUCTURAL PREDICTION OF SINE OCULIS

RESULTS AND DISCUSSION

E(SPL)MГ

EXTRAMACROCHAETAE

SINE OCULIS $\quad 59$

SIGNIFICANCE $\quad 64$

CK2 AND THE REGULATION OF E(SPL)MY $\quad 64$

CK2 AND THE REGULATION OF EXTRAMACROCHAETAE $\quad 65$

CK2 AND THE REGULATION OF SINE OCULIS $\quad 67$

CHAPTER 3: IDENTIFICATION AND GENETIC ANALYSIS OF 14-3-3 AS A REGULATOR OF E(SPL)MO ACTIVITY $\quad 82$

$\begin{array}{ll}\text { ABSTRACT } & 83\end{array}$

$\begin{array}{lr}\text { INTRODUCTION } & 84\end{array}$ 
MATERIALS AND METHODS

IDENTIFICATION OF 14-3-3 BINDING SITES

GENETIC ANALYSIS OF E(SPL)Mס

RESULTS ANDDISCUSSION

87

14-3-3 BINDING MOTIFS IN E(SPL)M8 AND E(SPL)MY

14-3-3 BINDING MOTIF IN E(SPL)M

88

14-3-3 BINDING MOTIFS IN HES1 AND HES4

14-3-3 AND THE E(SPL)M $\delta$ ENHANCEMENT OF $\mathrm{N}^{\text {SPL }}$ 


\section{List of Figures}

\begin{tabular}{|c|c|}
\hline \multirow{2}{*}{\multicolumn{2}{|c|}{$\begin{array}{l}\text { Figures } \\
\text { Chapter1 }\end{array}$}} \\
\hline & \\
\hline Fig. 1. Structure and substrate specificity of protein kinase CK2 & 36 \\
\hline Fig. 2. Notch mediated lateral inhibition during SOP selection & 37 \\
\hline Fig. 3. Structure of the $\mathrm{E}(\mathrm{spl})$ repressors & 38 \\
\hline $\begin{array}{l}\text { Fig. 4. Patterning and specification of the R8 photoreceptor in the } \\
\text { morphogenetic furrow }\end{array}$ & 39 \\
\hline Fig. 5. Sine Oculis and the retinal determination network & 40 \\
\hline Fig. 6. Notch mediated bristle SOP selection and fate specification & 41 \\
\hline Fig. 7. Regulation by $14-3-3$ cofactor binding & 42 \\
\hline Chapter 2 & \\
\hline Fig. 1. Computational identification of $\mathrm{E}(\mathrm{spl}) \mathrm{My}$ as a potential target of $\mathrm{CK} 2$ & 69 \\
\hline Fig. 2. Phosphorylation of E(spl)My by CK2 & 70 \\
\hline Fig. 3. Map the CK2 site(s) in E(spl)My & 71 \\
\hline Fig. 4. Modulate CK2 targeting of $\mathrm{E}(\mathrm{spl}) \mathrm{My}$ & 72 \\
\hline Fig. 5. Computational identification of EMC as a potential target for CK2 & 73 \\
\hline Fig. 6. Phosphorylation of EMC by CK2 & 74 \\
\hline Fig. 7. Map the CK2 site(s) in EMC & 75 \\
\hline Fig. 8. Modulate CK2 targeting of EMC & 76 \\
\hline Fig. 9. Computational identification and conservation CK2 of site(s) in SO & 77 \\
\hline Fig. 10. Phosphorylation of SO by CK2 & 78 \\
\hline Fig. 11. Map the CK2 site(s) in SO & 79 \\
\hline Fig. 12. Modulate CK2 targeting of SO & 80 \\
\hline Fig. 13. Structural insights into CK2 regulation of SO & 81 \\
\hline
\end{tabular}




\begin{tabular}{|l|c|}
\hline Chapter 3 & \\
\hline Fig. 1. 14-3-3 binding motifs in E(spl)M8 and E(spl)My & 93 \\
\hline $\begin{array}{l}\text { Fig. 2. Identification and conservation of a 14-3-3 binding site in E(spl)M } \delta \text { and } \\
\text { its homologs }\end{array}$ & 94 \\
\hline Fig. 3. Loss of 14-3-3 enhances E(spl)Mס repressor activity & 95 \\
\hline
\end{tabular}


CHAPTER 1

INTRODUCTION 


\section{PREFACE}

The development of metazoan organisms from a single cell is dependent upon precisely orchestrated genetic and biochemical programs. Most important among the processes involved in animal development are short range and long range signaling cues. These messages are conveyed in the form of small molecules, proteins or peptides and received through surface receptors on target cells or tissues. Remarkably, the diversity of cells in a developing organism are brought about by the integration of a modest collection of extracellular biochemical inputs that profoundly alter gene expression in the target cells (Mayya et al., 2009). Therefore, the position of a cell and the specific signals that are received by it result in diverse outcomes such as growth, migration, differentiation, or cell death.

The Notch pathway is among the small number of communication mechanisms involved in organismal development (Aitken, 1995; Yaffe et al., 1997; Bray, 1998; Gridley, 2003; Voas and Rebay, 2004; Bray, 2006; Artavanis-Tsakonas and Muskavitch, 2010; Bray and Bernard, 2010). The Notch receptor responds to its ligands on adjacent cells to mediate communication that is critical for juxtacrine signaling. Mechanistically, Notch receptor activation elicits expression of transcriptional repressors encoded by the Enhancer of Split Complex $(E(s p l) C)$, which affect fate specification in a cell autonomous manner, and are terminal effectors of this pathway (Knust et al., 1987; Preiss et al., 1988; Klambt et al., 1989; Delidakis and Artavanis-Tsakonas, 1991; Knust et al., 1992; Schrons et al., 1992). In this system, the signal sending and receiving cells take up divergent differentiated states, a process called 'binary cell fate determination'. This role in binary cell fate determination was first identified in neurogenesis. Since 
then, it has been found to operate in a remarkably similar manner in myogenesis, oogenesis, and somitogenesis and has served as a foundation to our understanding of mammalian Notch signaling (Louvi and Artavanis-Tsakonas, 2006). As the binary outcomes driven by Notch signaling hinge upon the activity of the $E(s p l)$ repressors, understanding regulation of these proteins through post-translational modifications is of paramount importance.

The original conception of the $E(s p l) C$ was that the seven bHLH repressors encoded by this locus were redundant and that differences in function were solely dependent upon variation in expression pattern (Cooper et al., 2000). This idea was drawn out of the observations, that the individual repressors were very similar in sequence except within an unstructured stretch of amino acids near the C-terminus, and because ectopic expression of individual $\mathrm{E}(\mathrm{spl})$ repressors led to generalized loss of mechanosensory bristles. However, no effects on eye development were induced, an unexpected finding because the onset of retinal neurogenesis is also under the control of $\mathrm{E}(\mathrm{spl})$ proteins (Nagel and Preiss, 1999; Nagel et al., 1999). Therefore, this region was concluded to be of little importance except for the invariant C-terminal WRPW motif that is essential for recruitment of the obligate corepressor, Groucho (Paroush et al., 1994). Later, this paradigm was challenged by a demonstration that specific modification by protein kinase CK2 alters repressor activity (Trott et al., 2001b). This highlights the yet to be illuminated diversity of regulatory consequences mediated by the C-terminal sequences.

Years of research have demonstrated that the Notch pathway is critical for proper development. However, the regulatory features of the seven $\mathrm{E}(\mathrm{spl})$ repressors in the 
diversification of Notch activity remain a poorly understood mechanism. Furthermore, the role of protein kinase CK2 in metazoan development and in the regulation of transcription factors involved in neurogenesis is incomplete. Therefore, this and subsequent chapters address structural features that mediate regulation of Enhancer of Split Complex repressors and the role of CK2 in regulating disparate stages of neuronal determination.

\section{Biochemistry of Protein Kinase CK2}

The serine/threonine protein kinase CK2 was originally identified in rat liver extracts as an enzyme that catalyzes the addition of phosphates to the protein casein (Burnett and Kennedy, 1954). CK2 is ubiquitously expressed in eukaryotic cells and targets hundreds of cellular proteins (reviewed in (Meggio and Pinna, 2003)). In all organisms studied to date, this protein kinase is a hetero-tetramer (Fig. 1), a composite of two $\alpha$-subunits, which bind to a dimer of $\beta$-subunits (Glover et al., 1983; Dahmus et al., 1984; Padmanabha and Glover, 1987; Bidwai et al., 1994; Niefind et al., 2001). The a-subunit harbors catalytic phosphotransferase activity, and it can utilize either ATP or GTP as a substrate (Hathaway and Traugh, 1979; Glover et al., 1983). The activity of CK2 $\alpha$ is stimulated by the regulatory $\beta$-subunit, which modulates substrate recognition and may provide stability to the $\alpha \beta \beta \alpha$ holoenzyme (HoloE, (Cochet and Chambaz, 1983)). Antibodies specific for the mammalian CK2 demonstrate cross reactivity with homologous proteins from Drosophila (Dahmus et al., 1984), the first line of evidence for strong conservation. In parallel, the CK2 $\alpha$ subunit from Drosophila, humans, and nematodes can functionally substitute for the yeast kinase and temperature sensitive phenotypes associated with the $\alpha$-subunit are suppressed by concomitant expression of 
human CK2 $\beta$ (Padmanabha et al., 1990; Bidwai et al., 1992; Dotan et al., 2001). These observations, along with extensive sequence identity among homologs, reveal that the subunits are evolutionarily conserved in both structure and function (Glover et al., 1994).

CK2 is distinguished from other protein kinases because it does not respond to second messengers and preferentially targets acidic substrates. Regarding the latter, the consensus sequence for CK2 has been identified as S/T-D/E-x-D/E (Fig. 1) where ' $x$ ' is neither of the basic amino acids lysine or arginine (Kuenzel and Krebs, 1985; Kuenzel et al., 1987). Additional acidic residues in proximity to the target serine/threonine further enhance CK2 activity toward target proteins. Given the hydrophilic nature of these acidic microdomains, it is likely that the region is solvent and surface accessible, which makes site identification more facile. Moreover, processive phosphorylation by CK2 is potentiated because phosphorylated residues can replace the requirement for acidic residues in the consensus. Therefore, if a CK2 consensus (for example SSSESE) is phosphorylated (SSSEpSE), it generates a series of hierarchical sites (SSSEpSE) (Fig. 1) that expands the acidity and charge of the region dramatically. This hierarchical phosphorylation can also involve other protein kinases, such as the coordinated regulation of protein phosphatase by GSK3 and CK2 (DePaoliRoach, 1984; Roach, 1991). One of the most dramatic examples is Nopp140, a nuclear cytoplasmic shuttle, which is phosphorylated in a hierarchical manner by CK2 at 82 sites (Meier and Blobel, 1992). 


\section{Biology of CK2}

In the years following the description of protein kinase CK2, a number of substrates have been identified. In a review by Meggio and Pinna (2003) some 307 targets are compiled and subdivided into groups. Examples of classified targets range from transcription factors and signaling molecules to metabolic enzymes and viral proteins (Meggio and Pinna, 2003). While the list of substrates is lengthy and diverse, perhaps the most important physiological roles for CK2 lie in cell cycle control, signaling and transcription factor regulation (Glover, 1998).

The role of CK2 in the cell cycle was first revealed by studies in the budding yeast Saccharomyces cerevisiae. In these cells, a complete loss of the two CK2 $\alpha$ subunits (CKA1 and CKA2) leads to cell death (Padmanabha et al., 1990), while a depletion of kinase levels results in cell cycle arrest as budded or unbudded cells as well as an elongated phenotype (Hanna et al., 1995; Rethinaswamy et al., 1998). These results have been recapitulated in the fission yeast, Schizosaccharomyces pombe (Snell and Nurse, 1994). Interestingly, loss of CK2 $\beta$ results in no overt phenotype, but combinatorial deletion of $\alpha$ and $\beta$ genes exhibits a slow growth phenotype, suggesting that CK2 is required for cell proliferation. Studies in Drosophila have revealed that CK2 is required for embryogenesis, cell fate specification (Jaffe et al., 1997; Karandikar et al., 2004; Bose et al., 2006), and the circadian clock (Lin et al., 2002; Akten et al., 2003). These findings correlate with mammalian model systems where CK2 is required for cell proliferation in the mouse (Buchou et al., 2003; Dominguez et al., 2011), survival in human cancer cell lines (Faust et al., 2000) and proper formation of developing structures during mouse embryogenesis (Lou et al., 
2008). However, knockouts of CK2 $\beta$ in the mouse model result in loss of proliferation, increased cell death, and embryonic lethality (Buchou et al., 2003).

In congruence with the observed phenotypes of cell survival and proliferation is CK2's targeting of tumor suppressors. The phosphatase PTEN, which influences cell migration, growth, and survival, is C-terminally phosphorylated by $\mathrm{CK} 2$, resulting in proteasomal degradation (Torres and Pulido, 2001). CK2 also regulates the levels of PML a key regulator of growth, apoptosis and cell division (Scaglioni et al., 2006). As a final example, DNA binding of p53 is promoted by CK2 phosphorylation (Blaydes and Hupp, 1998), though there is some disagreement regarding the phosphorylating kinase (Cox and Meek, 2010; Meek and Cox, 2011). These mechanisms are of note because of their significance in the regulation cellular events, but CK2 is also involved at multiple levels in signaling pathways, and these pathways participate in multiple biological outcomes.

As development is a synchronization of biochemical and genetic events, the role CK2 plays in signaling systems is of great importance. As an example, the kinase participates in the Wnt signaling pathway by phosphorylating $\beta$-catenin thereby potentiating its transcriptional activity through stabilization (Song et al., 2003); additionally, CK2 targeting of PKB/AKT maximizes that kinases activity with respect to $\beta$-catenin leading to upregulation of transcriptional output (Ponce et al., 2011). CK2 is also a critical component of the JAK/STAT pathway, where targeting of JAK2 prevents autophosphorylation and signal transduction (Zheng et al., 2011). Another role for CK2, and of particular relevance in this review and discussed in detail elsewhere, is in the Notch signaling pathway. One of the primary effectors of Notch signal transduction, 
$\mathrm{E}(\mathrm{spl}) \mathrm{M} 8$ in Drosophila or HES6 in humans, harbors a CK2 site that is critical for its repressor function (Gratton et al., 2003; Karandikar et al., 2004). Furthermore, CK2 also targets TLE1, the obligate corepressor of fly E(spl) and homologous mammalian HES proteins, thereby allowing its corepressor function to be activated during neurogenesis (Nuthall et al., 2004).

In addition to serving primary roles in various stages of signal transduction, CK2 also regulates transcription factors involved in the early stages of body plan establishment. For example, modification of the HOX transcription factor Antennapedia reduces its activity and inhibits cooperative DNA binding with the homeodomain Extradenticle (Jaffe et al., 1997). As an additional example, CK2 allows appendage formation by inactivating Ultrabithorax through phosphorylation of residues C-terminal to the homeodomain (Taghli-Lamallem et al., 2008).

Other aspects of CK2 regulation include modulation of cell structure and morphology as mediated by actin filament and microtubule assembly (Canton and Litchfield, 2006), phosphorylation of core (basal) components during gene transcription (Bierhoff et al., 2008), and protein folding mediated by Hsp90 (Miyata, 2009). It is the intimate association of $\mathrm{CK} 2$ with core cellular functions during gene expression, protein folding, growth, proliferation, survival, signaling, and development that make it an interesting topic of research. Also, many of the pathways in which CK2 is involved contribute to genetic disorders and neoplasia. These facts demonstrate that an understanding of CK2 and the consequences of its targeted phosphorylation are of key importance in understanding a variety of biological occurrences and disease states. 


\section{Signaling through the Notch receptor}

The 'notched' wing phenotype first observed by John S. Dexter led to the description of X-linked mutants of the Notch gene by T. H. Morgan (Morgan, 1916). Though the inheritance pattern of the Notch allele was clearly defined therein, a full investigation into the functional nature of the pathway would not be undertaken for nearly a quarter century. Studies by David Poulson demonstrated a lack of segmentation and improper germ layer formation in Notch mutants (Poulson, 1937). Furthermore, he suggested that there was an interdependence of neural hyperplasia and epidermal hypoplasia in Notch deficient organisms (Poulson, 1940). This was the first indication that Notch was involved in the selective determination between the neural and epidermal fates.

Owing to its role in binary cell fate determination, it comes as no surprise that the Notch pathway has ancient origins and is highly conserved in vertebrates and invertebrates. Homologs of Notch have been identified in Caenorhabditis elegans, Xenopus laevis, and four distinct homologs exist in mammals (Greenwald et al., 1983; Coffman et al., 1990; Uyttendaele et al., 1996). Additionally, extensive study of the Notch pathway has revealed many of its roles throughout development and in the adult organism. These include boundary formation, proliferation, apoptosis and stem cell maintenance. Specific outcomes mediated by Notch are always achieved through juxtacrine signaling cues that require close apposition of the signaling and responding cells, although this can occur across several cells through filopodia (Cohen et al., 2010; Milan and Cohen, 2010). Since Poulson's pioneering work, binary cell fate decisions influenced by Notch have been studied in astonishing detail during the patterning of the 
Drosophila retina and the mechano-sensory bristles. This process, termed lateral inhibition (Simpson et al., 1999; Simpson and Marcellini, 2006), occurs during neurogenesis to properly pattern neurons by progressively restricting neuronal-potential from a group of equipotent cells (reviewed in (Greenwald and Rubin, 1992). While lateral inhibition is the canonically cited function of Notch, it can induce changes in cell fates among independent cell types and it is also involved in asymmetric cell divisions (reviewed in (Lai, 2004)). Examples of these signaling strategies in Drosophila include boundary formation in the wing and cell divisions of neuroblasts in the developing bristle, respectively.

As described, research has clearly defined the Notch signaling pathway as one that influences diverse signaling outcomes in a variety of contexts. Its misregulation underlies a number of congenital and adult disease states in humans. Examples include heart valve defects (Garside et al., 2013), Allagile syndrome characterized by organ and skeletal abnormalities (McCright et al., 2002), the hematopoietic malignancy multiple myeloma (Colombo et al., 2013), the skeletal abnormality spondylocostal dysostosis (Sparrow et al., 2010), and neurodegenerative diseases such as Batten syndrome (Tuxworth et al., 2009). Additionally, the Notch pathway is of clinical interest for developing effective tissue transplantation strategies that mitigate host rejection (Tran et al., 2013). Because of its association with congenital defects, cancer etiology and clinical advancement, Notch is a prime candidate for continued investigation.

\section{Notch Signaling and Activation of Enhancer of Split Complex Genes}

Activation of the Notch signaling pathway is stimulated by the presence of transmembrane ligands on adjacent cells. In Drosophila these ligands are called $\Delta$ (DI) 
and Serrate (Ser) (Rebay et al., 1991). Receptor-ligand interaction results in exposure of an ADAM family metalloproteinase site on the extracellular side of the membrane, which is otherwise inaccessible (Mumm and Kopan, 2000) (Fig. 2). Subsequently, the exposed site is cleaved by Kuzbanian (Pan and Rubin, 1997). Ligand binding and proteolytic cleavage of the extracellular target site represents the critical regulated steps for signal transduction. However, further proteolytic cleavage by the presenilin $\mathrm{Y}^{-}$ secretase at sites within the transmembrane region is required to release the Notch intracellular $\left(\mathrm{N}^{\text {icd }}\right)$ domain and allow its translocation to the nucleus where it affects gene transcription (Schroeter et al., 1998; Okochi et al., 2002) (Fig. 2).

In the nucleus, the regulatory regions of the Enhancer of Split Complex $(E(s p l) C)$ genes are held in an inactive state (repressed) by Suppressor of Hairless $(\mathrm{Su}(\mathrm{H}))$ and a co-repressor complex comprised of Hairless $(\mathrm{H})$, C-terminal binding protein (CtBP), and Groucho (Gro) (Bailey and Posakony, 1995; Barolo et al., 2002). Following the proteolytic processing of Notch, the $\mathrm{N}^{\text {icd }}$ enters the nucleus mediated by its nuclear localization sequence (NLS) (Lieber et al., 1993). There, it transforms Su(H) into an activation complex by recruiting Mastermind (Mam), leading to transcriptional output from the previously repressed genes, particularly $E(s p l) C$ (Petcherski and Kimble, 2000) (Fig. 2).

\section{The Enhancer of Split Complex}

The etymology of this complex is derived from an enhancement of the split ( $s p /$ ) allele of the Notch receptor by the mutant 'Enhancer of split Dominant' $\left(E(s p l) D\right.$ or $\left.m 8^{*}\right)$, which results in near complete ablation of neural cell specification in the Drosophila eye (Welshons, 1965). Later, eight related transcriptional units were identified in the 
genomic locus mapping near $E(s p l) D$ on the $3^{\text {rd }}$ chromosome (Fig. 3). Seven of these encode highly conserved basic-helix-loop-helix $(\mathrm{bHLH})$ transcription factors $(E(s p l)-m 3$, $-m 5,-m 7, m 8,-m \beta,-m \delta,-m \gamma$ ) and the non-bHLH co-repressor groucho (gro) (Delidakis et al., 1991; Knust et al., 1992).

The seven $\mathrm{E}(\mathrm{spl})$ proteins share well conserved domains each with specific biochemical functions (Fig. 3). Nearest the N-terminus, the basic and HLH confer DNA binding and the capacity for dimerization among $\mathrm{E}(\mathrm{spl})$ members, respectively. The bHLH is followed by the Orange domain, another HLH necessary for complex formation with target proteins (see below). Finally, the extreme C-terminus harbors the invariant WRPW motif, which is required for interaction with Gro. Interestingly, while differences in primary sequence exist in each of the aforementioned domains (except WRPW), there is a region of hypervariablility that occurs in the intervening region between the end of the Orange domain and the WRPW motif. This region is called the C-terminal domain (CtD).

Early assessment of the $E(s p l) C$ suggested that the encoded proteins were functionally redundant. This was based primarily on the observation that only extensive deletions of the complex generated neurogenic phenotypes, while point mutations alone were insufficient (Preiss et al., 1988; Ziemer et al., 1988). The structural similarities among the proteins have unfortunately led to broadly held conceptual bias that $E(s p l)$ repressors are redundant for neural repression. However, this argument was substantially weakened by the conservation of particular motifs within the CtDs of E(spl)-M5, M7 and M8 (Maier et al., 1993). Moreover, molecular synteny of the locus between Drosophila melanogaster and Drosophila hydei, two species separated by 
some 60 million years of evolution, suggests that there are important functions mediated by the individual genes (Maier et al., 1993), and that the notion of redundancy is an erroneous oversimplification.

Later explanations of apparent redundant activity assumed that differential patterns of expression were dependent upon spatially restricted factors and that this served as the sole regulatory mechanism controlling $\mathrm{E}(\mathrm{spl})$ function (Cooper et al., 2000). This idea is supported by studies that find cell specific expression to be the product of the number and orientation of Suppressor of Hairless $(\mathrm{Su}(\mathrm{H}))$ binding sites (Cave et al., 2005). Furthermore, there is significant variability in $\mathrm{Su}(\mathrm{H})$ binding site occupancy among $E(s p l)$ enhancers (Krejci and Bray, 2007) and levels of transcriptional responses vary amongst $E(s p l)$ genes following activation of Notch (Housden et al., 2013). However, this is an apparent oversimplification of the regulatory mechanisms that impinge upon these transcription factors.

Research over the past decade has revealed post-translational mechanisms that alter the activity of $\mathrm{E}(\mathrm{spl})$ proteins. Specifically, $\mathrm{E}(\mathrm{spl})-\mathrm{M} 5,-\mathrm{M} 7$ and $-\mathrm{M} 8$ are phosphorylated in a shared sequence motif of the CtD by protein kinase CK2 (Trott et al., 2001a). This modification has since been shown to be of significant regulatory consequence to the repressive functions intrinsic to $E(s p l)$ proteins. In particular, $E(s p l)-$ M8 has served as the target of research that has revealed the necessity of posttranslational regulation in neural repression. 


\section{Repression by Enhancer of Split}

Because the DNA binding motifs of $\mathrm{E}(\mathrm{spl})$ proteins are conserved, it was initially proposed that enhancer binding was the primary means of transcriptional repression. This proposal was based on the observations that transcriptional output from reporters is dramatically reduced by E(spl)M7 (Van Doren et al., 1994), and that chimeras of $\mathrm{E}(\mathrm{spl}) \mathrm{M} 7$ with heterologous activation domains enhanced transcription in a DNA binding dependent manner (Jimenez and Ish-Horowicz, 1997). Additionally, the N-box binding consensus of $\mathrm{E}(\mathrm{spl})$ proteins is conserved in the $A S C$ enhancer whose activity is decreased by the presence of E(spl)M5 and E(spl)M8 (Oellers et al., 1994) and loss of DNA binding attenuates the phenotype associated with the dominant $E(s p /) D$ allele (Tietze et al., 1992). Contradictory studies indicated that neural suppression in the bristle was independent of the bHLH but depended only on a subset of helices within the repressor (Nakao and Campos-Ortega, 1996; Giebel and Campos-Ortega, 1997). The lack of bHLH requirement combined with the interaction affinity between proneural activators and $\mathrm{E}(\mathrm{spl})$ proteins led to the 'molecular tether model'. This model postulates that direct protein-protein complex formation between activators and repressors at the enhancer results in antagonism. Interaction is generally thought to be mediated by the Orange domain of all $\mathrm{E}(\mathrm{spl})$ repressors (Dawson et al., 1995). However, the means and the regulation of these seemingly simple binary interactions have proven to be more complex.

During bristle development, interaction of $\mathrm{E}(\mathrm{spl})$ proteins with Achaetae $(\mathrm{Ac})$ and Scute (Sc) occurs through the bHLH domains (Gigliani et al., 1996). However, during neurogenesis in the eye, the specific mechanism lacked clarity. It was apparent that 
$E(s p l)$ antagonized Atonal (Ato), the eye specific proneural activator, due to the severely reduced eye of the $E(s p l) D$ mutant (Nagel et al., 1999). Elucidation of the relevant mechanism was initiated with the finding that CK2 targets a conserved consensus motif in the CtD of $\mathrm{E}(\mathrm{spl}) \mathrm{M} 5, \mathrm{M} 7$ and M8 (Trott et al., 2001a). In vivo experiments demonstrated that phosphomimicry of CK2 sites potentiates interaction with Ato and that levels of interaction are similar to the truncated form of $\mathrm{E}(\mathrm{spl}) \mathrm{M} 8^{*}$, which lacks the CtD (Karandikar et al., 2004). As E(spl)M8, outside of a phosphorylated state, is unable to interact with Ato, an autoinhibitory model was proposed (Karandikar et al., 2004). Here, the unstructured CtD blocks the protein surface that would engage with Ato. Upon phosphorylation of $\mathrm{E}(\mathrm{spl}) \mathrm{M} 8$ by $\mathrm{CK} 2$, the autoinhibition is released and complex formation is allowed to occur, thereby inhibiting ato autoregulation. The structural model is supported by reversal of $\mathrm{E}(\mathrm{spl}) \mathrm{M} 8$ hypermorphic phenotypes by overexpression of the CtD segment (Kahali et al., 2010).

Thus, it appears that the CtD regulates formation of the $E(s p l) M 8 / A$ to complex. Interestingly, the CK2 target site lies in a serine rich region, raising the prospect of regulation through additional phosphorylation. Indeed, a number of phosphorylation consensus motifs exist in this region for other protein kinases, including MAPK (P-x-SP), CK1 (pS/T-x-x-S) and GSK3 (S/T-x-x-x-pS/T). Interestingly, a secondary phosphorylation mechanism has been described for the human and mouse HES6 homolog with respect to CK2 and MAPK (Belanger-Jasmin et al., 2007). This feature has garnered the region the description as a phosphorylation domain (P-domain).

These findings can be extrapolated to develop a deeper understanding of $E(s p l)$ repressor function and regulation. The conservation of the P-domain among Drosophila 
orthologs and its presence in paralogs suggests that this feature is of regulatory significance. Furthermore, the lack of this particular motif and variations in other homologs indicates that the large family of bHLH-Orange proteins that regulate diverse developmental programs employ distinct means to attain transcriptional repression. Therefore, divergence in post-translational regulation implies disparate function, which is specialized to the signaling systems active in a particular context. These ideas are a central to the thesis.

\section{Making a Drosophila Eye}

The Drosophila eye is composed of $750-800$ identical facets called ommatidia that are formed into a finely patterned hexagonal lattice (Fig. 4C). Each ommatidium is stereotypically composed of eight photoreceptors, called R1-8, four cone cells and pigment cells. Patterning of each ommatidium is dependent upon highly regulated selection of the 'founding R8'; so named because it recruits all other cells into each ommatidium. As any perturbation of retinal patterning is easily observable, the Drosophila eye has been used extensively to understand tissue development as it pertains to cell signaling and fate specification (Roignant and Treisman, 2009).

Body regions of the adult organism derive from individual compartments that arise during development called 'imaginal discs'. In the early embryo, approximately 20 cells are designated to form an epithelial monolayer of pluripotent cells of the 'eye imaginal disc' (Fig. 4A). Expression of 'retinal determination network' (RDN, Fig. 5) Pax genes such as twin of eyeless (toy), eyeless (ey), eyegone (eyg), and twin of eyegone (toe) marks the onset of retinal neurogenesis and is required for organ formation. These Pax genes then drive expression of other network members such as sine oculis 
(so) and eyes absent (eya) (Hirata et al.). SO and Eya form a bipartite transcription factor that regulates early steps in eye formation including morphogenetic furrow formation and movement (Pauli et al., 2005) and expression of the retinal neuron specific proneural gene ato, described below (Zhang et al., 2006) (Jarman et al., 1994; Jarman et al., 1995). Earlier studies implicated phosphorylation dependent regulation of Eya, but this appears to be an artifact ((Jusiak et al., 2012). In contrast, regulation of SO by post-translational modification has not been described and is the subject of studies in Chapter 2 (see below).

During the first and second larval stages, the eye imaginal disc grows in size, but cell fate specification (commitment and differentiation) does not commence until the third larval stage. The beginnings of neural specification in this tissue require the expression of ato, a bHLH transcriptional activator (Jarman et al., 1994). Initially, groups of equipotent cells, the 'proneural clusters' (PNC), have comparable ato activity. However, only a single cell from each PNC is allowed to maintain sufficient levels of ato expression to become an 'R8 founding neuron' (R8). Without ato, R8s do not form and the eye is lost, whereas excess specification of R8s leads to a 'rough' eye phenotype (White and Jarman, 2000). R8s are selected through a process in which Notch is critically involved (Artavanis-Tsakonas et al., 1999). During specification, Notch activities are biphasic and separated in space and time about a wave of differentiation that sweeps toward the anterior of the developing primordia, the morphogenetic furrow (Fig. 4A and B).

The morphogenetic furrow (MF) is marked by an apico-basal constriction (Ready et al., 1976; Cagan and Ready, 1989; Wolff and Ready, 1991a; Wolff and Ready, 
1991b). Cells anterior to the MF remain unspecified and undifferentiated (Fig. 4A); however, as the MF passes across the disc, cells alter their expression patterns and execute genetic programs that drive specification and differentiation (Ready et al., 1976). Because there are distinct transitional phases during R8 specification in the MF, it is subdivided into four distinct stages of progressive refinement.

The secreted factor Hedgehog $(\mathrm{Hh})$ is expressed in differentiating photoreceptors at the posterior margin of the MF (Heberlein et al., 1995). It is critical for progression of the MF as one of its targets, decapentaplegic (Dpp), is a long range signaling factor that drives expression of ato and its negative regulators hairy $(h)$ and extramacrochaetae (emc) (Brown et al., 1995). Ultimately, the cells anterior to the MF will undergo differentiation and themselves express $h h$, the result is MF wave-like movement. Additionally, $\mathrm{Hh}$ along with Notch, stimulates expression of ato in a band of cells immediately anterior to the MF, while Notch down regulates the repressors $h$ and emc (Baonza and Freeman, 2001). Thus, regulation of ato is restricted to areas anterior to the MF, imparting directionality to the furrow. Overall, this is stage 1 of the MF (Fig. 4) and is commonly referred to as 'proneural enhancement' due to the broad and uniform augmentation of the proneural gene activity. This regulatory mechanism is required to establish neuronal competency and drives the formation of the PNCs from which R8s are derived. Importantly, in this context Notch function is independent of $\mathrm{Su}(\mathrm{H})$ or the bHLH repressors of $E(s p l) C$ (Baker et al., 1996). This contrasts the second role of Notch during lateral inhibition.

Several cells compose each PNC. It is imperative that only a single cell from each cluster be designated the founding R8 so that the patterning of the tissue is 
maintained (Fig. 4). This is achieved through lateral inhibition and is mediated by Notch at stage $2 / 3$ of the MF (Muskavitch, 1994). Initially, a single cell establishes a higher level of ato activity. This presumptive-R8 initiates lateral inhibition because it expresses the Notch ligand, $\Delta$, at higher levels than other cells of the PNC (Kunisch et al., 1994). As a result, Notch activity is higher in the non-R8s as is the expression of the $E(s p l) C$ antagonists of ato. Ultimately, the expression of the proneural Ato protein is extinguished in all other cells except the R8.

After R8s are specified, the secondary cells are recruited sequentially, during and after stage 4 (Fig. 4), to the final sensory unit. The ordered recruitment orchestrated by the $R 8$ involves specification of $R 2 / R 5, R 3 / R 4, R 1 / R 6, R 7$, cone cells and the pigment cells. This process of secondary cell acquisition represents an inductive process mediated by the Notch receptor (Roignant and Treisman, 2009).

\section{Retinal Determination Factor Sine Oculis}

The identification of the SIX-family of transcription factors originated with the description of sine oculis (so) in Drosophila (Kumar, 2009a; Kumar, 2009b). Consistent with its inclusion in the retinal determination network (Fig. 5), compromised so function leads to abnormalities in all facets of the visual system including absence of the eye in the adult organism (Cheyette et al., 1994; Serikaku and O'Tousa, 1994). Later, the SIXfamily grew when two additional paralogs of so were revealed. These genes, termed optix and DSix-4, are involved in other developmental programs. Further genome comparisons indicated that all of these genes are conserved in vertebrates, where duplication events resulted in expansion of gene number. Here, I primarily consider so and its vertebrate homolog six1. 
Structurally, SIX proteins are composed of two domains: a homeodomain (HD), classically defined in protein-DNA interactions, and the namesake SIX domain, involved in the formation of protein complexes (Kumar, 2009a; Kumar, 2009b). The most well studied protein interaction for SO/SIX1 is its engagement with the transcriptional activator and tyrosine phosphatase, Eya . It is the combination of the DNA binding ability of SO and the activation domain of Eya that allows this bipartite transcription factor to regulate gene expression. The importance of this complex is apparent as any disruption of the complex results in severe developmental defects (reviewed in (Xu, 2013)) and combined overabundance is associated with neoplasticity (reviewed in (Christensen et al., 2008)).

While the protein interaction between SO and Eya is well established, there is disagreement in the literature regarding the mechanism by which SO binds DNA. As a first indication, molecular dissection of SO suggested that a region of the protein corresponding to the HD was stable and could reliably complex with DNA (Hazbun et al., 1997). These results are contrasted by human SIX2, a close paralog of SIX1, where the HD does not interact with DNA; however, full-length SIX2 does bind DNA (Hu et al., 2008). This suggests other parts of the protein, perhaps the SIX domain, endow or augment DNA interaction. This idea is buttressed by the observation that spontaneous mutations in the SIX domain of SIX1 abrogate DNA binding and manifest as brachiooto-renal (Huang et al., 2009) syndrome, a developmental disorder marked by hearing and kidney problems (Patrick et al., 2009). Furthermore, recent structural determination of the human SIX1-EYA complex reveals that the $\alpha-6$ helix of the SIX domain is available for interaction while in complex with EYA (Patrick et al., 2013). 
This problem of DNA binding by SO/SIX1 is compounded by the finding that phosphorylation by CK2 results in a decrease of SIX1 DNA binding affinity (Ford et al., 2000). A clarification of the mechanism of DNA interaction for SO/SIX1 and its regulation by $\mathrm{CK} 2$ is critical to our understanding of the molecular functioning of a conserved transcriptional modulator.

\section{Making the Macrochaetae}

The macrochaetae of Drosophila are mechanosensors, a component of the peripheral nervous system (Ghysen and Richelle, 1979; Simpson, 1990; Garrell and Campuzano, 1991; Gomez-Skarmeta et al., 2003). Bristles of the notum maintain bilateral stereotyped patterns in the dorsocentral and dorsolateral regions and on the shield shaped scutellum of the posterior thorax. Each bristle is composed of four specialized cells: neuron, sheath, shaft and socket (Fig. 6). These cells arise through asymmetric division of a single 'sensory organ precursor' (SOP), whose specification (like the R8 photoreceptor, see above) is Notch dependent. The onset of the bristle development is dependent upon expression of proneural activators derived from the Achaetae-Scute Complex (Romani et al., 1987; Guindon et al., 2010). Unlike ato, expression of the ASC genes does not rely on Notch, but reflects the influence of prepattern factors (Calleja et al., 2002). However, the SOP is selected through lateral inhibition from a group of cells composing the PNC in a manner akin to the R8 photoreceptor (Simpson, 1990) (Fig. 6).

As is typical of lateral inhibition, one cell gains an advantage over other cells of a PNC with respect to ASC expressivity. This cell initiates Notch mediated lateral inhibition and a single cell is established as the SOP (Fig. 6), as ASC gene activity is 
extinguished in the non-SOP cells. The SOP cell yields the pl neuroblast, which undergoes sequential asymmetric divisions. First the pl divides into the plla and pllb cells. The former divides and differentiates into the shaft and socket cells while the latter divides into the glial and plllb cells. Finally, the plllb cell goes on to form the sheath and neuron. This series of divisions is highly dependent upon proper signaling through the Notch pathway and $E(s p l)$ (Schweisguth et al., 1996).

The role of Notch in bristle development is well established through a number of loss of function phenotypes. An absence of Notch function during lateral inhibition results in juxtaposed supernumerary bristles, i.e. little spacing between them. This is the result of excess SOP specification. Conversely, over activation of Notch or the $\mathrm{E}(\mathrm{spl})$ repressors ablate bristle formation as cells of the PNC lose the potential to become the SOP. Loss of bristle phenotypes can also be due to a later (post-SOP) loss of Notch activity, as improper formation of pllb cells prevents plla from forming the external shaft cell. Furthermore, a loss of Notch function during asymmetric cell divisions results in abnormal shaft formations. For example, split bristles are an aberration wherein the plla cellular progeny both differentiate into shaft cells. Thus, the bristle lineage serves as a model for reiterated Notch functions during specification and asymmetric division that are distinct from the eye.

\section{Extramacrochaetae regulates bHLH activity}

A genetic screen in Drosophila by Botas et al. in 1982 identified the extramacrochaetae (emc) mutation as a dominant modifier of multicopy expression of the proneural activators encoded by ASC (Botas et al., 1982). Further analysis of the gene revealed that loss of emc elicited extra bristles in otherwise wild type flies and 
concomitant loss of ASC expression ameliorated those effects (Delprado and Garciabellido, 1984) suggesting a close association between gene products. Dissection of the encoded protein indicated that EMC (an HLH protein) lacks a basic domain that is required for interaction with DNA (Ellis et al., 1990; Garrell and Modolell, 1990). Subsequent analysis revealed that EMC dimerizes with ASC bHLH activators, and thereby inhibits transcription of proneural target genes (Van Doren et al., 1991).

The sequestration mechanism used by Emc is employed iteratively during development. In Drosophila, for example, Emc regulates sex determination (YoungerShepherd et al., 1992), antagonism of neuronal differentiation and patterning in the bristle (Botas et al., 1982), timing of furrow movement and R-cell specification in the eye (Brown et al., 1995; Bhattacharya and Baker, 2009; Spratford and Kumar, 2013), cell proliferation and vein formation in the wing (Baonza and Garcia-Bellido, 1999), and Malpighian tubule and trachea formation in the digestive tract (Cubas et al., 1994).

Studies of 'inhibitors of DNA binding' ID1-4, the murine homologs of Emc, uncovered striking similarities in the function and mechanism of these proteins. Specifically, loss of Id1 and Id3 leads to premature neuronal differentiation in the developing embryo (Lyden et al., 1999). Additionally, Id proteins are involved in angiogenesis (Lyden et al., 1999), which requires the formation of tubular structures similar to that of the Malpighian tubules and trachea. Also, owing to its role in preventing differentiation, overexpression of Id proteins is commonplace in a number of tumor models where they prevent differentiation and promote cell proliferation. 
Of interest with respect to this thesis is the apparent reliance of the Notch signaling pathway on Emc. During secondary recruitment by the R8, Emc acts in an epistatic cell autonomous manner to Notch in the R7 and cone cells; furthermore, Emc is required for proper expression of $E(s p l) C$ bHLH repressors (Bhattacharya and Baker, 2009). The striking similarities in the roles of Emc/ld during development, signaling and cancer underscore the importance of understanding in better detail this mechanism of action. In this regard, our knowledge of post-translational regulation of EMC/ID remained unexplored (see Ch. 2). Therefore, understanding this aspect of protein modulation could provide insight into how cell fates are determined and differentiation is regulated.

\section{The 14-3-3 Family of Proteins}

A 1967 survey of bovine brain tissue resulted in the identification of a new family of proteins (Moore et al., 1967). These proteins, dubbed 14-3-3s, derive their name from a combination of their elution position in DEAE cellulose chromatography and starch gel-electrophoresis. At a mass of $30 \mathrm{kDa}$, these acidic proteins are expressed in

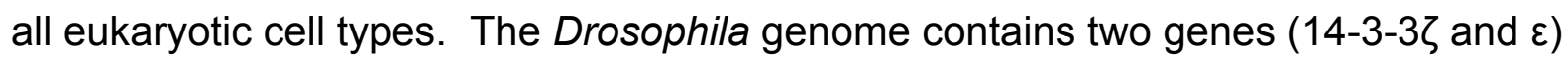
while the human genome encodes seven distinct isoforms $(14-3-3 \beta, \gamma, \varepsilon, \eta, \omega, \tau$ and $\zeta)$. Proteins of this family typically function as dimers, with some isoforms preferentially forming homodimers, while others function as heterodimers.

14-3-3s were the first group to be described as phosphoprotein binding proteins (Fu et al., 2000; Dougherty and Morrison, 2004; Aitken, 2006). Specifically, a largescale screen identified two motifs that drive protein-protein interaction: mode-1, R-S-xpS/pT-x-P, and mode-2, R-x-F/Y-x-pS/pT-x-P, where ' $x$ ' is any amino acid and 'pS/pT' 
indicates a phosphorylated serine or threonine residue (Yaffe, 2002; Wilker et al., 2005). While these phosphospecifc motifs are considered to be optimal, a number of verified binding sites diverge from the strict consensus and others bear no similarity. For example, the 14-3-3 interaction motif of the ADP-ribosyltransferase S of Pseudomonas is identified as D-A-L-D-L (Henriksson et al., 2002) and the binding site of human p53 is K-G-Q-S-T-pS-R-G (Waterman et al., 1998). Interestingly, many of the identified sites $(\sim 75 \%-90 \%)$ are located in or near regions predicted to be structurally disordered (Bustos and Iglesias, 2006). The emerging view is that regions of 'disorder' are often the sites for regulatory post-translational modification, which serve to impose structural stability. Regardless of the sequence motif that causes complex formation, 14-3-3 proteins regulate hundreds of proteins involved in signal transduction (Tzivion et al., 1998), transcriptional regulation (Ren et al., 2010; Yu et al., 2013), chromatin structure (Healy et al., 2011), and vesicle trafficking (Li et al., 2012), among others.

Functional modulation by $14-3-3$ s can occur through a variety of mechanisms (reviewed in (Darling et al., 2005)) (Fig. 7). The molecular anvil hypothesis (Yaffe, 2002) describes a mechanism in which binding the highly structured 14-3-3 acts as a foundation for conformational change or stabilization. Also, binding by 14-3-3 can prevent phosphatase access and thereby sterically blocking dephosphorylation and maintaining an altered functional state. Interaction between two proteins can be prevented if a binding interface is occluded or 14-3-3 might serve as a molecular scaffold and facilitate binding if both partners contain a target site. Finally, interaction with 14-3-3 can drive compartmental sequestration or trafficking by serving as a 
molecular escort. These mechanisms are implemented in a number of contexts to influence a variety of cellular events.

Cellular processes regulated by $14-3-3$ s include signal transduction, transcription factor localization, cell cycle progression and apoptosis. Examples include strict regulation of Raf (Fu et al., 1994) by maintaining an active conformation of the kinase (Tzivion et al., 1998), regulation of the cell cycle phosphatases Cdc25B/C (Peng et al., 1997; Forrest and Gabrielli, 2001), cytoplasmic restriction of the transcription factor Yorkie (Ren et al., 2010) and sequestration of the apoptotic promoting protein BAD (Zha et al., 1996). The Raf and Yorkie examples of 14-3-3 functions have been elucidated in the Drosophila model system, particularly the eye. This suggests that $14-3-3$ s have roles in regulating pathways important for neurogenesis and cell fate specification.

Though expression of 14-3-3 is ubiquitous, its expression is maximal posterior to the MF where photoreceptor differentiation occurs (Kockel et al., 1997). These are the regions (discussed above and Fig. 4) where Notch is involved in lateral inhibition and secondary photoreceptor induction. Given a concomitant increase in 14-3-3 and $E(s p l) C$ expression, there may be a significant regulatory consequence underlying this coexpression. Perhaps these two proteins are involved in a developmental context whereby multiple $E(\mathrm{spl})$ repressors are regulated through interaction with 14-3-3s.

\section{GSK3 and Neuronal Development}

Glycogen-Synthase-Kinase-3 (GSK3) is a serine/threonine kinase originally identified as a key regulator of glucose metabolism (Woodgett and Cohen, 1984). Since this initial report, new roles for the kinase have been uncovered in clinical contexts, 
circadian rhythm, as well as development. Relevant developmental roles for the kinase include neurogenesis, neuronal migration and polarization, and axon growth and guidance (Hur and Zhou, 2010).

GSK3 is specialized in its substrate recognition in that it preferentially modifies proteins that have already been phosphorylated. Typically, the phosphorylated residue is four or five positions C-terminal to the candidate serine or threonine. Thus, the general consensus has been described as $S / T-x-x-x-p S / p T$ where ' $x$ ' is any residue and 'pS/pT' represents a phosphorylated serine/threonine. This 'priming' dramatically increases affinity for a particular substrate and serves to regulate GSK3 targeting. However, priming is an enigmatic phenomenon because it is not necessary for some substrates, or relevant sites may be located distal the target residue (reviewed in (Sutherland, 2011)).

In addition to its unique target preferences, GSK3 is distinguished by its high basal activity in resting cells. Stimulation of upstream signaling components results in decreased kinase activity, which is counter to the norm. For example, GSK3 is responsive to growth factors through receptor tyrosine kinase (RTK) signaling. Activation of the phosphatidylinositol-3-phosphate kinase pathway (PI3K) leads to an inhibitory phosphorylation of GSK3 by Akt (Cross et al., 1995). Additionally, the Wnt signaling pathway leads to GSK3 inactivation by forcing it to dissociate from its substrate $\beta$-catenin. Ultimately, the kinase is recruited to the membrane where it is sequestered by complex formation with the Wnt coreceptor LRP5/6 (Piao et al., 2008). 
Studies in mammalian systems have revealed a role for GSK3 in the regulation of Notch signal transduction. Specifically, phosphorylation of the $\mathrm{N}^{\text {icd }}$ by GSK3 results in protein stabilization by blocking proteasomal degradation (Foltz et al., 2002). Conversely, another study suggested that phosphorylation by GSK3 prevented proper signal transduction by Notch in the nucleus (Espinosa et al., 2003). This represents and interesting conundrum, but the prospects presented by each scenario indicate a complex receptor-kinase interrelationship. Interestingly, GSK3 has been implicated in regulating other pathways that are involved in neural progenitor proliferation (Wnt, $\mathrm{Hh}$ ). During neurogenesis, a body of evidence suggests GSK3 regulation of these pathways is critical. Overall, it is implied that GSK3 activity is responsible for supporting differentiation while inhibition allows progenitor proliferation (Hur and Zhou, 2010).

With respect to this thesis, the regulation of transcription factors is of particular interest. Phosphorylation by GSK3 results in a number of potential outcomes similar to the regulatory mechanisms employed by other systems. For example, in the case of $\beta$ catenin, sequential phosphorylation of the protein by GSK3 leads to destabilization via proteasomal degradation (Aberle et al., 1997). Also, DNA binding ability can be modulated by blocking physical interaction or preventing nuclear localization (Beals et al., 1997; Neal and Clipstone, 2001). These regulations impinge upon transcription factors that are important for development and neurogenesis.

\section{Conclusion}

This review of the literature describes the relationship protein kinase CK2 shares with components of developmental pathways. As we have come to understand the prolific nature of this kinase, it has also been realized that a more detailed 
understanding of factors regulated by CK2 is required. Additionally, investigation of CK2 activities has opened new avenues of study regarding the post-translational regulation of the $\mathrm{E}(\mathrm{spl})$ repressors. Therefore, in the subsequent chapter I will describe in detail three new CK2 transcription factor substrates using bioinformatics to find CK2 consensus sequences, characterizing specific target residues by kinase assay, and verifying CK2 as the active kinase. Then, I will describe a novel regulatory mechanism involving 14-3-3 proteins and $E(\mathrm{spl})$ repressors by identifying consensus sequences for 14-3-3 binding in divergent homologs and genetic analysis to evaluate biological significance. 


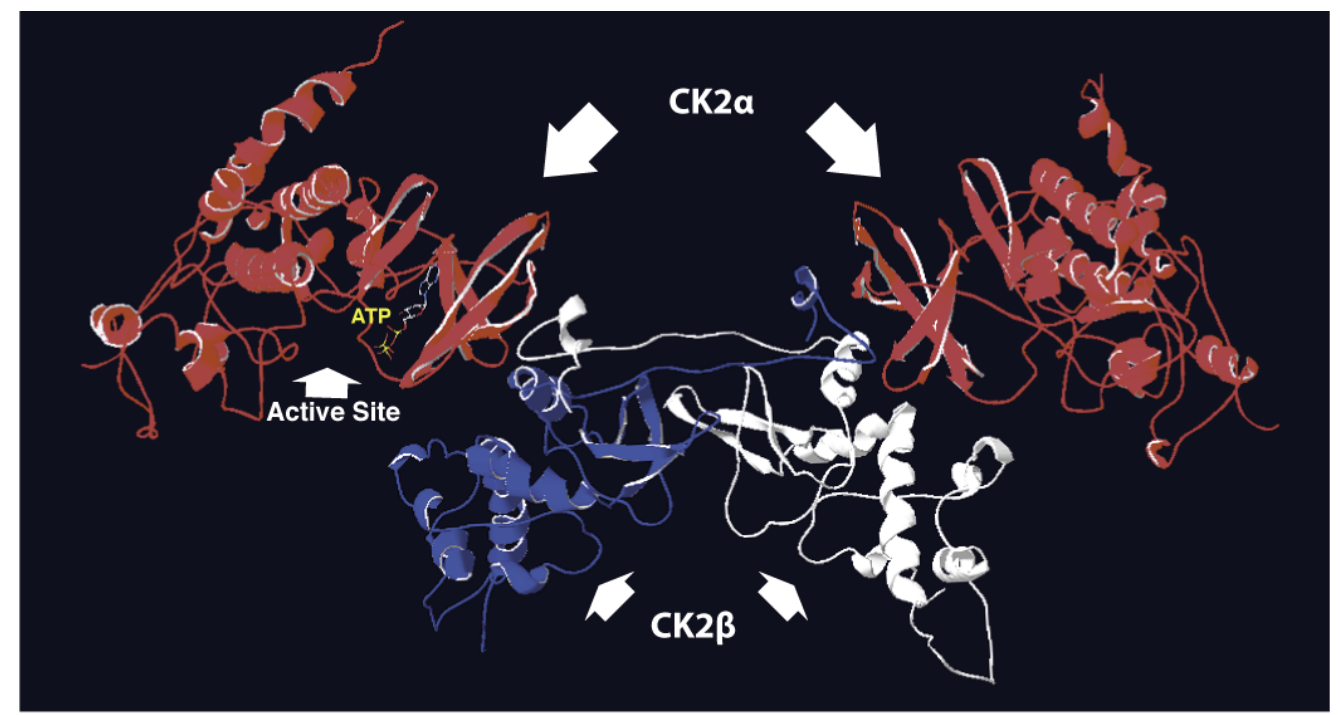

\title{
CK2 TARGET PHOSPHORYLATION:
}

\author{
Consensus $=$ S-D/E-X-D/E
}

\section{Many $\mathrm{E}(\mathrm{spl}) \mathrm{C}$ repressors are bona fide targets:}

\author{
CK2 \\ E (SPL) M8 GYH $\overline{\text { SDCD }}$ SPAP \\ E (SPL)M5 GYHSDNEDSQS \\ E (SPL) M7 GYASDNESLLQ
}

\section{Acidic addition yields sequential phosphorylation:}

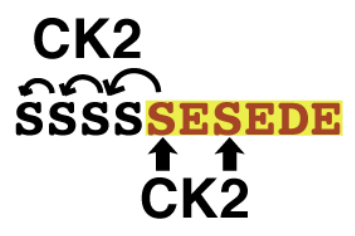

Figure 1: Protein kinase CK2 is a rotationally symmetrical, multimeric enzyme composed of two $\boldsymbol{\alpha}(\mathrm{red}) / \boldsymbol{\beta}($ blue and white) dimers. The dimers interface between the two regulatory $\beta$-subunits while the catalytic $\alpha$-subunits occupy distal points of the tetramer. The active site is positioned facing toward the $\beta$ subunit, which influences selectivity and reaction rates. Substrate targeting is specific to serine and threonine residues located within acidic microdomains (highlighted). Addition of acidic phosphoryl-groups can substitute for D/E, resulting in sequential phosphorylation. CK2 structure as determined by (Niefind et al., 2001) (PDB: 1JWH). 


\section{Presumptive SOP}

\section{NON-SOP}

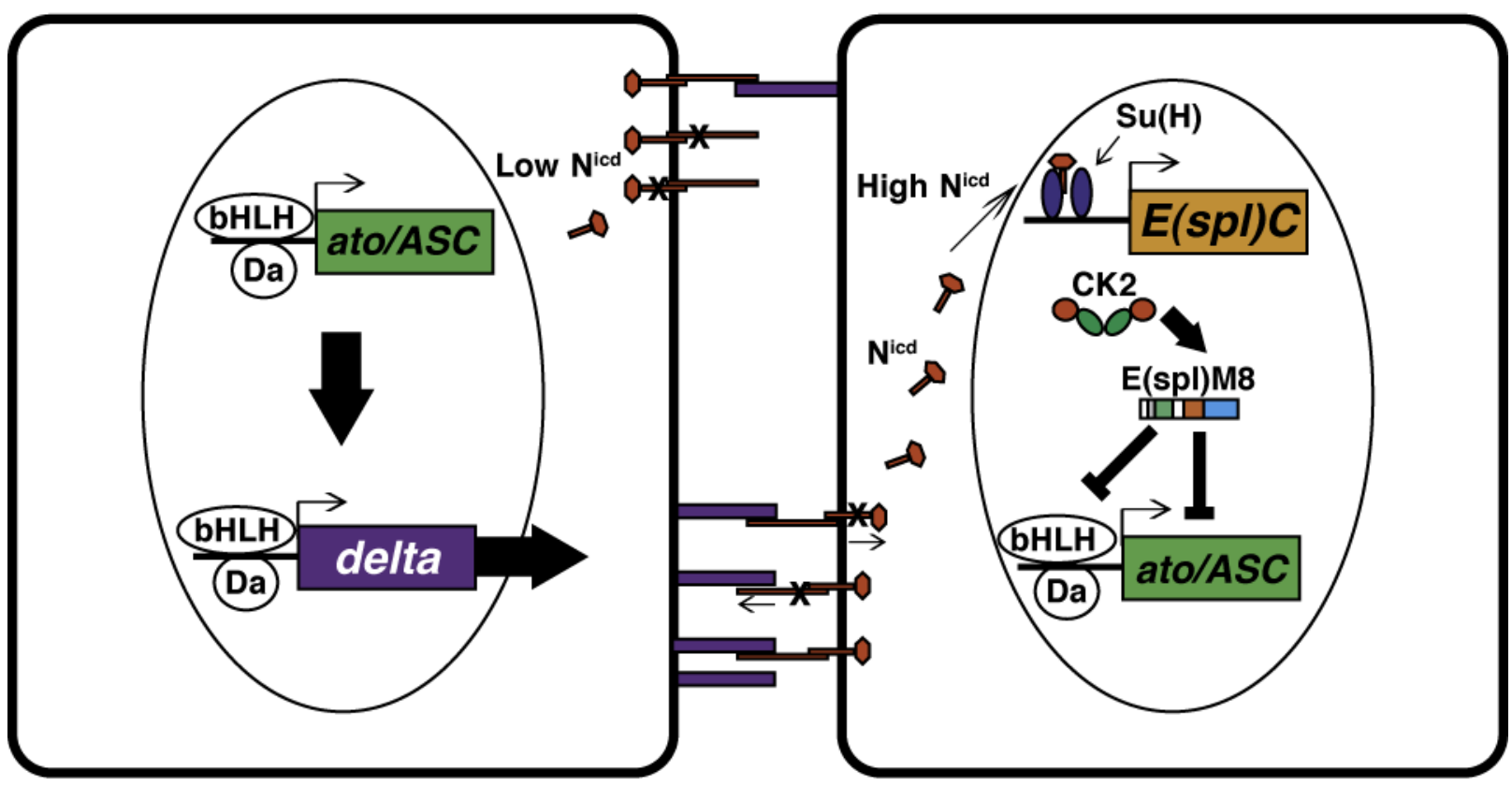

Figure 2: Notch $(\mathrm{N})$ mediated lateral inhibition is required for the specification of SOPs from a group of equipotent precursors. This process is initiated at the interface of two cells that express the components of Notch signaling $(\Delta(\mathrm{DI})$ ligand $=$ purple; $\mathrm{N}$ receptor $=\mathrm{red})$. Here, the presumptive SOP has achieved a higher level of atonal (ato) expression and therefore expresses higher levels of DI than the adjacent cells. In this way, $\mathrm{N}$ receptors on the non-SOP are activated and undergo proteolytic cleavage. This releases the $\mathrm{N}$ intracellular domain $\left(\mathrm{N}^{\mathrm{icd}}\right)$, which translocates to the nuclease where it complexes with Supressor of Hairless $(\mathrm{Su}(\mathrm{H}))$. Expression and post translational activation of $\mathrm{E}(\mathrm{spl}) \mathrm{M} 8$ antagonizes atonal autoexpression, which indirectly lowers Delta. Ultimately, a single cell is designated as the SOP, which establishes the adult organ. 


\begin{tabular}{|l|l|l|l|l|l|}
\multicolumn{2}{c}{ Basic HLH } & \multicolumn{2}{c}{ Orange } & C-Terminal Domain \\
\hline & & & & & \\
\hline
\end{tabular}

Basic

Helix-Loop-Helix

E(spl)M8
E(spl)M5
E(spl)MGamma
E(spl)M7
E(spl)MDelta
E(spl)M3
E(spl)MBeta

E ( spl) M8

E ( spl)M5

E (spl) MGamma

E ( spl) M7

E (spl)MDelta

E ( spl)M3

E (spl) MBeta

E(spl)M8
E(spl)M5
E(spl)MGamma
E(spl)M7
E(spl)MDelta
E(spl)M3
E(spl)MBeta

E (spl) M8

E ( spl) M5

E (spl) MGamma

E (spl)M7

E (spl)MDelta

E (spl)M3

E (spl) MBeta

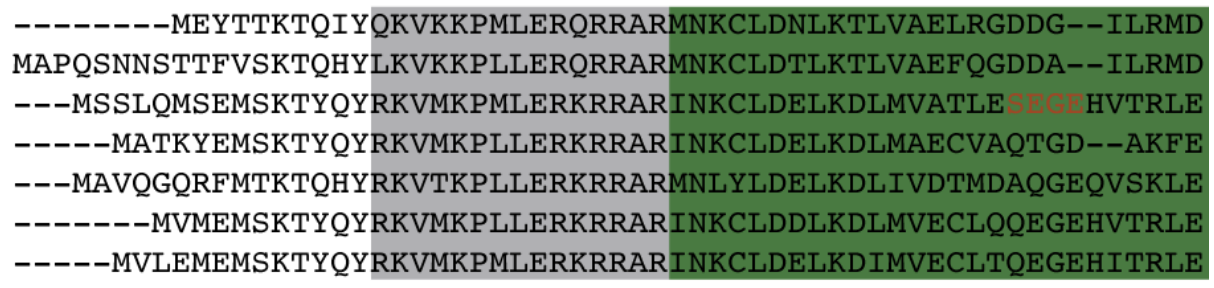

$: * * * * * * *: * * *: * * *: * \quad * * * * \quad::$. $\quad$.: :

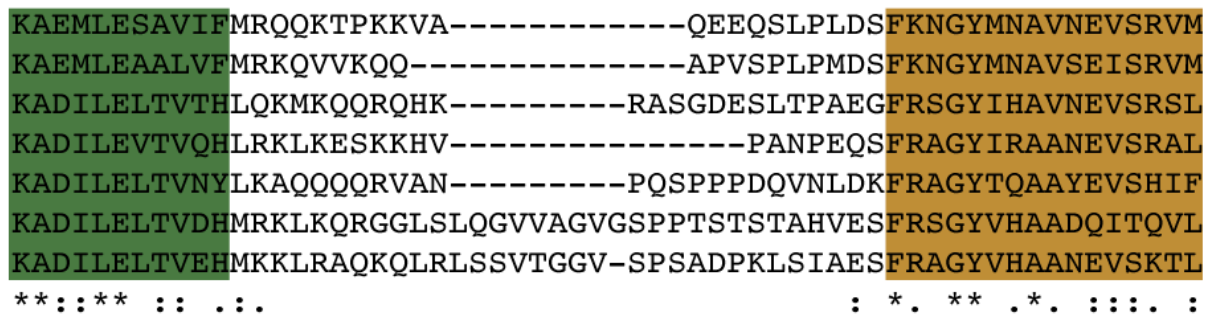

Orange

C-Terminal Domain

ASTPGMSVDLGKSVMTHLGRVYKNLQ-QFHEAQSAADF IQNSMDCSSMDKA-------ACTPAMSVDVGKTVMTHLGVEFQRML----------QADQVQTSVTTSTPR--------SQLPGMNVSLGTQLMTHLGQRLNQIQPAEKEVLPVTAPLSVHIANRDAYSV--------ASLPRVDVAFGTTLMTHLGMRLNQLE------QPMEQPQAVNTPLSIVCGSSSSSSTYSS STVPGLDLKFGTHLMKQLGHQLKDMK-----------------QEEEI IDMAEEPVNLAD LQTQQTD-EIGRK IMKFLSTRL IELQ-TQLLQQQQQQQQHQQQQIPQSSGRLAF PLLGGY AAVPGVSVDLGTQLMSHLGHRLNYLQ-VVVPSLPIGVPLQAPVEDQAMVTPPPSECDSLE . . * * * * :

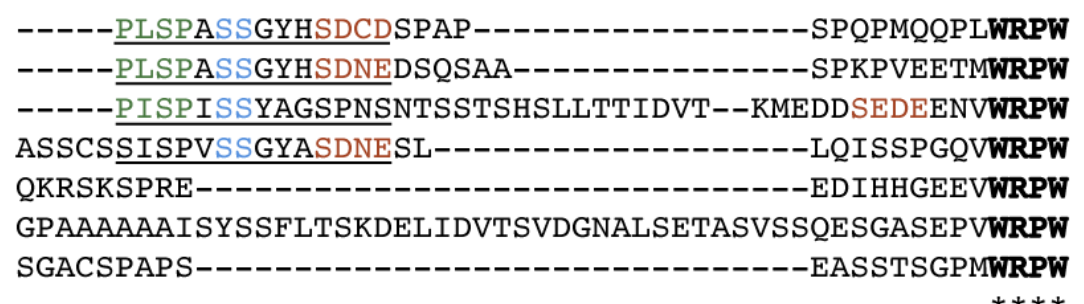

$\star * * *$

Figure 3: The $E(s p l) C$ encodes seven bHLH-Orange transcriptional repressors. Each repressor is composed of four generalized domains. The basic domain (gray highlight) is required for interaction with DNA while the HLH (green highlight) and the namesake Orange domain (orange highlight) allow dimerization. Importantly, it has been posited that the C-terminal domain imparts a regulatory function. Indeed, the obligate co-repressor Gro interacts with the invariant WRPW-motif (bold) while E(spl)M $\delta$ interacts with CtBP through its unique PVNLA (bold) sequence. Additionally, conserved phosphorylation sites have been verified (CK2=red, MAPK=green) and others predicted (CK1 and GSK3=blue). 

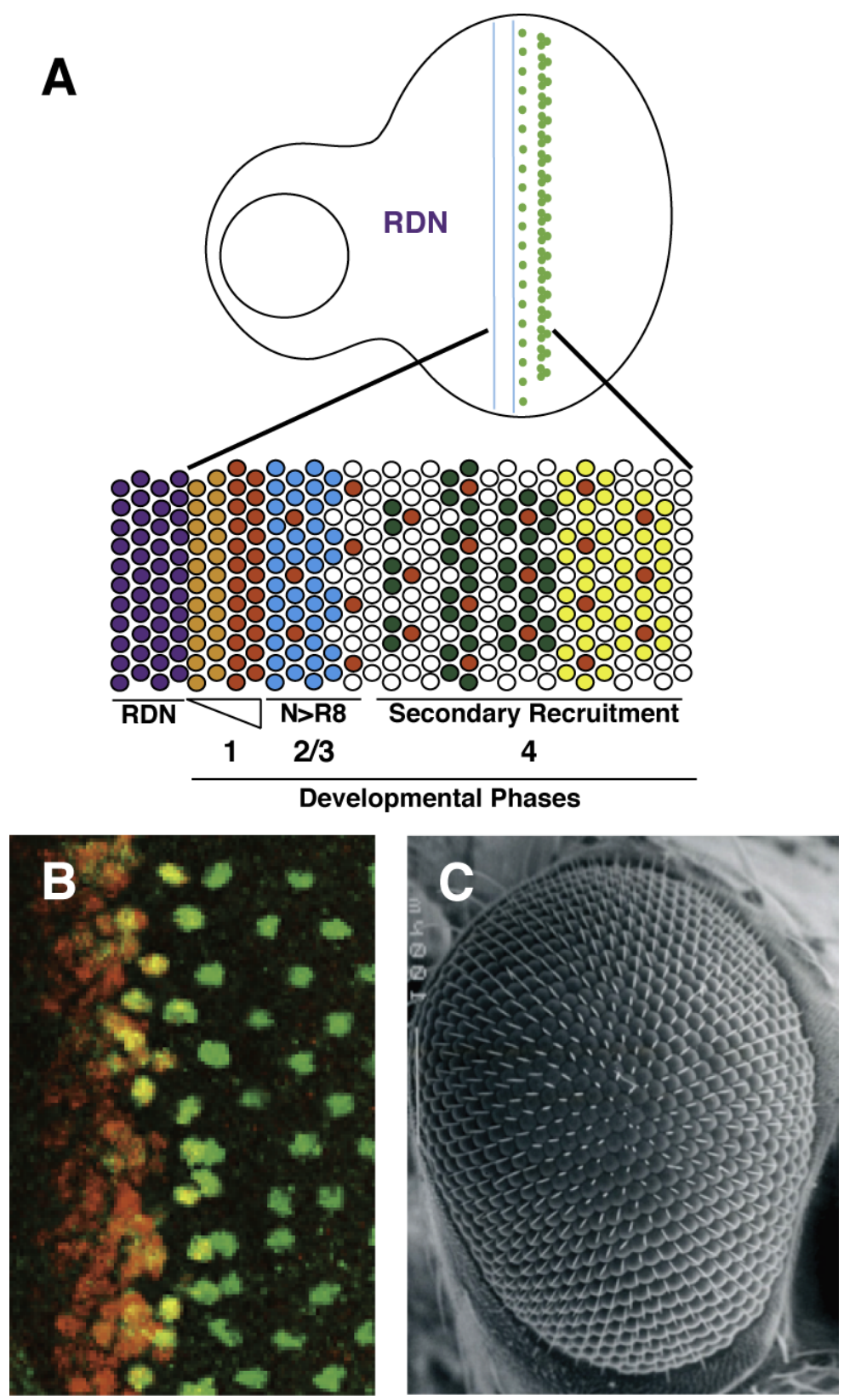

Figure 4: (A) Specification of the Drosophila eye is initiated by expression of genes that compose the retinal determination network (RDN, purple). Subsequently, the patterning of the retina is laid down about a wave of differentiation, the morphogenetic furrow (MF). During proneural enhancement (stage 1) the bHLH activator atonal is upregulated (orange to red) by Notch $(\mathrm{N})$ and Hedgehog signalling. Then, lateral inhibition (stage $2 / 3$ ) restricts the R8 fate to a single cell (red). This single cell then progressively recruits secondary photoreceptors (R1-R7) and accessory cells into the adult organ during stage 4. (B) Confocal imagery of the morphogenetic furrow shows the stages of retinal patterning (Atonal = red; 'R8'=green). (C) The adult eye is composed of approximately 800 individual facets called ommatidia. Each unit eye originates from a single R8 and is strictly patterned into a hexagonal array. 


\section{Retinal Determination Network}

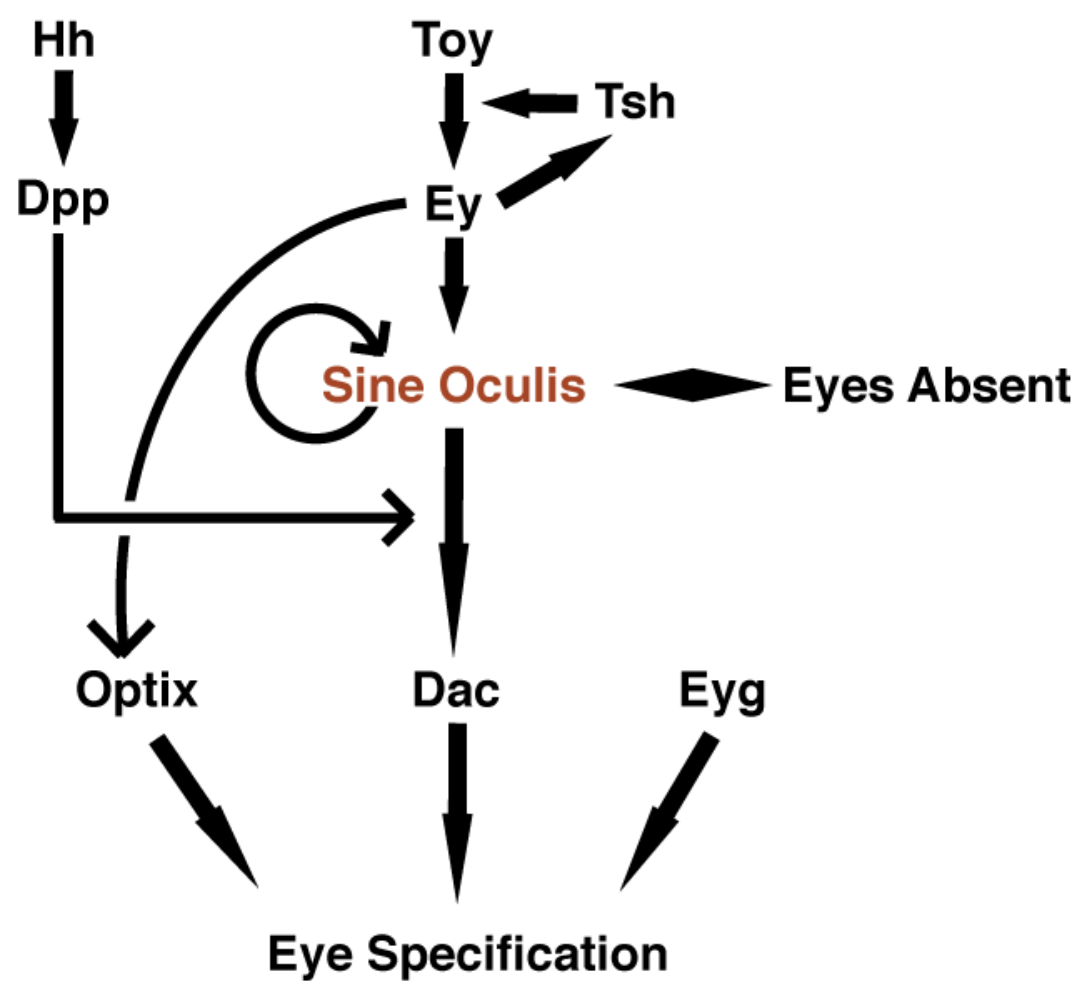

Figure 5: The retinal determination network $(R D N)$ is a set of transcriptional regulators whose expression is required retinal development. Initially, twin of eyeless (toy) expression, activates eyeless (ey) which drives expression of Sine Oculis (SO). This SIX family protein binds DNA, but requires Eyes Absent (Eya) to elicit target gene expression. Progression through a complex system of regulatory relationships leads to eye specification. 

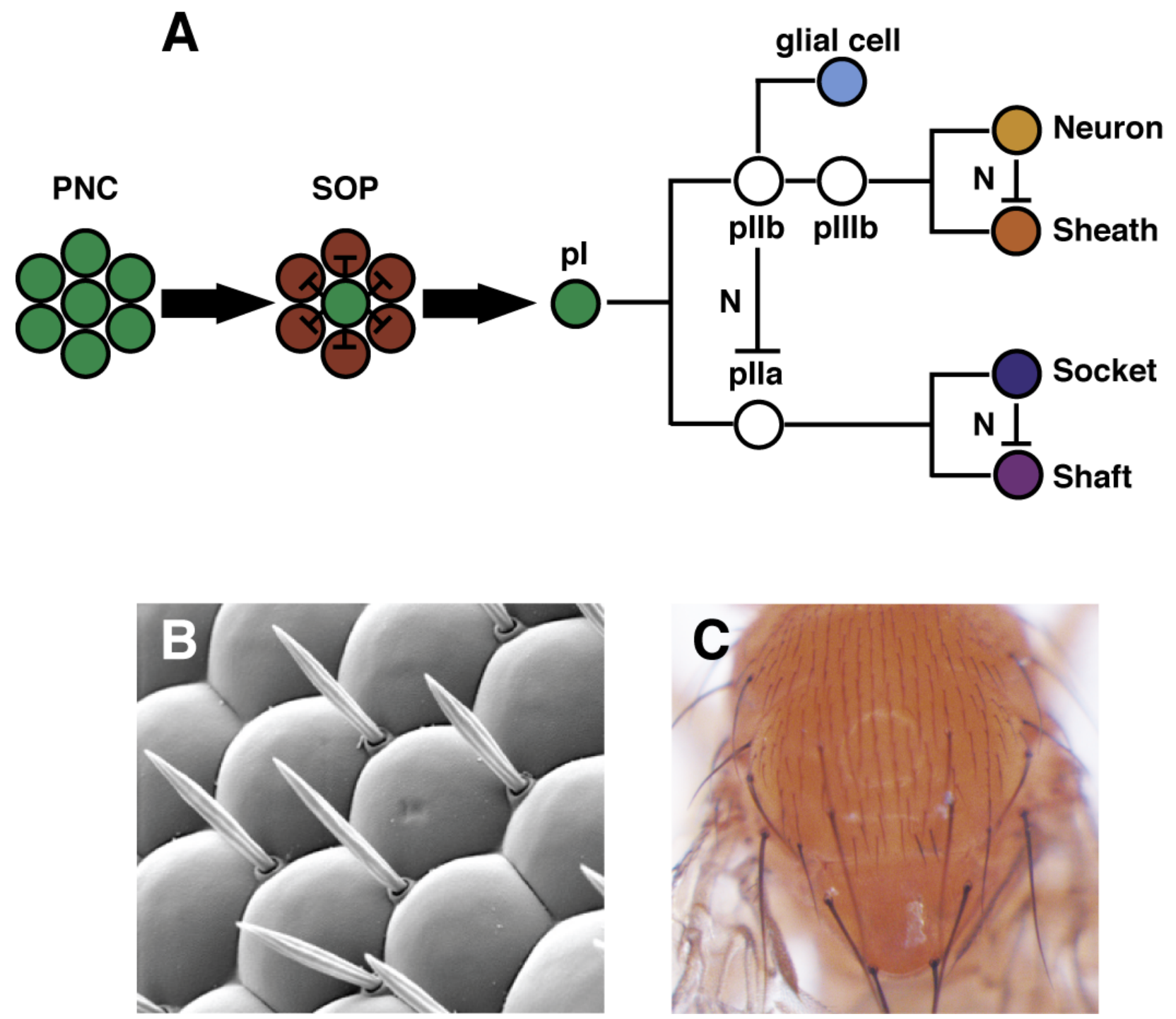

Figure 6: (A) Bristles development begins with selection of the SOP from a group of equipotent cells that express high levels of $A S C$ bHLH activators (PNC). Excessive SOP density is restricted by interspersed expression of emc, an antagonist of bHLH activators. Upon specification, the so-called pl then undergoes a series of Notch signaling and $E(s p l) C$ dependent asymmetric divisions. Ultimately, four cells (neuron, sheath, socket, and shaft) assemble into the adult organ. (B) Interommatidial bristles are present at alternating vertices within the hexagonal array of the Drosophila eye. (C)The 22 macrochaetae of the thorax are stereotypically patterned and bilaterally symmetrical about the long axis of the animal. The microchaetae are dispersed in linear arrays on the notum except for the scutellum. 

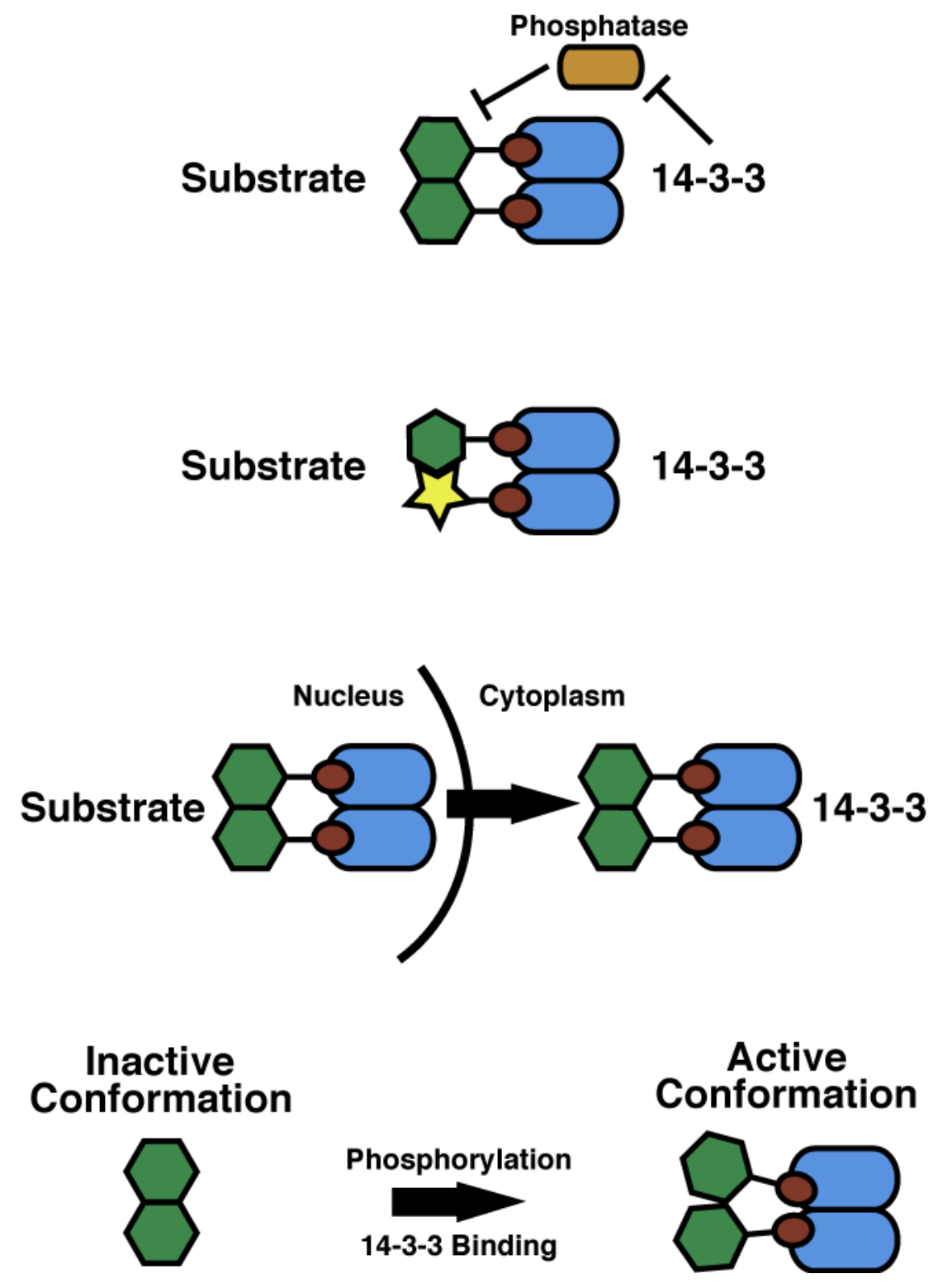

Figure 7: 14-3-3 proteins regulate diverse cellular activities including signal transduction, transcription factor localization, and chromatin structure by binding to phosphorylated substrates. The mechanisms by which 14-3-3 renders its effects include steric occlusion of phosphatases, stabilization of complexes, shifts in nuclear localization, and maintenance of a specific conformational state (molecular anvil hypothesis). 


\section{CHAPTER 2}

Identification and Characterization of E(spl)My, Extramacrochaetae and Sine Oculis as targets for CK2 


\begin{abstract}
Protein kinase CK2 phosphorylates and activates the bHLH protein E(spl)M8, an effector of Notch signaling. This regulation has been studied during eye development in the Drosophila model organism. The eye defects of CK2 hypomorphic mutants led us to hypothesize that CK2 also targets other proteins involved in retinal histogenesis. The studies described here employ bioinformatics and biochemistry to identify 3 new targets of CK2; these are $\mathrm{E}(\mathrm{spl}) \mathrm{My}$, Extramacrochaetae and Sine Oculis, all of which are known to be vital for proper retinal development. In addition, the site(s) of phosphorylation in all 3 proteins have been identified, and sequence analysis reveals that these are conserved in all Drosophila homologs, and in their vertebrate counterparts. Because each of these proteins is expressed in a spatiotemporally distinct manner within the developing eye, these studies expand the participation of CK2 to additional time points of retinogenesis.
\end{abstract}




\section{INTRODUCTION}

CK2 was identified in 1954 as the first enzyme that could phosphorylate another protein and was originally called 'protein phosphokinase'. It has since been shown that this enzyme preferentially phosphorylates regions in proteins (or peptides) that are rich in negatively charged (acidic) amino acids. Additionally, its prolific nature has become apparent, with hundreds of known targets in eukaryotic proteomes. CK2, unlike other kinases (PKA, PKC, etc.), does not respond to second messengers, but relies on association with the regulatory CK2 $\beta$-subunit to engender changes in activity and target specificity, as well as through the formation of multiprotein complexes (Giot et al., 2003). Though there are many questions left to be answered, it is known that CK2 functionality is required during the most critical phases of the cell cycle, growth and development, and rhythmic protein expression, and in all of these cases phosphorylation of the relevant targets is spatially or temporally controlled. The mechanism underlying this control remains to be revealed.

Some of the first biological experiments on CK2 were performed in the budding yeast, Saccharomyces cerevisiae system. These investigations demonstrated the requirement for $\mathrm{CK} 2$ during the cell cycle, as kinase deficient cells arrested during intermediate phases (G1/S and G2/M) of cell division. In metazoans, the functional conservation of CK2 becomes apparent because depletion of CK2 activity is lethal during the early stages of metazoan development when cell proliferation rate is high, and that CK2 has a role in later stages of embryogenesis when boundary formation and organ development occur. Moreover, the importance of CK2 persists into the adult organism where it is involved in regulating the circadian clock. It is through 
phosphorylation of a key oscillatory transcription factor Period (Per) that CK2 instigates Per protein degradation and regulates timing of biological clocks in fungi, flies, and mammals (Chiu et al., 2008; Duvall and Taghert, 2011; Menet and Rosbash, 2011; Querfurth et al., 2011; Hubaud and Pourquie, 2013).

It is now widely recognized that CK2 maintains a central role in the regulation of many transcription factors. During the cell cycle, CK2 phosphorylates p53 thereby blocking its DNA binding and allowing progression through a critical checkpoint of the cell cycle (Levine, 1997). Also, CK2 phosphorylates the homeodomain transcription factor Antennapedia and prevents its cooperative DNA binding with Extradenticle during early embryogenesis (Jaffe et al, 1997). More recent studies reveal roles for CK2 in cell fate specification during neurogenesis through regulation of $\mathrm{E}(\mathrm{spl}) \mathrm{M} 8$, a repressor whose activity is essential for development of the central and peripheral nervous systems (Karandikar et al, 2004).

It is the role of CK2 during neurogenesis, spurred by the strong phenotypes associated with $\mathrm{E}(\mathrm{spl}) \mathrm{M} 8$ and its CK2 site specific variants that have been the focus of our laboratory. A direct role for CK2 in neurogenesis was revealed by the observation that compromising CK2 activity leads to the specification of supernumerary sensory organ precursors during bristle and eye development (Bose et al., 2006; Kunttas-Tatli et al., 2009). These ectopic sensory organs are attributed to the loss of E(spl)M8 activity (lateral inhibition), based on the similarity among Notch, E(spl), and CK2 loss of function phenotypes. This intimate association between CK2 and the Notch signaling pathway demonstrates the critical nature of $\mathrm{CK} 2$, and established that $\mathrm{E}(\mathrm{spl})$ proteins require phosphorylation by CK2 to mediate the effects of Notch signaling. Given the variety and 
number of CK2 substrates, it seems likely that additional factors involved in neurogenesis remain to be identified.

Using online bioinformatic tools to identify CK2 consensus sites, several candidate proteins known to be involved in tissue patterning and neurogenesis were identified. The first is a member of the $\mathrm{E}(\mathrm{spl})$ complex, $\mathrm{E}(\mathrm{spl}) \mathrm{My}$. Interestingly, its predicted CK2 phosphorylation site is distinct from those identified in $\mathrm{E}(\mathrm{spl}) \mathrm{M} 8,-\mathrm{M} 5$ and -M7. Additionally, the expression characteristics of $\mathrm{E}(\mathrm{spl}) \mathrm{My}$ is markedly distinct from $\mathrm{E}(\mathrm{spl}) \mathrm{M} 8,-\mathrm{M} 5$ and $-\mathrm{M} 7$. Therefore, the possibility is high that $\mathrm{E}(\mathrm{spl}) \mathrm{My}$ plays a different role during neural development. The second candidate, EMC, is a negative regulator of the bHLH proneural activators (such as Ato, ASC) required for neuronal fate specification and its CK2 site is conserved in the ID class of proteins from vertebrates and invertebrates. Finally, SO, a member of the retinal determination network, is required for eye formation and the site for CK2 is highly conserved in the homologs from human and mouse, SIX1. Together, these findings implicate CK2 regulation at all stages of eye neurogenesis and bristle development.

The studies described in this chapter identify and characterize the phosphorylation of the aforementioned proteins by $\mathrm{CK} 2$, the role of the regulatory CK2 $\beta$ subunit in these modifications, the sensitivity of these modifications to inhibition and activation of CK2, and identification of the site(s) of phosphorylation. Subsequent studies provide a foundation for future analyses in Drosophila and higher organisms so that the role of CK2 in organismal growth, development and disease might be better defined. The identification of EMC as a substrate of kinase phosphorylation represents the first identified post-translational modification of the ID protein class. 


\section{MATERIALS AND METHODS}

\section{Identification of Conserved CK2 Sites}

Use of the sequence motif search tool at 'prosite.expasy.org' allowed the identification of transcription factors involved in eye development that contain the amino acid sequences commonly recognized by CK2. The primary sequences of the relevant Drosophila orthologs were downloaded from the online database at 'flybase.org'. Compiled sequences were transformed into FASTA format for global alignment by the MUSCLE online software using default parameter settings. Visual inspection of the multiple sequence alignment revealed representative protein kinase CK2 targets (SD/E-X-D/E) that are highly conserved within the proteins being analyzed.

\section{Isolation of the E(spl)My Open Reading Frame}

Single, wild type flies were ground in $50 \mu \mathrm{L}$ genomic extraction buffer $(10 \mathrm{mM}$ Tris, $1 \mathrm{mM}$ EDTA, $250 \mathrm{mM} \mathrm{NaCl}, 0.2 \mu \mathrm{g} / \mu \mathrm{L}$ Proteinase $\mathrm{K}$ ). The proteinase was heat inactivated by incubation at $95 \mathrm{C}$ for 5 minutes (Gloor et al. 1993). The $\mathrm{E}(\mathrm{spl}) \mathrm{My}$ open reading frame (ORF) was PCR amplified from the genomic extract using convergent primers complementary to the $5^{\prime}$ and 3 ' ends of the gene which contains no intronic regions. The forward and reverse primers incorporated EcoR1 and Xho1 restriction sites at the 5' and 3' ends, to allow for cloning into multiple vectors. Additionally, the forward primer contained a Kozak sequence (double underlined) for efficient expression in eukaryotic systems (CCCGAATTCAACATGTCGTCGCTACAAATGTCCGAGATGTCC, CTCGAGCTACCAGGGACGCCAGACGTTCTCC). The PCR product was cloned into PBS2(SK+) and the ORF was verified by sequencing. 


\section{Mutagenesis of CK2 Sites in E(spl)My, EMC, and Sine Oculis}

Several variants of $\mathrm{E}(\mathrm{spl}) \mathrm{My}, \mathrm{EMC}$ and SO were generated for site mapping using complementary primer sets which introduce alanine substitutions at the appropriate serine/threonine residues. The respective open reading frames were subjected to PCR amplification and the methylated template DNA was removed by Dpn1 digestion. The remaining product was transformed into the E. coli DH5a strain. Specific clones were sequenced for verification that only the intended mutations were introduction.

Additional variants specific to the C-terminal regions of $\mathrm{E}(\mathrm{spl}) \mathrm{My}$ (GIn134>Stop) were generated using convergent primers. The forward primer included an EcoR1 restriction site and a Kozak sequence while the reverse primer contained an Xho1 restriction site. These variants included $M Y-C t D$ and $M Y-C t D-S^{195} A$, which were generated using sequenced clones $\left(\mathrm{MrS}^{195} \mathrm{~A}\right.$ and $\left.\mathrm{MY}\right)$ as template. All sequence and structural variants generated were subcloned in frame pZEX or pMAL-c4x for expression and affinity based protein purification.

\section{Purification of GST-Fusion Proteins}

pZEX plasmids expressing GST-Fusions were transformed into E. coli BL21 cells containing PT-TRX, a thioredoxin expressing plasmid. Cell cultures were grown to a target $\mathrm{OD}_{600}$ of 0.7 in $2 x Y T A$ containing $150 \mu \mathrm{g} / \mathrm{mL}$ ampicillin and $15 \mu \mathrm{g} / \mathrm{mL}$ chloramphenicol. Protein expression was induced using a final concentration of $1 \mathrm{mM}$ IPTG at $30 \mathrm{C}$ with vigorous shaking for approximately 3 hours. Cells were harvested by centrifugation and resuspended in $8 \mathrm{~mL}$ of phosphate buffered saline containing $5 \mathrm{mM}$ EDTA, $0.1 \mathrm{mM}$ PMSF and $0.2 \% \beta$-mercaptoethanol. Cells were treated with lysozyme at 
a concentration of $1 \mathrm{mg} / \mathrm{mL}$ on ice for 30 minutes followed by pulse sonication for approximately 30 seconds. Nearly complete lysis was verified by phase contrast microscopy. Subsequently, $10 \%$ Triton-X 100 was added to a final concentration of $1 \%$ and the lysed fraction was incubated at $4 \mathrm{C}$ for approximately 1 hour. Insoluble components were precipitated by centrifugation. The GST-protein supernatant was applied to $4 \%$ agarose matrix crosslinked to reduced glutathione (MCLabs) and incubated at $4 \mathrm{C}$ with nutation for $\sim 2$ hours. The bead matrix was then washed with 10 bed volumes of phosphate buffered saline containing $5 \mathrm{mM}$ EDTA and $0.1 \mathrm{mM}$ PMSF. Bound protein was eluted in five $1 \mathrm{~mL}$ fractions of elution buffer( $15 \mathrm{mM}$ reduced glutathione, $50 \mathrm{mM}$ Tris $\mathrm{pH}-8.0$ ). Pooled fractions were then concentrated and exchanged into storage buffer (10 mM Tris pH-8.0, 0.5 mM EDTA, 5\% glycerol, $150 \mathrm{mM}$ $\mathrm{NaCl}, 0.1 \mathrm{mM}$ PMSF, $0.02 \%$ Sodium Azide) using an Amicon Ultra-15 10K device $(10,000 \mathrm{MWCO})$. Stability and purity were confirmed by SDS-PAGE and concentration was estimated by comparison to known BSA standards.

\section{Purification of MBP-Sine Oculis}

pMAL-c4x plasmids expressing MBP-Fusions were transformed into E. coli BL21 cells containing pT-TRX, a thioredoxin expressing plasmid. Cell cultures were grown to a target $\mathrm{OD}_{600}$ of 0.7 in $2 x Y T A$ containing $150 \mu \mathrm{g} / \mathrm{mL}$ ampicillin. Protein expression was induced using a final concentration of $1 \mathrm{mM} \mathrm{IPTG}$ at $30 \mathrm{C}$ with vigorous shaking for approximately 3 hours. Cells were harvested by centrifugation and resuspended in $8 \mathrm{~mL}$ of phosphate buffered saline containing $5 \mathrm{mM}$ EDTA, $0.1 \mathrm{mM}$ PMSF and $0.2 \% \beta$ mercaptoethanol. Cells were treated with lysozyme at a concentration of $1 \mathrm{mg} / \mathrm{mL}$ on ice for 30 minutes followed by pulse sonication for approximately 30 seconds. Nearly 
complete lysis was verified by phase contrast microscopy. Subsequently, 10\% Triton-X 100 was added to a final concentration of $1 \%$ and the lysed fraction was incubated at 4C for approximately 1 hour. Insoluble components were precipitated by centrifugation. The MBP-protein supernatant was applied to amylose resin (NEB) and incubated at $4 \mathrm{C}$ with nutation for $\sim 2$ hours. The bead matrix was then washed with 10 bed volumes of column buffer (20 mM Tris- $\mathrm{HCl}, \mathrm{pH}$ 7.4, $0.2 \mathrm{M} \mathrm{NaCl}, 1 \mathrm{mM}$ EDTA, $1 \mathrm{mM}$ DTT and 0.1 $\mathrm{mM}$ PMSF). Bound protein was then eluted in five $1 \mathrm{~mL}$ fractions using column buffer supplemented with maltose $(10 \mathrm{mM})$. Pooled fractions were then concentrated and exchanged into storage buffer (10 mM Tris pH-8.0, $0.5 \mathrm{mM}$ EDTA, 5\% glycerol, $150 \mathrm{mM}$ $\mathrm{NaCl}, 0.1 \mathrm{mM}$ PMSF, $0.02 \%$ Sodium Azide) using an Amicon Ultra-15 10K device $(10,000 \mathrm{MWCO})$. Stability and purity were confirmed by SDS-PAGE and concentration was estimated by comparison to known BSA standards.

\section{Protein Kinase CK2 Phosphorylation Assay}

Each kinase reaction was performed at approximately $25 \mathrm{C}$ in $50 \mathrm{mM}$ Tris, $\mathrm{pH} 8.5$ $100 \mathrm{mM} \mathrm{NaCl}, 10 \mathrm{mM} \mathrm{MgCl}_{2}, 10 \mu \mathrm{M}$ ATP, $2.5 \mu \mathrm{Ci}$ of [Y- $\left.{ }^{32} \mathrm{P}\right] \mathrm{ATP}$ and $\sim 2 \mu \mathrm{g}$ of the respective GST or MBP-Fusion of $\mathrm{E}(\mathrm{spl}) \mathrm{My}, \mathrm{EMC}$, and Sine Oculis proteins in a total volume of $40 \mu \mathrm{L}$. The reaction was initiated with the respective enzymes (dCK2 $\alpha$ or CK2-HoloE) to a final concentration of $0.5 \mathrm{ng} / \mu \mathrm{L}$ using $5 \mu \mathrm{L}$ of $4 \mathrm{ng} / \mathrm{mL}$ kinase solution in $20 \mathrm{mM}$ Tris, pH 8.0, 0.4 mM EDTA, $200 \mathrm{mM} \mathrm{NaCL}, 10 \%$ glycerol, $0.5 \mathrm{mM}$ DTT, and $0.05 \%$ Triton $X-100$. The individual modulators were added to the reactions such that the final concentrations were GTP $(60 \mu \mathrm{M})$, heparin $(1 \mu \mathrm{g} / \mathrm{mL})$, protamine $(125 \mu \mathrm{g} / \mathrm{mL})$, spermine $(500 \mu \mathrm{g} / \mathrm{mL})$ and poly-lysine $(100 \mu \mathrm{g} / \mathrm{mL})$. Reaction termination was achieved using $10 \mu \mathrm{L} 5 \mathrm{x}$ sample buffer (312 mM Tris-Cl, pH 6.8, 10\% SDS, $25 \% \beta$ - 
mercaptoethanol and $40 \%$ glycerol) and boiled for 10 minutes. Samples were resolved by SDS-PAGE using the Laemmli system and stained with Coomassie. Radioactivity was detected using BlueDevil Film ${ }^{\mathrm{TM}}$ and developed using Kodak GBX developer and fixer.

\section{Structural Prediction of Sine Oculis}

The primary sequence of SO was downloaded from 'flybase.org' and submitted to the iTASSER online 3D structural prediction software (Zhang, 2008; Roy et al., 2010). Additionally, the serines of SO determined to be targets of protein kinase CK2 (Ser ${ }^{290-292}$ and $\mathrm{Ser}^{294}$ ) were changed to phosphomimetic aspartate residues. The two highest scoring structures were then compared using the SwissPDB Viewer. 


\section{RESULTS AND DISCUSSION}

\section{E(spl)My}

\section{Computational Identification of E(spl)My as a potential target for CK2}

The primary sequences of $\mathrm{E}(\mathrm{spl}) \mathrm{My}$ were obtained from flybase.org and aligned using the online software 'MUSCLE'. These sequences represent approximately 50 myr of Drosophila evolution and include 13 species. It was found that $\mathrm{E}(\mathrm{spl}) \mathrm{My}$ from all 13 species contain three highly conserved consensus sites for CK2 (Fig. 1). Two of these sites $\left(\mathrm{Thr}^{45}\right.$ and $\left.\mathrm{Ser}^{48}\right)$ are located within the loop of the HLH domain that immediately follows the N-terminal basic motif. It is of interest to note that of the seven $\mathrm{E}(\mathrm{spl}) \mathrm{bHLH}$ O proteins, $\mathrm{E}(\mathrm{spl}) \mathrm{My}$ is the only member to contain a potential site for CK2 within the HLH (see Fig. 3, Ch. 1). The second site $\left(\operatorname{Ser}^{195}\right)$ is located near the C-terminal WRPW motif and is notable because this region is especially rich in acidic amino acids (D/E) a hallmark of 'high likelihood' targets of CK2. In contrast, the N-terminal CK2 sites present the possibility of hierarchical phosphorylation, i.e., phosphorylation of $\mathrm{Ser}^{48}$ is predicted to lead to substrate modification of $\mathrm{Thr}^{45}$.

\section{Phosphorylation of E(spl)My by CK2}

To determine if $\mathrm{E}(\mathrm{spl}) \mathrm{My}$ is phosphorylated by $\mathrm{CK} 2$, two forms of the enzyme were employed. These include monomeric Drosophila CK2 $\alpha(\mathrm{dCK} 2 \alpha)$ purified from yeast lacking endogenous CK2 genes and rescued by a cDNA encoding dCK2 $\alpha$ (Bidwai et al., 1992), and native $\alpha 2 \beta 2$ holoenzyme (CK2-HoloE) purified from Drosophila embryos. Both preparations are essentially pure based on Coomassie staining (Fig. 2). The weak stain of CK2 $\beta$ relative to CK2 $\alpha$ (Fig. 2) does not reflect sub-stoichiometric 
CK2 $\beta$, but instead weak staining of this phosphoprotein, which has been noted earlier (Bidwai et al., 1992).

The two isoforms of CK2 were used to determine if phosphorylation of $\mathrm{E}(\mathrm{spl}) \mathrm{My}$ is promoted or inhibited by $\mathrm{CK} 2 \beta$, as has been observed for other proteins. In these assays, $20 \mathrm{ng}$ of dCK2 $\alpha$ or CK2-HoloE were used and consequently proteins with the mobility of $d C K 2-\alpha / \beta$ are not discernable in SDS-PAGE gels stained with Coomassie (Fig. 2, top). E(spl)My was purified as a GST fusion, while GST-alone and GST$\mathrm{E}(\mathrm{spl}) \mathrm{M} 8$ were used as negative and positive controls, respectively. As shown in Figure 2, $\mathrm{E}(\mathrm{spl}) \mathrm{My}$ was robustly phosphorylated by $\mathrm{dCK} 2 \alpha$ and CK2-HoloE. Phosphorylation is specific to $\mathrm{E}(\mathrm{spl}) \mathrm{My}$ as GST-alone was not modified by either isoform. A comparison of the band intensities reveals that CK2-HoloE phosphorylates $\mathrm{E}(\mathrm{spl}) \mathrm{My}$ to a greater extent than that with $\mathrm{dCK} 2 \alpha$. This difference more likely reflects greater activity of the holoenzyme, rather than a requirement for CK2 $\beta$. Phosphorylation of E(spl)M8 (positive control) was also observed with both isoforms, although the presence of CK2 $\beta$ appears to diminish the extent of phosphorylation. Thus, like $\mathrm{E}(\mathrm{spl}) \mathrm{M} 8, \mathrm{E}(\mathrm{spl}) \mathrm{My}$ is an in vitro target for CK2.

\section{Map the CK2 site(s) in E(spl)My}

Because $\mathrm{E}(\mathrm{spl}) \mathrm{My}$ harbors multiple CK2 consensus sequences, the protein was dissected to identify sites that are phosphorylated in vitro. The protein was divided into two regions. The first, $\mathrm{E}(\mathrm{spl}) \mathrm{MY}^{*}$, represents the $\mathrm{N}$-terminus through the end of the Orange domain (Fig. 3), whereas the second, E(spl)My-CtD, represents sequences from the end of Orange to the WRPW motif (Fig. 3). These two regions isolate the CK2 sites within the HLH from the one proximal to the WRPW motif. Constructs were 
generated by PCR and verified by sequencing (Fig. 3). In addition, site directed mutagenesis was used to replace potential CK2 phosphoacceptors with Ala to generate non-phosphorylatable variants. All of these variants have been verified by sequencing (Fig. 3).

$\mathrm{E}(\mathrm{spl}) \mathrm{My}$ variants were purified to homogeneity and phosphorylated using CK2HoloE as described above. Because the CK2 $\beta$ subunit does not inhibit targeting of $\mathrm{E}(\mathrm{spl}) \mathrm{M} \gamma$, phosphorylation reactions employing dCK2 $\alpha$ were deemed unnecessary for mapping studies. In brief, $20 \mathrm{ng}$ of CK2-HoloE was used to phosphorylate $0.5-1.0 \mu \mathrm{g}$ of $\mathrm{E}(\mathrm{spl}) \mathrm{My}$ variants under conditions (steady state) where enzyme activity is linear with time. GST-alone was used as a negative control. As shown in Fig. 3, My-CtD was efficiently phosphorylated by CK2, a reaction that was completely blocked by replacing $\operatorname{Ser}^{195}$ with Ala. This absence of phosphorylation is seen even though equivalent amounts of MY-CtD and its $\mathrm{S}^{195} \mathrm{~A}$ variant were used in the assays (Fig. 3, see gel). Furthermore, Ser ${ }^{195}$ appears to be the primary site for phosphorylation by CK2, as its replacement with Ala in full-length My also blocked phosphorylation (Fig. 3, see FL$\mathrm{S}^{195} \mathrm{~A}$ ). To independently verify that CK2 does not target sites in the HLH, studies were

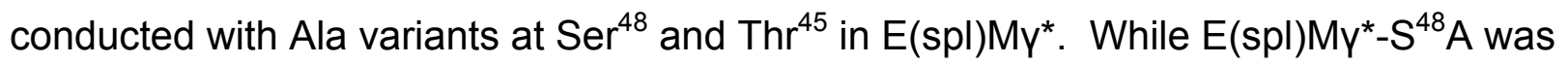

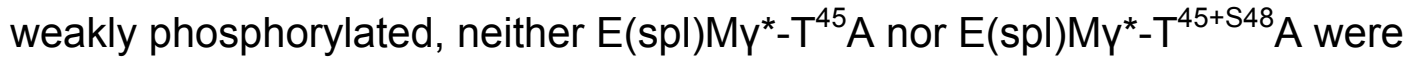

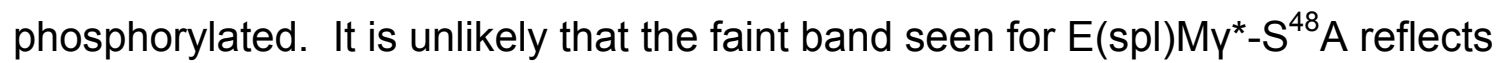
modification of $\mathrm{Thr}^{45}$, because full-length $\mathrm{E}(\mathrm{spl}) \mathrm{My}$ with the $\mathrm{S}^{195} \mathrm{~A}$ mutant displays no such baseline phosphorylation. It is therefore more likely that the faint band with $\mathrm{E}(\mathrm{spl}) \mathrm{MY}{ }^{*}-\mathrm{S}^{48} \mathrm{~A}$ is an in vitro artifact. Thus, $\mathrm{E}(\mathrm{spl}) \mathrm{My}$ is modified only at $\mathrm{Ser}^{195}$ by CK2. 


\section{Modulate CK2 targeting of E(spl)MY}

It remained possible that a minor enzyme contaminant from either the CK2HoloE preparation or the GST-E(spl)My purification was responsible for the observed phosphorylations. To exclude this possibility, the CK2-HoloE phosphorylation of GST$\mathrm{E}(\mathrm{spl}) \mathrm{My}$ wild type protein was tested in the presence of various small molecule competitors (GTP), inhibitors (Heparin), or polybasic activators (Fig. 4).

First, the unusual property that CK2 can use GTP as an alternative phosphodonor was exploited. In this assay, phosphorylation reactions contained [ $\left.\mathrm{Y}^{32} \mathrm{P}\right]-$ ATP at a concentration of $15 \mu \mathrm{M}(1 \mathrm{xKm})$, but were supplemented with cold-GTP at a concentration of $60 \mu \mathrm{M}$. In this assay, cold-GTP would compete with $\left[\mathrm{Y}^{32} \mathrm{P}\right]-\mathrm{ATP}$, resulting in a decrease in phosphorylation, but only if the enzyme is CK2. Indeed, GTP $(60 \mu \mathrm{M})$ decreases ${ }^{32} \mathrm{P}$-incorporation into GST-E(spl)My. Likewise, the oligosaccharide heparin $(1 \mu \mathrm{g} / \mathrm{mL})$, a CK2 specific inhibitor, also effectively diminished phosphorylation of GST-E(spl)My.

It has been previously shown that polybasic compounds interact with negatively charged residues in the CK2 $\beta$ subunit and thereby stimulate the activity of CK2-HoloE. In these experiments reactions were conducted in the presence of, protamine, spermine and poly-lysine $(125 \mu \mathrm{g} / \mathrm{mL}, 500 \mu \mathrm{g} / \mathrm{mL}$, and $100 \mu \mathrm{g} / \mathrm{mL}$, respectively). It was found that these compounds modestly increase phosphorylation of GST-E(spl)My. Because GSTalone is not phosphorylated by CK2-HoloE in the absence of these effectors (Fig. 4), or in their presence (Trott et al., 2001a; Trott et al., 2001b), the phosphorylation sites are specific to the $E(s p l) M y$ fusion component and the associated modulation of kinase 
activity is consistent with CK2. Taken together, these studies confirm E(spl)My as a bona fide substrate of CK2.

\section{Extramacrochaetae}

\section{Computational Identification of EMC as a potential target for CK2}

The primary sequences of 11 Drosophila EMC orthologs were downloaded from flybase.org and aligned using the online software 'MUSCLE' (Fig. 5). From this alignment, two CK2 consensus sites were identified. The first site lies near the Cterminal end of the $\mathrm{HLH}$ within the sequence $\mathrm{T}^{77}$-E-L-E. This motif is invariable among the 11 Drosophila homologs analyzed (Fig. 5). The second site, located approximately 30 residues $\mathrm{C}$-terminal of the $\mathrm{HLH}$, is in a highly acidic region characteristic of CK2 target sites. This feature makes this site a primary candidate for CK2 phosphorylation. Though the latter site is variable in both sequence and position (Fig. 5), the persistence of these two consensus motifs through 50 myr of evolution is suggestive of phosphoregulation in a region near the HLH.

Interestingly, the human homolog ID1 maintains a CK2 site immediately after the second helix of the HLH, analogous to one of the two sites in Drosophila homologs at $\mathrm{Thr}^{77}$ (Homo sapiens ID1, Fig. 5). Interestingly, the CK2 site in hsID1 is known to be a phosphoprotein based on mass-spectroscopic analysis (Mayya et al., 2009). The conservation of the CK2 site and its position in EMC/ID1 raise the likelihood that this motif is of regulatory importance. 


\section{Phosphorylation of EMC by CK2}

The two isoforms of dCK2 (described above, see Fig. 3) were used to determine if EMC is a target for this protein kinase. To this end, EMC was purified as a GSTfusion while GST-alone and GST-E(spl)M8 served as positive and negative controls, respectively. Qualitatively, CK2 $\alpha$ and CK2-HoloE have similar kinase activities with respect to EMC, revealing that targeting of this protein is neither dependent upon CK2 $\beta$ nor inhibited by it (Fig. 6). GST-alone was not phosphorylated by either CK2 isoform, indicating that phosphorylation is specific to EMC. Similarly, phosphorylation of $\mathrm{E}(\mathrm{spl}) \mathrm{M} 8$ occurred in the presence of both kinase isoforms, though the CK2-HoloE produced significantly less phosphoprotein as previously described (see above, Fig.2). These results reveal that EMC is targeted by CK2.

\section{Map the CK2 site(s) in EMC}

EMC contains multiple CK2 consensus sequences and thus required the generation of non-phosphorylatable variants to identify which of these are targeted in vivo. Site directed mutagenesis was used to substitute Ala for $\operatorname{Thr}^{77}\left(T^{77} A\right)$ and $\operatorname{Ser}^{106}$ $\left(S^{106} A\right)$ individually or in combination $\left(T^{77} A+S^{106} A\right)$ (Fig. 7). All mutants were verified by sequencing.

The aforementioned EMC-variants were purified as GST-fusions and their ability to be phosphorylated was tested using the CK2-HoloE. Equivalent amounts of wild-type and mutant proteins were used in the phosphorylation experiments (Fig. 7, gel). While WT-EMC was robustly phosphorylated, the $T^{77} A+S^{106} A$ mutant was refractory. Additionally, substitution of $\mathrm{Ser}^{106}$, but not $\mathrm{Thr}^{77}$, caused complete loss of ${ }^{32} \mathrm{P}$ - 
incorporation. In these assays, GST-alone was not targeted by CK2. These experiments confirm that $\mathrm{Ser}^{106}$ is the sole CK2 phosphoacceptor in EMC.

\section{Modulate CK2 targeting of EMC}

The possibility that a contaminating enzyme is responsible for phosphorylation was addressed using specific modulators of CK2 function. GST alone was used as a negative control and exhibited no detectable phosphorylation (arrow, Fig. 8). GTP (60 $\mu \mathrm{M})$ and heparin $(1 \mu \mathrm{g} / \mathrm{mL})$ were used to compete with [Y $\left.{ }^{32} \mathrm{P}\right]$ ATP as substrate and attenuate kinase activity, respectively. It was found that both of these molecules decrease the phosphorylation of wild-type EMC in their respective reactions (Fig. 8). Conversely, the polybasic activators protamine $(125 \mu \mathrm{g} / \mathrm{mL})$ and spermine $(500 \mu \mathrm{g} / \mathrm{mL})$ did not enhance phosphorylation of EMC (Fig. 8), whereas poly-lysine resulted in a slightly decrease in phosphorylation. This is the first example of poly-lysine causing a decreased phosphorylation of a protein and the reasons remain unclear. Taken together, these results authenticate the phosphorylation of EMC by CK2 and provide a foundation for future analysis in vivo.

\section{Sine Oculis}

\section{Computational Identification of Sine Oculis as a potential target for CK2}

Drosophila Sine Oculis (SO) contains a stretch of 4 serines in an acidic motif that lies in the vicinity of the homeodomain (Ser ${ }^{290}$ to $\operatorname{Ser}^{294}$ Fig. 9A). Ser ${ }^{292}$ and $\operatorname{Ser}^{294}$ fit the strict CK2 consensus, while Ser ${ }^{290}$ and $\operatorname{Ser}^{291}$ are candidates for hierarchical phosphorylation originating from the former high affinity sites (Figure 9A). It is interesting that these orthologs are highly conserved throughout the homeodomain and 
CK2 motif but little conservation exists in regions immediately C-terminal (Figure 9A and not shown). Additionally, human homologs of fly SO, i.e. SIX1 and SIX2, maintain these CK2 sites, though they have been displaced toward the C-terminus by several residues (Figure 9B). Because the SIX1 and SIX2 phosporylation sites have become displaced from the primary DNA interacting helix of the homeodomain, it is possible that a more complex conformational shift accounts for changes in DNA binding affinity. Regardless, extensive site conservation marks CK2 as a prime regulator of SO/SIX activity. While previous work has demonstrated that CK2 phosphorylation prevents DNA binding by SIX1 (Ford et al., 2000), little is known about the CK2 targeting of the Drosophila homolog or the consequences in vivo.

\section{Phosphorylation of Sine Oculis by CK2}

GST-fusions of SO were not used because of excessive susceptibility to degradation (data not shown). Moreover, it has been found that human SIX1 cannot be purified as a GST-fusion, but can be when fused to maltose binding protein (MBP). Even when purified as an MBP-fusion, SO displays three major and several minor bands on SDS-PAGE gels stained with Coomassie (Fig. 10, gel). These bands are seen despite the presence of protease inhibitors and likely reflect degradation in vivo ( $E$. coli). This problem has also been encountered with human SIX1 (Hieda Ford, personal communication).

The two isoforms of dCK2 (described above, Fig. 3) were used in kinase assays to test of isoform specificity. To determine if $\mathrm{SO}$ is a target of CK2, MBP-SO was purified to homogeneity along with the negative and positive controls MBP-alone and GST-M8. While MBP-alone was not phosphorylated by either dCK2 $\alpha$ or CK2-HoloE, 
GST-M8 displayed higher levels of phosphorylation by the monomeric catalytic subunit (Fig.10). The purified MBP-SO was unstable and multiple degradation products are visible in Coomassie staining. It is clear CK2 $\alpha$ and CK2-HoloE robustly phosphorylate SO, indicating that targeting is independent of CK2 $\beta$. Additionally, because only the two largest products are phosphorylated by CK2, it is likely that the observed degradation originates from the $\mathrm{C}$-terminus. These results demonstrate that $\mathrm{SO}$ is a substrate of CK2.

\section{Map the CK2 site(s) in Sine Oculis}

To identify the residues of SO that are phosphorylated, three substitution variants containing alanine at the relevant positions were generated by site directed mutagenesis and verified by sequencing (data not shown). The wild type protein contains the sequence motif $\mathrm{S}^{290}$ SSDSEME ${ }^{297}$ that was targeted for mutagenesis. The mutants that were generated are $\mathrm{S}^{290+291} \mathrm{~A}$ (AASDSEME), $\mathrm{S}^{292+294} \mathrm{~A}$ (SSADAEME) and $\mathrm{S}^{290+291+292+294} \mathrm{~A}$ (AAADAEME). These variants were purified to homogeneity as MBPfusions and each exhibit instability comparable to the wild type protein, as described above.

Phosphorylation reactions were conducted using only the CK2-HoloE, because both isoforms of CK2 exhibit equivalent activities. Also, identical amounts of protein were used though the $\mathrm{S}^{292+294} \mathrm{~A}$ variant appears to be slightly less abundant (Fig. 11, gel) MBP-alone (negative control) nor the $\mathrm{S}^{290+291+292+294} \mathrm{~A}$ were phosphorylated by the CK2-HoloE, verifying that kinase activity is specific to the computationally predicted motif (Figure 11). Both wild type $\mathrm{SO}$ and $\mathrm{S}^{290+291} \mathrm{~A}$ exhibit equivalent and high levels of phosphorylation establishing $\operatorname{Ser}^{292}$ and $\operatorname{Ser}^{294}$ as CK2 targets. Low levels of 
phosphorylation that was observed for the $S^{292+294} A$ variant positively identified phosphorylation of $\mathrm{Ser}^{290}$ and $\mathrm{Ser}^{291}$. A modest decline in radioactivity for $\mathrm{S}^{290+291} \mathrm{~A}$ as compared to wild type protein serves as an indication that $\operatorname{Ser}^{290}$ and $\mathrm{Ser}^{291}$ are phosphorylated. The phosphorylation of $\operatorname{Ser}^{290}$ and $\operatorname{Ser}^{291}$ independent of phosphoaddition to $\operatorname{Ser}^{292}$ and $\mathrm{Ser}^{294}$ demonstrates that modification of the former is not exclusively hierarchical (see Ch. 1, Fig. 3 and Ch. 2, Fig. 11). However, it is likely that acidification of the region through phosphorylation of the high affinity sites (Ser ${ }^{290}$ and $\operatorname{Ser}^{291}$ ) enhances targeting of the Ser residues nearby. Thus, it has been demonstrated that the residues in the conserved CK2 consensus motif are phosphorylated in vitro.

\section{Modulate CK2 targeting of Sine Oculis}

The possibility remained that a contaminating enzyme from the MBP purification or CK2 kinase preparations was responsible for the observed phosphorylations. To eliminate this possibility, cold GTP $(60 \mu \mathrm{M})$ and the CK2 specific inhibitor heparin $(1 \mu \mathrm{g} / \mathrm{mL})$ were used to compete with [Y $\left.{ }^{32} \mathrm{P}\right]$ ATP as substrate or inhibit enzyme activity, respectively. It was found that the addition of GTP potently decreases the levels of radioactivity incorporated into MBP-SO. Unexpectedly, heparin did not inhibit the CK2 reaction as expected, instead the levels of radioactivity increased (Fig. 12). The possibility is likely that this is an experimental artifact.

I next tested if SO phosphorylation was modulated by the poly-basic activators. Protamine $(125 \mu \mathrm{g} / \mathrm{mL})$ and spermine $(500 \mu \mathrm{g} / \mathrm{mL})$ did not further increase phosphorylation of MPB-SO as compared to the unmodulated reaction (Fig. 12). In contrast and unexpectedly, poly-lysine $(100 \mu \mathrm{g} / \mathrm{mL})$ dramatically decreased phosphorylation of SO (Fig. 12). This effect was greatest with the high molecular weight 
rather than the low molecular weight degradation product. These results are inconsistent with expectation and may reflect a procedural error whereby the heparin and poly-lysine modulated reactions was interchanged. The results of the isoform and mapping experiments together, demonstrate that CK2 is a potent post-translational modifier of SO.

\section{Structural insights into CK2 regulation of Sine Oculis}

Ford et al. (2001) demonstrated that human SIX1 phosphorylation by CK2 abrogates DNA binding. This is likely due, in part, to the proximity of the phosphorylation sites to the nearly invariant DNA binding helix of the homeodomain. However, the mechanism by which DNA binding is altered by phosphorylation has remained unexplored. To make inferences about the underlying mechanism, the wildtype primary sequence and the phosphomimetic version $\left(S^{290+291+292+294} D\right)$ were submitted to the iTASSER structural prediction software (Zhang, 2008; Roy et al., 2010). The algorithm produced very similar outputs for the two sequences. However, one striking difference is the rotation of an $\alpha$-helix in the C-terminal region of the SIX domain (Fig. 13). Upon further inspection, the last $\alpha$-helix of the SIX domain (hereafter $\alpha-6)$, nearest the $\mathrm{N}$-terminus of the homeodomain, contains a number of basic residues, similar to a basic motif present in DNA binding molecules.

BindN+, a bioinformatics tool that predicts DNA binding based on primary sequence, indicates that $\alpha-6$ is an excellent candidate for protein-DNA interface (Fig. 13). Moreover, DISPLAR, which takes into account 3D structural features in predicting DNA interaction, identifies $\alpha-6$ as a potential DNA interactor for both models (not shown). These findings are suggestive of an incomplete understanding of SIX family 
protein function and regulation. It could be that the $\alpha-6$ helix is important for stable formation of the SO/Eya complex with DNA. Alternatively, CK2 phosphorylation may block DNA interaction through the homeodomain while simultaneously unmasking a-6 for DNA binding. This effect could change the sequence specificity of the transcriptional activation complex. As these data are predictive, biochemical and genetic analysis are needed to provide direct evidence for these inferences.

\section{SIGNIFICANCE}

\section{CK2 and the regulation of E(spl)My}

The phosphorylation of $\mathrm{E}(\mathrm{spl}) \mathrm{My}$ by $\mathrm{CK} 2$ brings to four the number of $\mathrm{E}(\mathrm{spl}) \mathrm{C}$ repressors targeted by this kinase. While $\mathrm{E}(\mathrm{spl}) \mathrm{M} 8$ has been studied at length and the autoinhibition model is supported by trans-inhibition of hypermorphic variants (Kahali et al., 2010), a similar molecular mechanism can not be transposed to E(spl)My. Though all CK2 sites are located in the CtD of these repressors, the relative location in $\mathrm{E}(\mathrm{spl}) \mathrm{My}$ is distinct in that it is juxtaposed to the WRPW. Given the proximity of this kinase site to the Gro interaction motif, a simple and eminently testable hypothesis is that CK2 influences co-repressor (Gro) binding capacity. If this were the case, CK2 would serve to inhibit $\mathrm{E}(\mathrm{spl}) \mathrm{My}$ repressor activity, an effect opposite that observed in the case of E(spl)M8.

Additionally, alignment of distant homologs indicates the continual presence of the 'PLSP' sequence motif may be of importance. Kinases that have demonstrated preferential targeting of this sequence motif include a number of cyclin dependent kinases (CDKs), mitogen activated protein kinases (MAPKs), and GSK3. In E(spl)M8, 
phosphomimicry at an analogous motif, in both sequence and position, leads to a more potent repressor activity (Bandyopadhyay, personal communication).

It seems as though the complement of kinases that target the $E(s p l)$ repressors that are active during eye development has been conserved to some extent (CK2, MAPKs etc.). However, the associated consequences may be varied. For example, if the phosphorylation of $\mathrm{E}(\mathrm{spl}) \mathrm{My}$ prevents binding of the corepressor Gro, dimerization with other repressors could negatively regulate repression. Alternatively, formation of a stable complex between $\mathrm{E}(\mathrm{spl}) \mathrm{My}$ and Gro might serve as a regulatory mechanism for the timing of transcriptional events. Genetic testing and biochemical studies will be required to evaluate these hypotheses.

\section{CK2 and the regulation of Extramacrochaetae}

While previous high throughput studies have indicated that the human ID1 is phosphorylated at an analogous site, the identification of CK2 as a post-translational modifier of EMC/ID1 is the first of its kind. It can be seen that the region in which the Drosophila CK2 sites are located have experienced insertion or deletion (indel) events (Fig.5). However, the resilience of the CK2 site in both proteins, along with the phosphorylation status of human ID1 (see above), suggests an important regulatory function, yet to be fully understood. For Drosophila, it is difficult to infer a simple mechanism because the region of phosphorylation tends to be hyper-acidic. However, when considering the conservation of a CK2 site near the C-terminus of the stereotyped $\mathrm{HLH}$ in ID1, it seems reasonable to estimate that dimerization involving EMC/ID1 and other HLH proteins is being modulated. If so, phosphorylation could establish a negatively charged surface that forms stabilizing interactions with the basic domain of 
target proteins or other regions through charge interactions such as salt bridges. Conversely, phosphorylation may block the ability of EMC/ID1 to form stable interactions due to conformational alteration or steric hindrance.

These findings have interesting implications for a number of developmental processes in Drosophila. First, EMC is known to be required for the formation of tubular structures in the wing and digestive tract, an as yet unexplored role for CK2. Also, a relationship between EMC and CK2 during neurogenesis is a new and critical association. This is because regulation of morphogenetic furrow movement is strongly dependent upon EMC and could be post-translationally controlled by CK2. With respect to bristle development, EMC loss of function yields ectopic macrochaetae (Ellis et al., 1990; Garrell and Modolell, 1990; Cubas et al., 1994), as does CK2 loss of function (Bose et al., 2006). This is likely a direct consequence of enhanced proneural activity and compromised lateral inhibition, respectively. However, phospho-regulation of EMC could be an additional, underlying mechanism that drives the observed effects of CK2 deficiency. Combinations of emc and CK2 alleles would allow for assessment of their genetic interactions.

Extension of these findings into the human system is a paramount aspect of future studies, because this single phosphorylation may have relevance in understanding the development of disease states. For example, ID1 is an involved factor during angiogenesis, which is required for the survival of large, often invasive tumors (Lyden et al., 1999). Additionally, expression of ID1 expression is commonplace in neoplastic tissues as it prevents the onset of differentiation. Therefore, analysis of 
EMC/ID1 will contribute to an understanding of why inhibition of CK2 may be contraindicated or aid in the chemotherapeutic inhibition of cancerous growth.

\section{CK2 and the regulation of Sine Oculis}

As it is for SIX1, phosphorylation of SO by CK2 is likely a critical regulatory event. Specifically, during eye development, DNA binding and transcriptional activation by the SO/EYA complex is an area of immediate investigation. The consequences of this are yet to be analyzed, but the failure to accomplish retinal determination is a potential outcome. The investigation of this question is possible using specific expression of the mutants in the relevant tissues and time points via the UAS-GAL4 system. Based on the effects of variants that mimic constitutively phosphorylated SO (Asp substitutions) or those that are refractory to phosphorylation by CK2 (Ala substitutions, see above), a more detailed understanding of the in vivo consequences underlying CK2 phosphorylation of SO can be acquired.

Structurally, phosphorylation by CK2 may instigate conformational changes, which shift the DNA binding of SO/SIX1 from the homeodomain to the SIX-domain. Previous assessments of DNA binding have used double stranded oligonucleotides whose sequence is homeodomain specific (Hazbun et al., 1997; Ford et al., 2000; Liu et al., 2012). This result makes sense for SIX1, as the CK2 phosphorylation sites are in close proximity to the conserved primary DNA binding helix of the homeodomain. However, the DNA interaction of the $\alpha-6$ helix remains undetermined. Based on the high density of basic residues in this helix, the ability to interact with DNA is inferable. This idea is further supported by the observation that SIX1 mutants causing the condition known as BOR syndrome contains amino acid substitutions in $\alpha-6$ that replace 
a number of the basic residues (Patrick et al., 2009). These mutants are deficient in DNA binding activity as assessed for the homeodomain. Moreover, analysis has indicated that slight variations at specific primary sequence positions in the $\alpha-6$ helix account for distinguished sets of cofactor interactions (Kenyon et al., 2005). Therefore, it seems that a source of functional variation among SIX proteins resides in this specific helix and, for SIX1/SO, this could include shifts in DNA binding specificity.

The regulation of DNA binding by SO/SIX1 by CK2 has important implications for cancer onset and progression. Indeed, many neoplastic tissues overexpress both SIX1 and Eya (reviewed in (Christensen et al., 2008)). Additionally, CK2 phosphorylation of SIX1 has been shown to occur in mitotically active cells (Ford et al., 2000). Therefore, a complete understanding of the regulatory mechanism underlying SO/SIX1 DNA binding and transcriptional regulation is important for understanding not only the retinal determination network, but also oncogenesis and other diseases in humans. 


\section{CK2 Phosphorylation sites in E(spl)My}

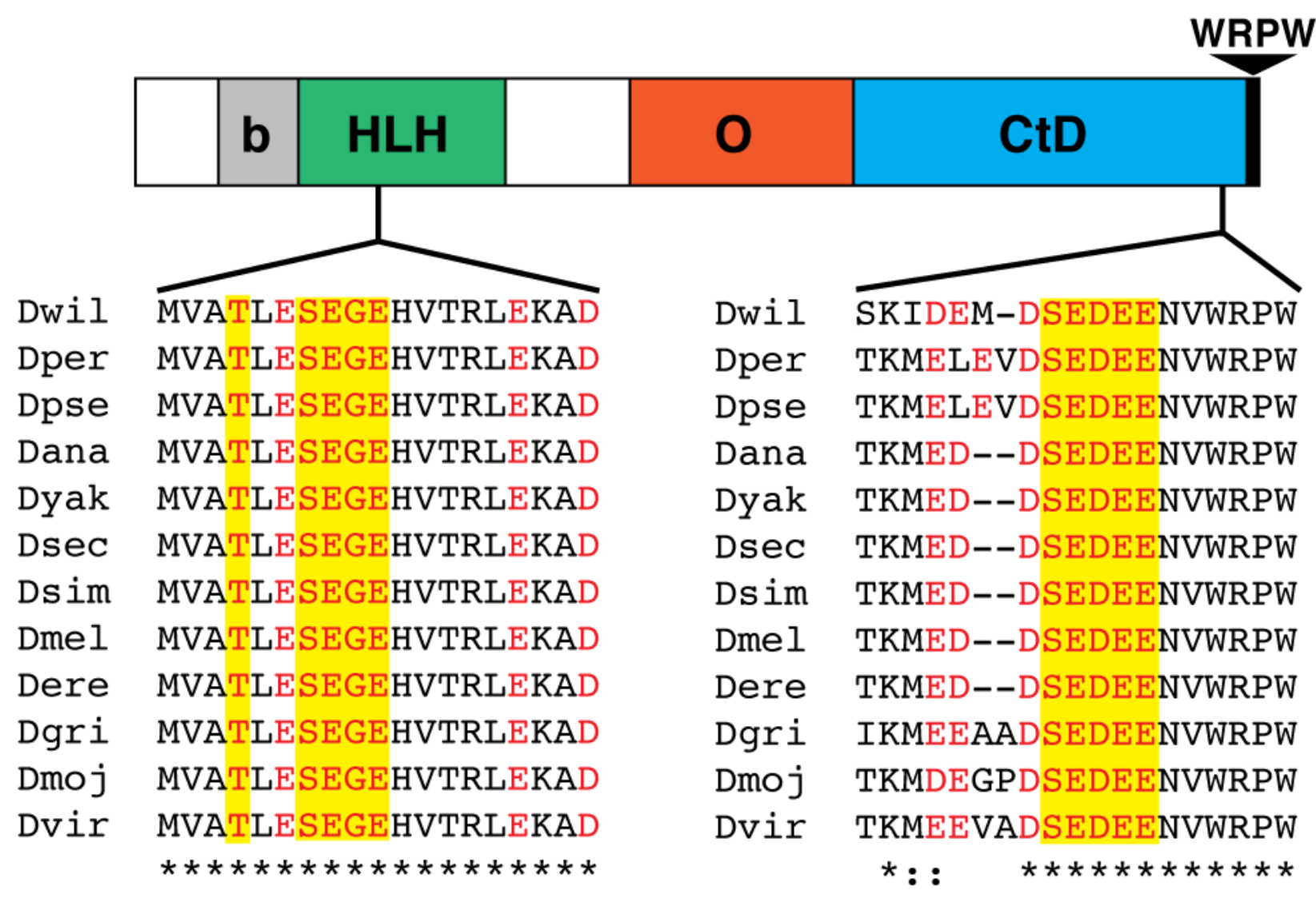

Figure 1: The sequence alignment of $\mathrm{E}(\mathrm{spl}) \mathrm{My}$ homologs reveals $\mathrm{CK} 2$ sites in two disparate locations of the protein. The first site is located within the HLH at Ser ${ }^{48}$. Phosphorylation of this residue could increase local acidity sufficiently to stimulate modification of $\mathrm{N}$-terminal residues, in this case $\mathrm{Thr}^{45}$. An additional site exists in the C-terminus of the protein near the WRPW. Here, Ser195 is positioned in a region of acidic residues, making it a likely target of CK2. The positioning of this phosphorylation site so near the WRPW co-repressor binding motif raises the possibility of repressor inhibition or activation as a consequence of CK2 targeting. Drosophila melanogaster (Dmel), D. willistoni (Dwil), D. pseudoobscura (Dpse), D. ananassae (Dana), D. yakuba (Dyak), D. sechellia (Dsec), D. simulans (Dsim), D. erecta (Dere), D. grimshawi (Dgri), D. mojavensis (Dmoj), D. virilis (Dvir). 


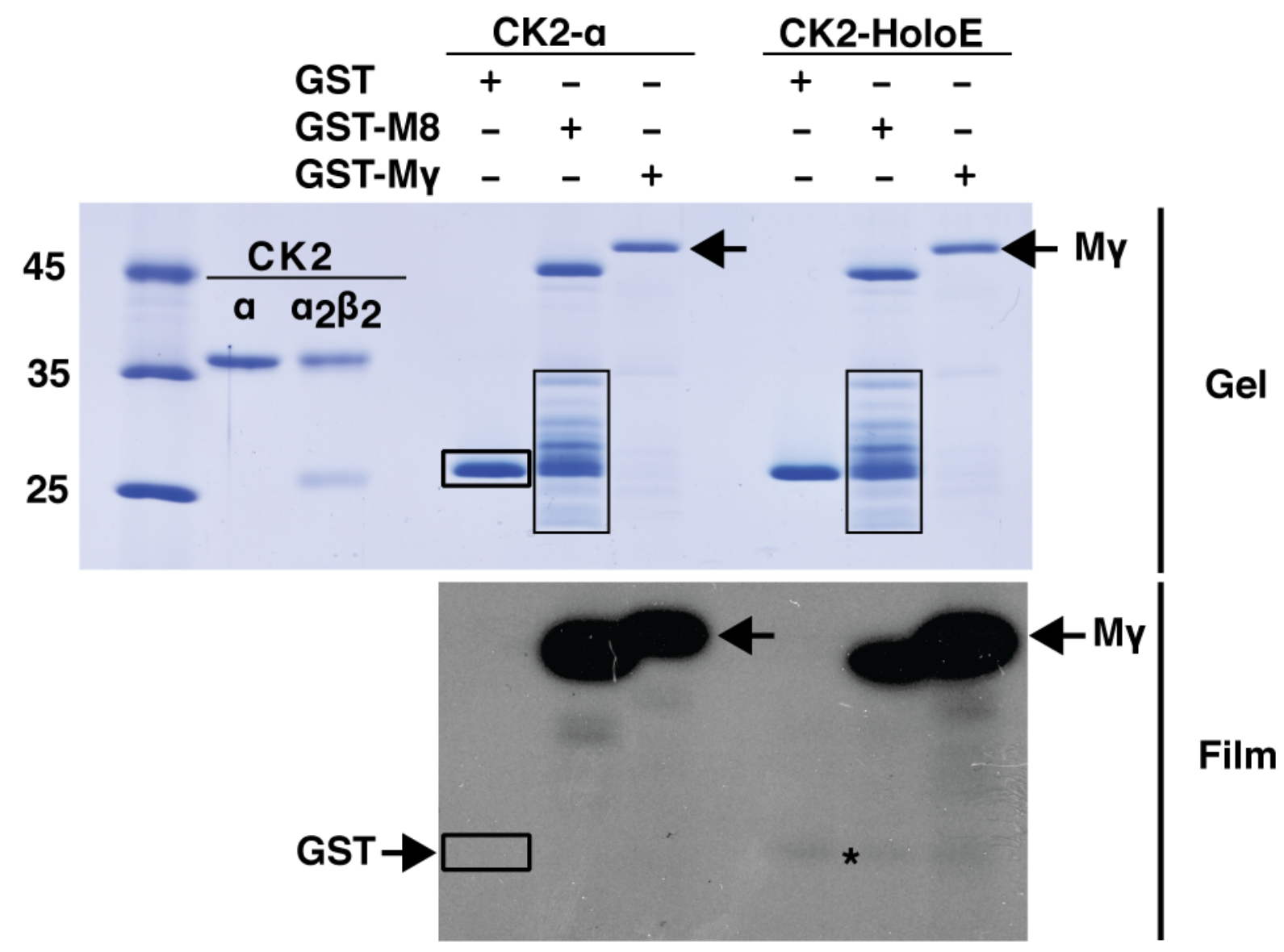

Figure 2: The CK2 isoforms used in these studies are highly pure and stable as observed by Coomassie staining. The negative control (GST, arrow) displays no radioactivity and therefore is not a target of CK2. The positive control, $\mathrm{E}(\mathrm{spl}) \mathrm{M} 8$ exhibits robust phosphorylation in the presence of both CK2 isoforms, demonstrating that the kinase is active. Here, it can be seen that CK2 recognizes $\mathrm{E}(\mathrm{spl}) \mathrm{My}$ as a substrate and this targeting is enhanced by the $\beta$-subunit. Asterisk $\left(^{*}\right)=\beta$-subunit autophosphorylation. Boxes $=\mathrm{E}(\mathrm{spl}) \mathrm{M} 8$ degradation. Arrow $=\mathrm{GST}$. 

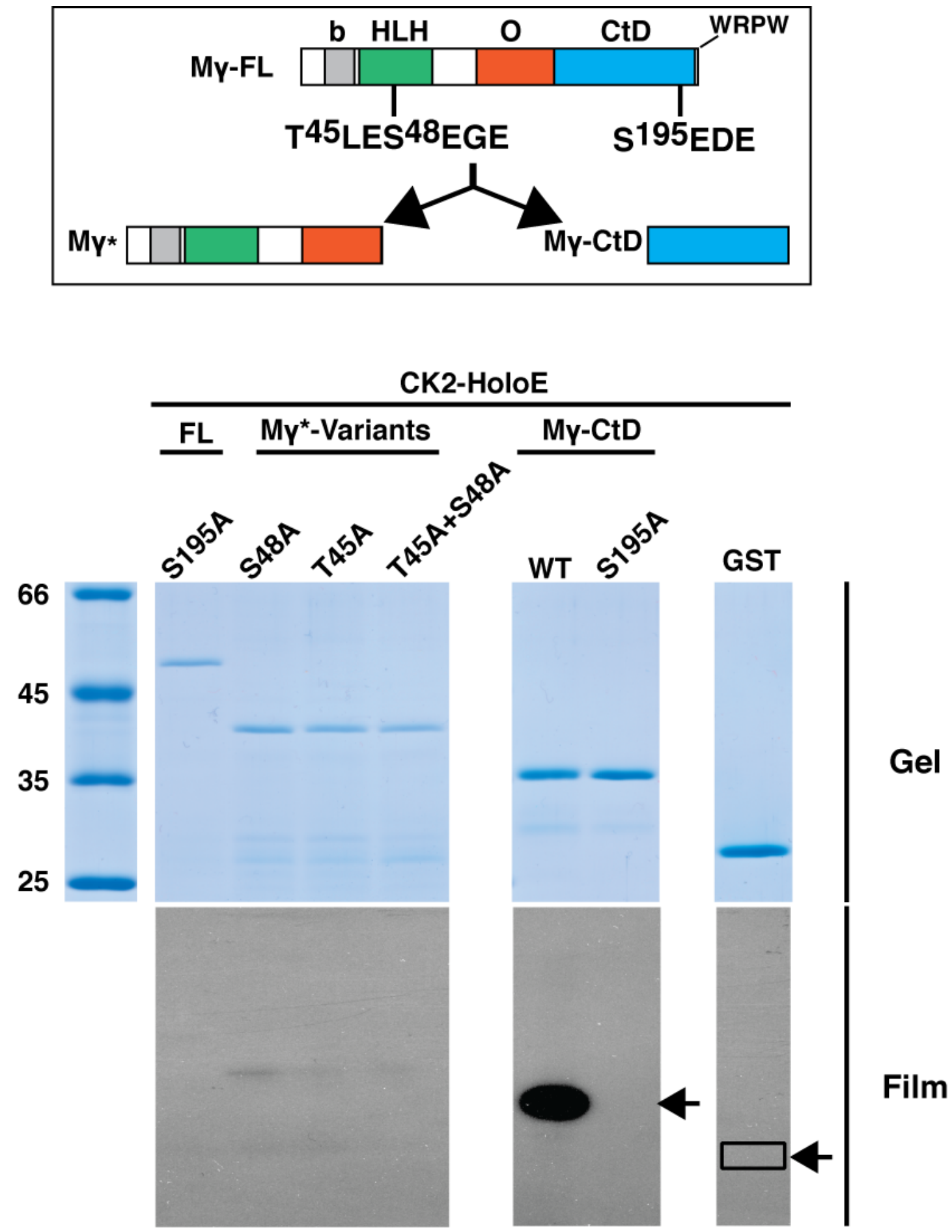

Figure 3: Due to multiple CK2 sites in E(spl)My, it was necessary to disect the protein in order to determine which sites are phosphoacceptors. The scematic shows the respective CK2 sites and the fragments used to isolate candidate residues. Here, the reactions reveal that the sites within the HLH are not targeted in the full length repressor and only mildly it the absence of the CtD. Conversely, the Cterminal site proximal to the 'WRPW' motif is robustly phosphorylated and likely serves as a regulatory switch in vivo. 


\section{CK2-HoloE}

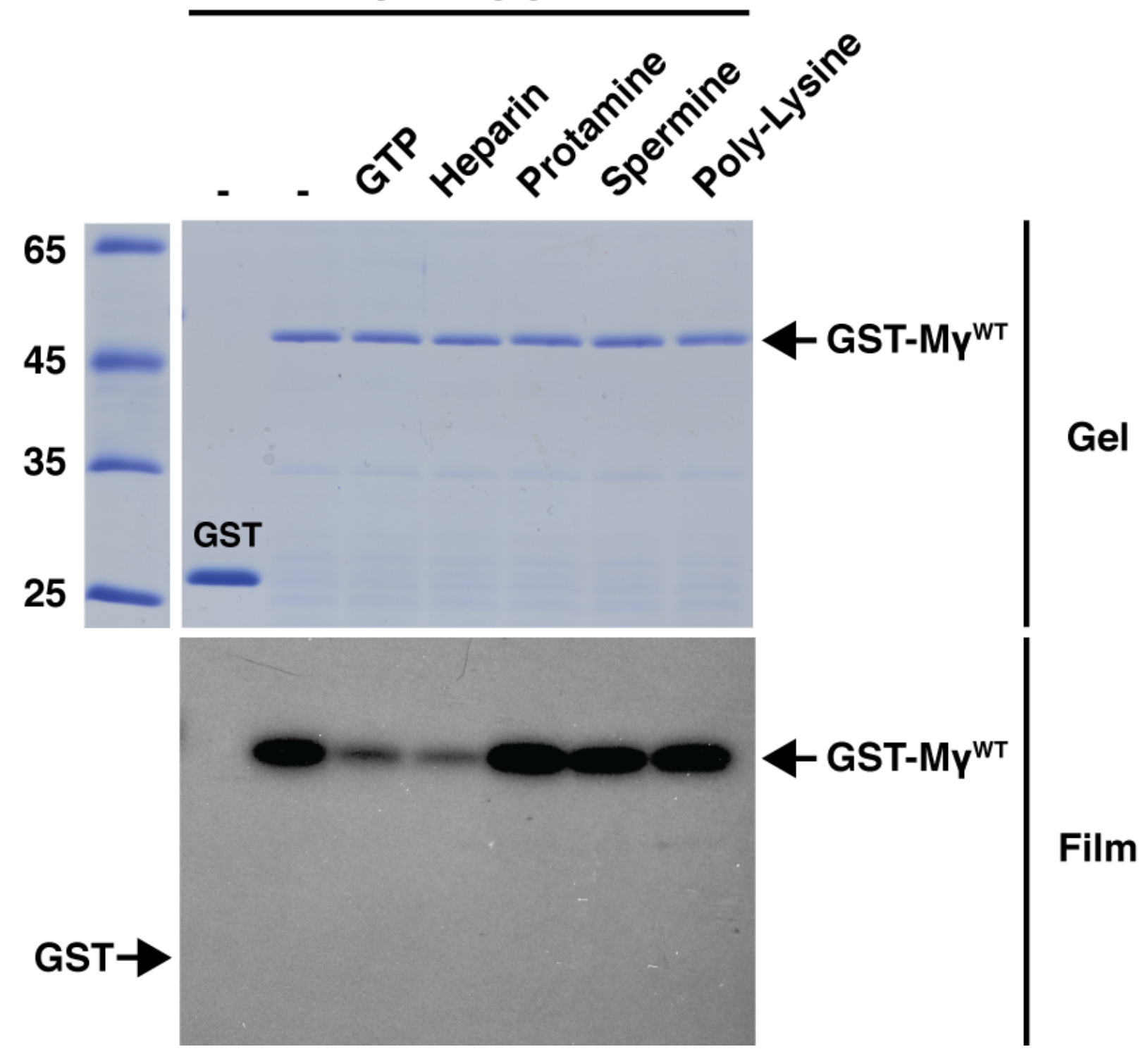

Figure 4: Direct modulation of CK2 activity verifies that a contaminating kinase is not confounding the observations. Both GTP $(60 \mu \mathrm{M})$ and heparin $(1 \mu \mathrm{g} / \mathrm{mL})$ compete with radioactive ATP as substrate as both reactions display lowered band intensity. On the other hand, the polybasic activators protamine (125 $\mu \mathrm{g} / \mathrm{mL})$, spermine $(500 \mu \mathrm{g} / \mathrm{mL})$, and poly-lysine $(100 \mu \mathrm{g} / \mathrm{mL})$ show comparable or increase rates of substrate turnover. Taken together, these experiments justify calling $\mathrm{E}(\mathrm{spl}) \mathrm{My}$ a CK2 substrate. 
38

Helix-Loop-Helix

hSID-1 QVNVLLYDMNGCYSRLKELVPTLPQNRKVSKVEILQHVIDYIRDLQLELNSESEVGTPGG

DWil_EMC ------EMKMYLSKLKDLVPFMPKNRKLSKLEIIQHVIDYICDLQTELETHPEINNFDA

Dper_EMC

Dpse_EMC

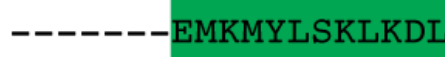
VPFMPKNRKLSKLEIIQHVIDYICDLQTELETHPEMNNFDA

Dana_EMC

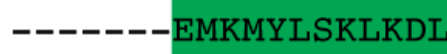

LVPFMPKNRKLSKLEIIQHVIDYICDLQTELE THPEMNNFDA

Dmel EMC Dsec_EMC

Dere_EMC

-------ELIKI

Dsim_EMC

-------

Dgri_EMC

Dvir_EMC

-------EIK

Dmoj_EMC

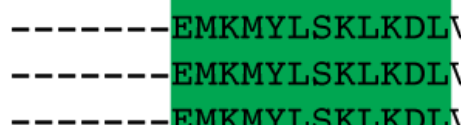

VPFMPKNRKLSKLEIIQHVIDYICDLQTELETHPEIGNFDA

EMKMYLSKLKDLVPFMPKNRKLTKLEI IQHVIDY ICDLQTELETHPEMGNFDA

EMKMYLSKLKDLVPFMPKNRKLTKLEI IQHVIDY ICDLQTELETHPEMGNFDA

EMKMYLSKLKDLVPFMPKNRKLTKLEI IQHVIDY ICDLQTELETHPEMGNFDA MKMYLSKLKDLVPFMPKNRKLTKLEI IQHVIDY ICDLQTELETHPEMGNFDA MKMYLSKLKDLVPFMPKNRKLSKLEI IQHVIDY ICDLQTELETHPEINNFDA

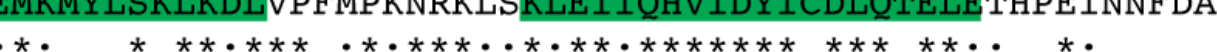

hSID-1

91

CK2

Dwil_EMC

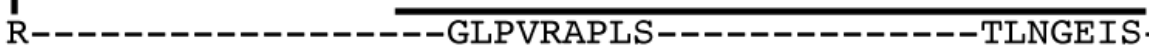

$-A L$

Dper_EMC AAALTAAA----------NMEDDSEDEMHHMEDDEA-----DLEADAD----DLLSQRL

Dpse_EMC AAALTAAA----------NMEDDSEDEMHHMEDDEA-----DLEADAD----DLLSQRL

Dana_EMC AAALTSV------------ALHRDDDSD---MEDDDA-----EVDSDAD-----VLAQRL

Dmel_EMC AAALTAVN-----------GLHEDEDSD---MEDADA-----EAEAEVD---PDILAQRL

DSec_EMC AAALTAVN----------GLHEDEDSD---MEDADA-----EAEAEVD---PDVLAQRL

Dere_EMC AAALTAVN-----------GLHEDEDSD---MEDADA-----EAEAEVD---PDVLAQRL

Dsim_EMC AAALTAVN----------GLHEDEDSD---MEDADA-----EAEAEVD---PDVLAQRL

Dgri_EMC AAALSGVAAAAAVAAGNSEGDDDDDDEEVVEEEEDDAMRGVVEERSEQLVAGSDVLAQRL

Dvir_EMC AAALSGVAAAAAA------GGSEEEEDE---EEEDEE-----OMELDTAAAGGDVLAMRL

DMOj_EMC AAALSGVAAAAAA------GGSEDEDES---D----------EMDLDAA---DDVLAQRL

Figure 5: The Drosophila EMC orthologs contain two consensus sequences for CK2, one located at the end of the HLH (TELE) and another in approximately thirty (30) residues C-terminal to the HLH (yellow and red). The former site is invariant while the latter is positioned in a region of considerable variability. Conservation of the site suggests an important regulation. The Homo sapiens ID1 (top line) contains a CK2 site juxtaposed to the HLH. Drosophila melanogaster (Dmel), D. willistoni (Dwil), D. pseudoobscura (Dpse), D. ananassae (Dana), D. yakuba (Dyak), D. sechellia (Dsec), D. simulans (Dsim), D. erecta (Dere), D. grimshawi (Dgri), D. mojavensis (Dmoj), D. virilis (Dvir). 


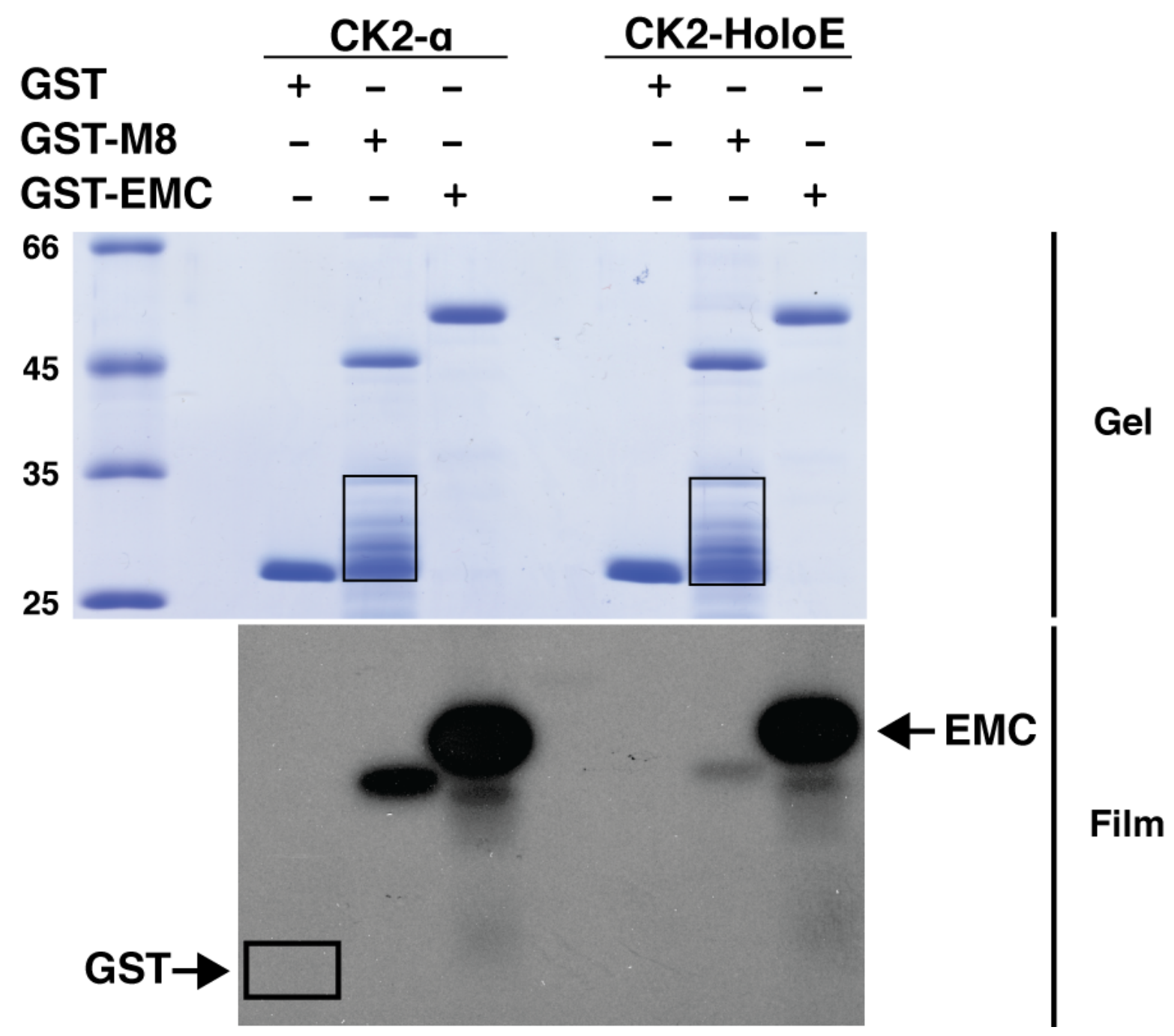

Figure 6: The two isoforms of CK2 were tested for their ability to phosphorylate EMC. It can be observed that the GST tag is not phosphorylated (arrow+box) and the respective kinases behave as expected with respect to $\mathrm{E}(\mathrm{spl}) \mathrm{M} 8$, which has degraded (box). For EMC, both the monomeric kinase and the holoenzyme are effective modifiers of the protein. 

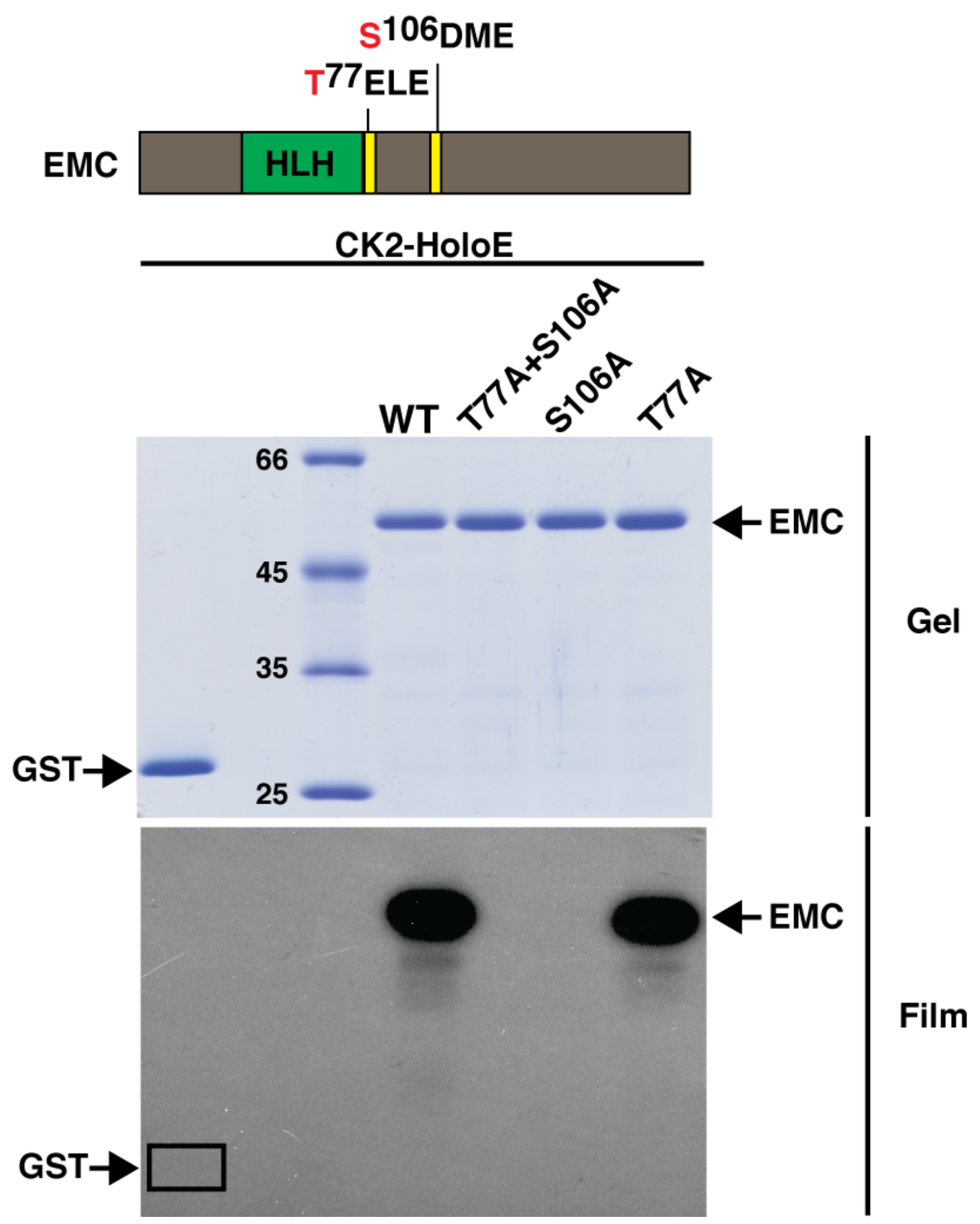

Figure 7: To resolve the specific EMC residues modified by CK2, a set of alanine substitutions was generated for the two described consensus sites. The $T^{77}+S^{106} A$ mutant does not exhibit phosphorylation verifying that only the suspect sites are potential targets. Because the $S^{106} \mathrm{~A}$ mutant is not phosphorylated but the $T^{77} A$ mutant is phosphorylated, it has been determined that only one residue is targeted by CK2. The GST tag is not phosphorylated by CK2 (arrow+box). 


\section{CK2-HoloE}

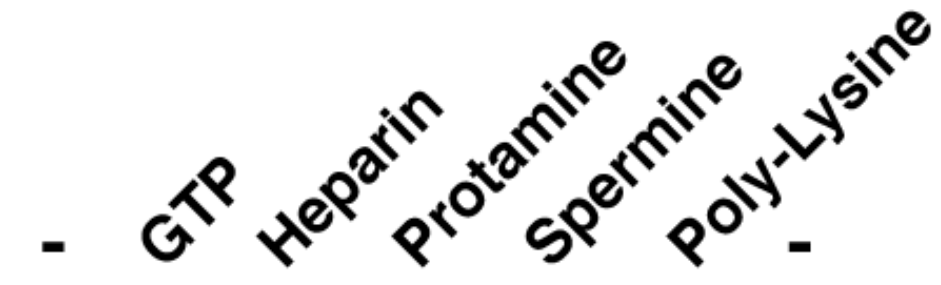

66

\section{5}

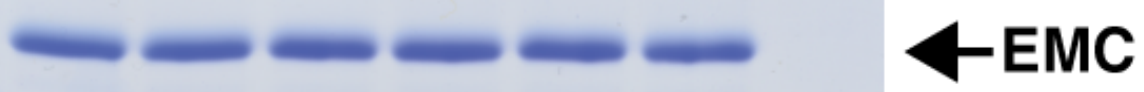

\section{5}

25

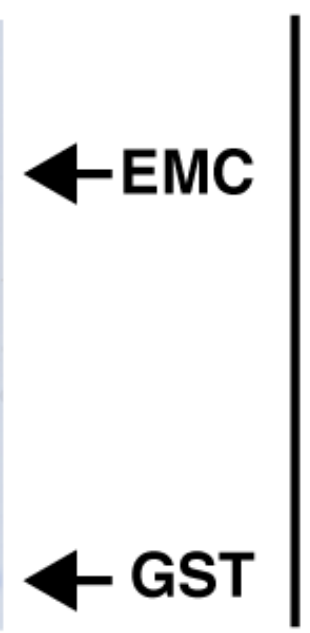

Gel

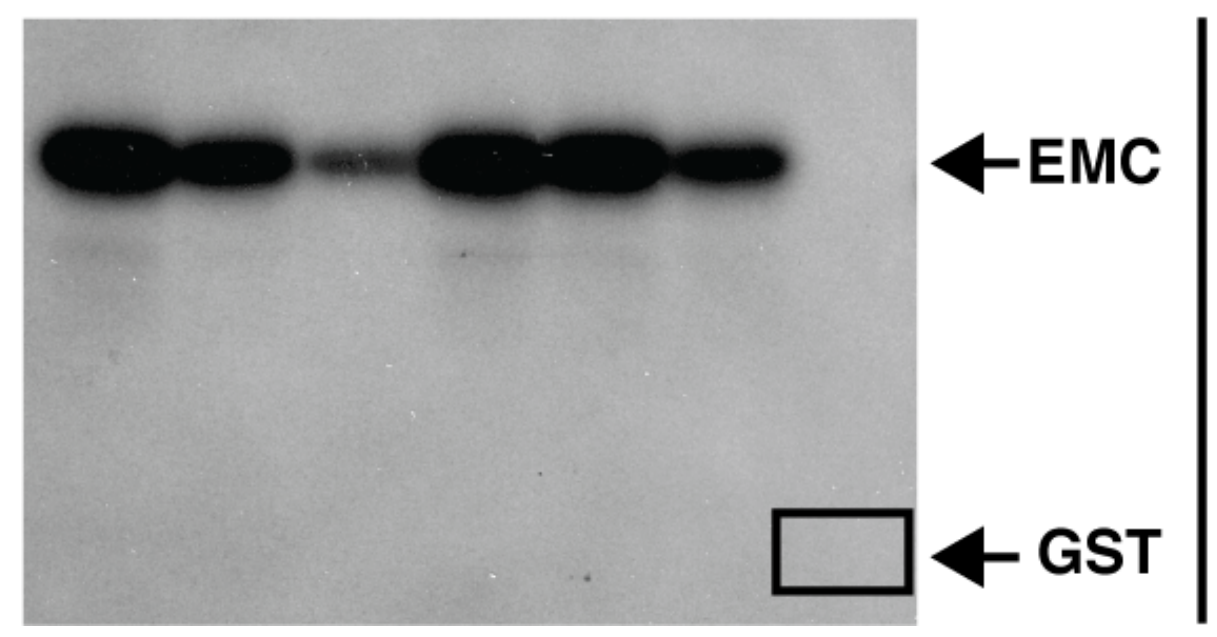

Film

Figure 8: To verify that CK2 was the kinase involved in the observed kinase reactions, specific modulators of its activity were used in congruent reactions. It can be seen that both GTP $(60 \mu \mathrm{M})$ and heparin $(1 \mu \mathrm{g} / \mathrm{mL})$ were able to decrease the level of turnover in their respective reactions. In contrast the polybasic activators protamine $(125 \mu \mathrm{g} / \mathrm{mL})$ and spermine $(500 \mu \mathrm{g} / \mathrm{mL})$ maintained or enhanced enzyme activity. Quizzically, the poly-lysine $(100 \mu \mathrm{g} / \mathrm{mL})$ reaction showed lowered kinase function. 


\section{The HD and CK2 Phosphorylation}
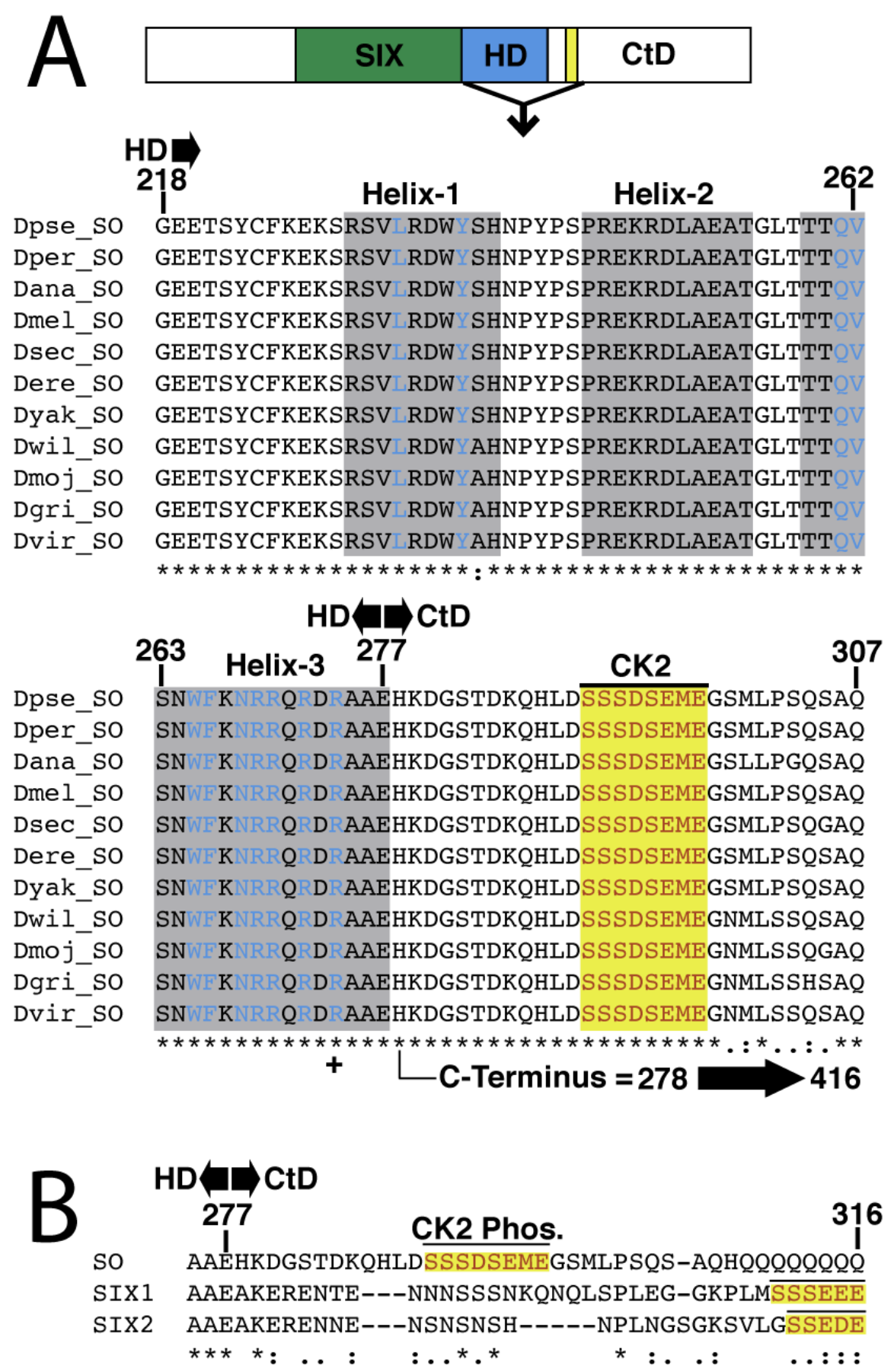

Figure 9: (A) The homeodomain and CK2 sites of Drosophila SO are highly conserved. These sites are very near the DNA binding Helix-3 of the homeodomain and potentially undergo hierarchical phosphorylation (B) The mammalian homologs SIX1 and SIX2 share the CK2 sites, though they are displaced toward the C-terminus. Drosophila melanogaster (Dmel), D. willistoni (Dwil), D. pseudoobscura (Dpse), D. ananassae (Dana), D. yakuba (Dyak), D. sechellia (Dsec), D. simulans (Dsim), D. erecta (Dere), D. grimshawi (Dgri), D. mojavensis (Dmoj), D. virilis (Dvir). 


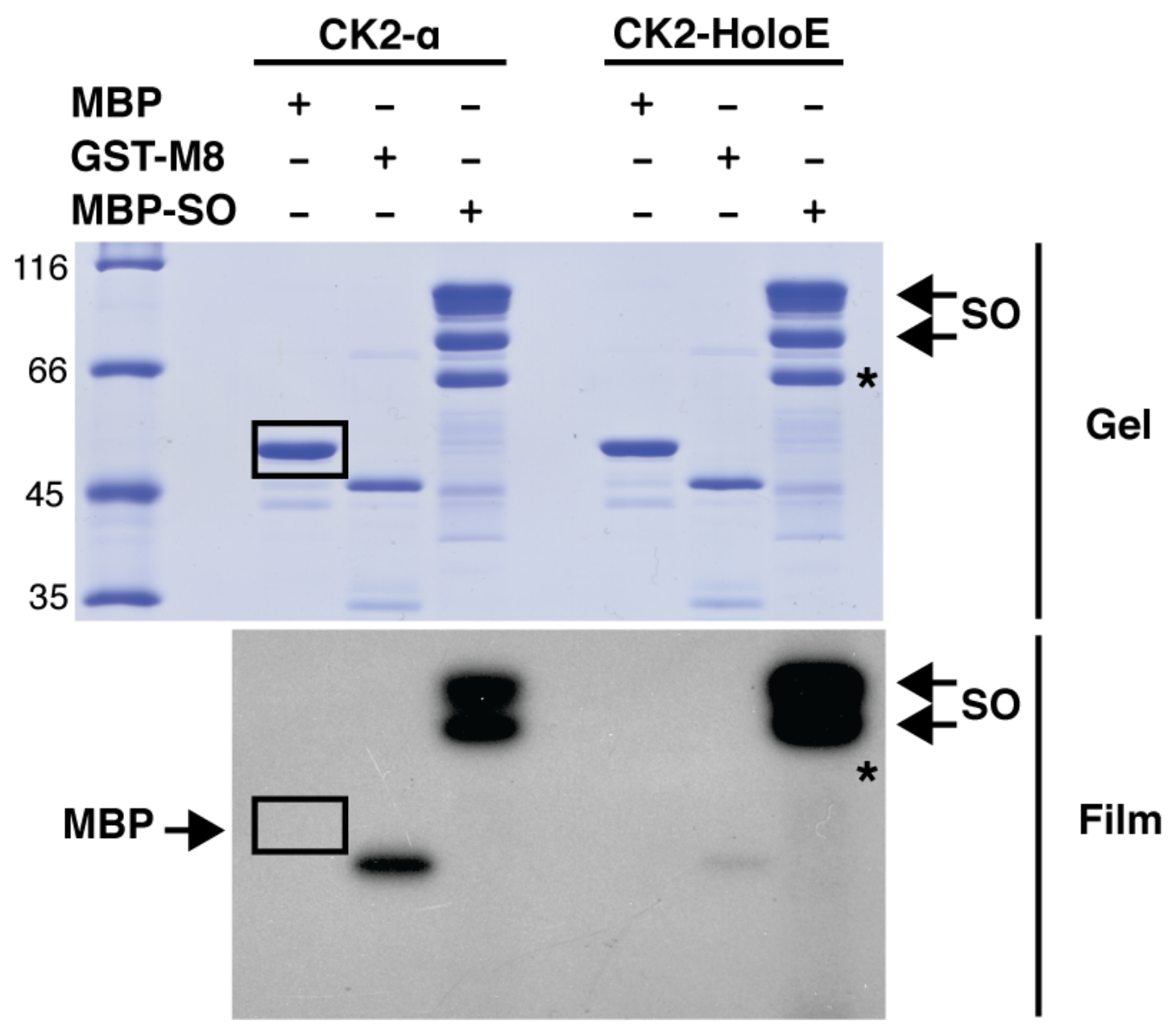

Figure 10: Initial experiments using MBP as substrate suggest that both isoforms are capable of modifying CK2. Based on the differential band intensity between the monomer and holoenzyme, it appears that the $\beta$-subunit enhances targeting by CK2. The smaller degradation product of SO (asterisk) is not phosphorylated, whereas the larger peptides maintain affinity (arrows). E(spl)M8 in the presence of holoenzyme is just observable in the film due to the short exposure time and MBP is not phosphorylated (arrow+box). 


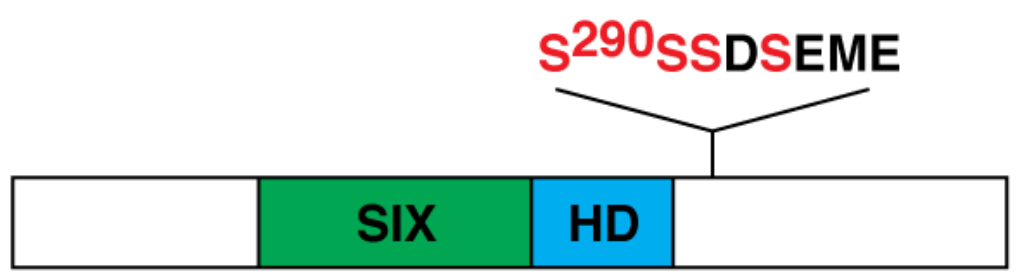

\section{CK2-HoloE}

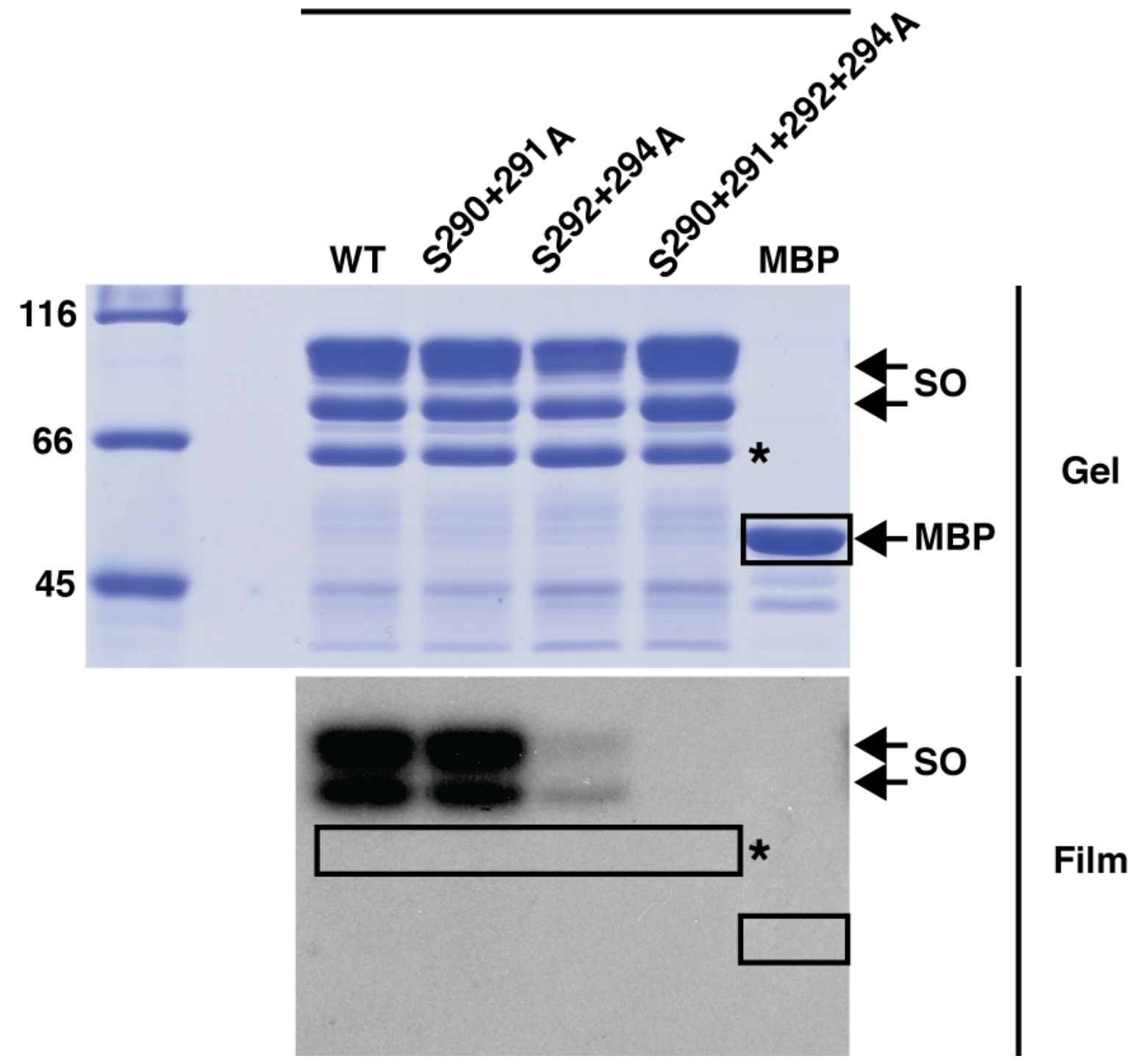

Figure 11: The potential for hierarchical phosphorylation of SO remained undetermined. Using various alanine substitutions the serine residues modified by CK2 was determined. Here, the alteration of all serines results in an unmodified protein and verifies that only the suspect residues are targeted. The $S^{290+291} A$ mutant exhibits comparable phosphorylation to wild-type while CK2 maintained slight affinity for the $S^{292+294} A$ mutant. These findings suggest that at least three of the serine residues are phosphorylated by CK2. The smaller degradation products of SO are not phosphorylated (asterisk+box) while the larger proteins maintain their CK2 sites (arrows). MBP is not phosphorylated (box+arrow) 


\section{CK2-HoloE}

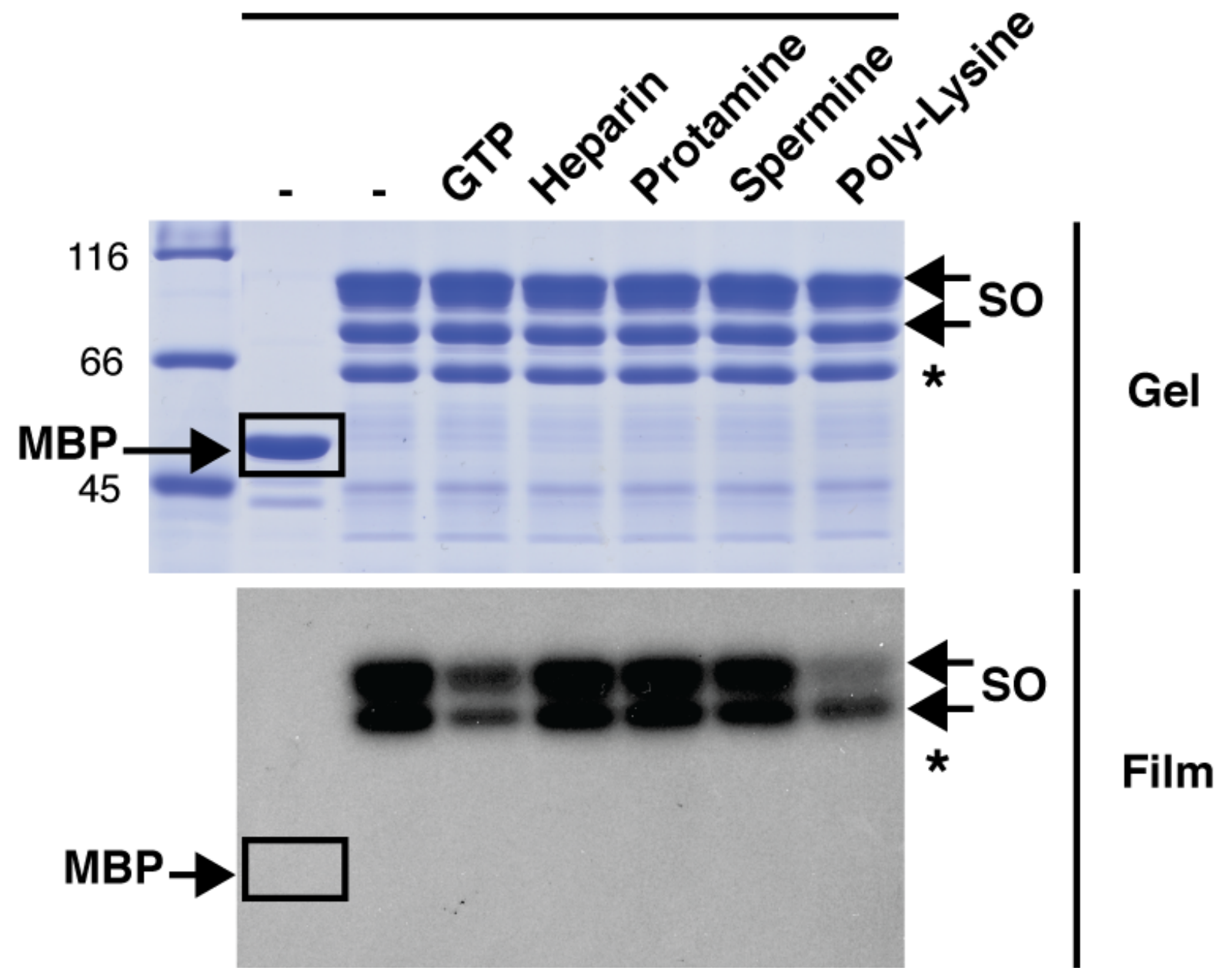

Figure 12: To verify that CK2 is the kinase responsible for the observed phosphorylations, specific modulators of kinase activity were used. GTP $(60 \mu \mathrm{M})$ is a potent competitor while protamine (125 $\mu \mathrm{g} / \mathrm{mL})$ and spermine $(500 \mu \mathrm{g} / \mathrm{mL})$ activate kinase function. Curiously, heparin $(1 \mu \mathrm{g} / \mathrm{mL})$ has little effect on reaction rate and poly-lysine $(100 \mu \mathrm{g} / \mathrm{mL})$ depletes kinase activity. It is a possibility that the two reactions were interchanged; for absolute clarity, these experiments should be repeated. 

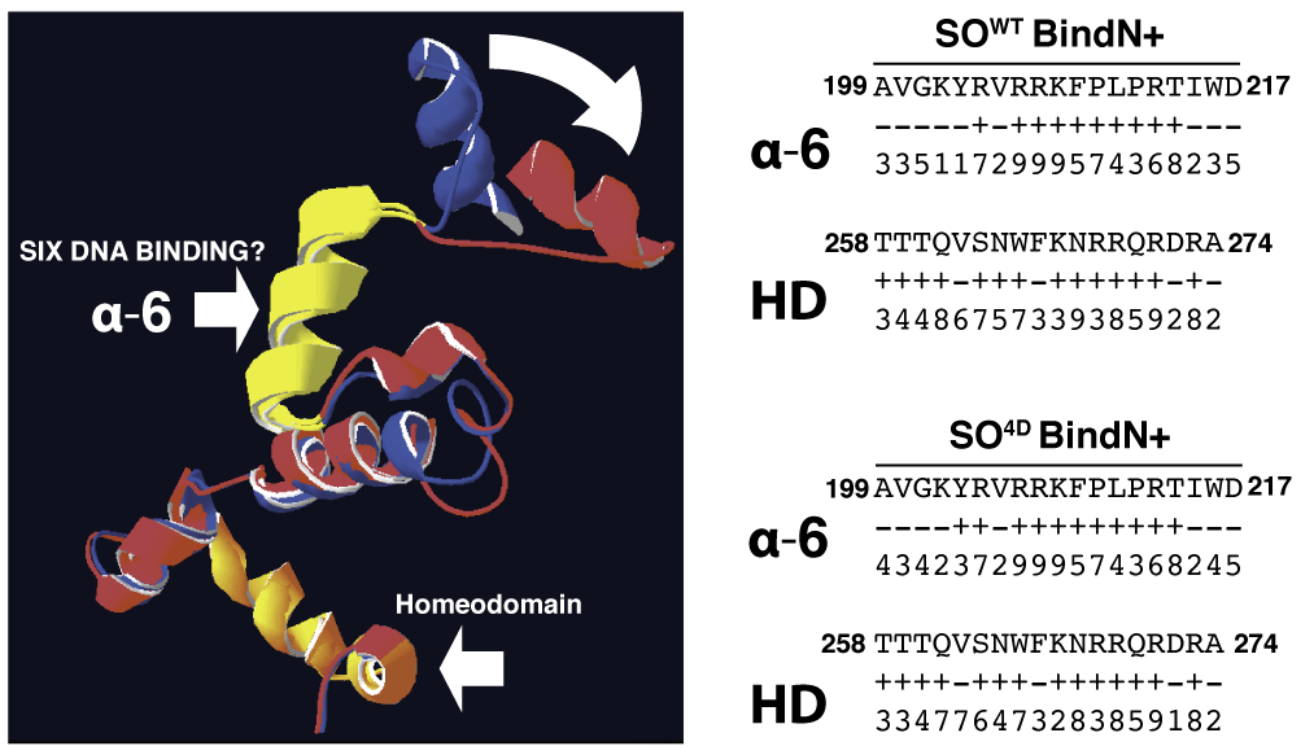

\author{
258 TTTQVSNWFKNRRQRDRA 274 \\ HD $\quad 344867573393859282$
}

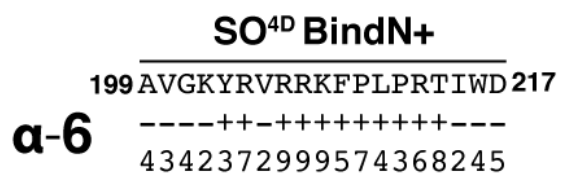

258 TTTQVSNWFKNRRQRDRA 274

HD $\quad 334776473283859182$

B

a-6 DNA Binding?

SO Homeodomain AVI

SIX

DSIX4 AVDIKYRLRKKYPLPKTIWDGEETVYCFKEKSRNALKDCYLTNRYPTPDEKKTLAKKTGLTLTQVSNWFKNRRORDR SIX4 AVDKKYRLRRKFPLPRTIWDGEETVYCFKEKSRNALKELYKONRYPSPAEKRHLAKITGLSLTQVSNWFKNRRQRDR SIX5 AVDKKYRLRKKFPLPKTIWDGEETVYCFKERSRAALKACYRGNRYPTPDEKRRLATLTGLSLTQVSNWFKNRRQRDR Optix PVDKYRVRKKFPLPPTIWDGEQKTHCFKERTRSLLREWYLODPYPNPTKKRELAKATGLNPTOVGNWFKNRRQRDR SIX3 PVDKYRVRKKFPLPRTIWDGEQKTHCFKERTRSLLREWYLODPYPNP SKKRELAOATGLTPTQVGNWFKNRRQRDR SIX6 PVDKYRVRKKFPLPRTIWDGEQKTHCFKERTRHLLREWYLQDPYPNP SKKRELAOATGLTPTQVGNWFKNRRQRDR

Figure 13: (A) Structural prediction of $\mathrm{SO}^{\mathrm{WT}}$ and a phosphomimetic (Ser to Asp substitution) SO ${ }^{4 \mathrm{D}}$ imply that conformational shifts may occur in the vicinity of $\alpha-6$ upon CK2 phosphorylation. Specifically, a helix toward the $\mathrm{N}$-terminus of $\alpha$ six rotates clockwise to expose basic residues. The residues in this helix are predicted to be DNA binding using primary sequence (BINDN+) and structural inference (DISPLAR, not shown). (B) There are very few sequence differences among homologs (groups, arrows = nonconservative), and nearly no variation in the homeodomain Helix-3 (DNA binding) across groups. Helices 1 and 2 of the homeodomain exhibit some variation, but the movement near a helix with described functional variability is intriguing. 


\section{CHAPTER 3}

Identification and Genetic Analysis of 14-3-3 as a Regulator of E(spl)Mס Activity 


\begin{abstract}
The C-terminal domains of Enhancer of Split Complex repressors were long considered a non-specific linker between the body of the protein and the invariant WRPW co-repressor binding motif. However, previous studies have revealed complex post-translational regulation of the repressors $\mathrm{E}(\mathrm{spl}) \mathrm{M} 8,-\mathrm{M} 5$ and $-\mathrm{M} 7$. This involves phosphorylation and repressor activation by CK2 and MAPK, followed by the release of an apparent autoinhibition. In contrast to this well described mechanism, it remained poorly understood how other $E(\mathrm{spl})$ repressors, which lack the specific sequence motifs of the aforementioned paralogs, might be regulated. Based on immunoprecipitation and $\mathrm{Y} 2 \mathrm{H}$ assays, 14-3-3 proteins were raised as a possible regulator of $\mathrm{E}(\mathrm{spl})$ repressors. Here, bioinformatics was used to identify a novel, high affinity, deeply conserved 14-3-3 binding motif in $\mathrm{E}(\mathrm{spl}) \mathrm{M} \delta$. Additionally, genetic analysis infers that this site is important for the repressor activity mediated by $\mathrm{E}(\mathrm{spl}) \mathrm{M} \delta$, a protein known to modulate eye development. The bioinformatics suggest that the 14-3-3 site in $\mathrm{E}(\mathrm{spl}) \mathrm{M} \delta$ may be targeted by protein kinases distinct from those that regulate E(spl)M8, -M5, and M7. These findings reveal that post translational modification and cofactor regulation of the $\mathrm{E}(\mathrm{spl}) \mathrm{bHLH}$ proteins are likely to be unique and thus non-redundant.
\end{abstract}




\section{INTRODUCTION}

Regulation of transcription factor activity is perhaps the most important aspect of a cell response during a developmental program. The previous chapter discussed the potential effect of CK2 phosphorylation of E(spl)My, EMC, and Sine Oculis. In addition to kinase modification, further layers of transcription factor modulation are possible and represent critical mechanisms in changing cellular behavior. This chapter considers the potential for $14-3-3$ s and their binding to $\mathrm{E}(\mathrm{spl})$ repressors as a means to induce altered activity.

It is well established that $14-3-3$ proteins preferentially interact with phosphorylated proteins (see Introduction). The canonical example of 14-3-3 function is in the binding to Raf (Fu et al., 1994). In a model proposed by Tzivion et al (1998), a 14-3-3 dimer binds to phosphorylated Raf and maintains the inactive conformation. Subsequent displacement of 14-3-3 by Ras-GTP, allows further phosphorylation and activation of Raf, a form that is stabilized by interaction with 14-3-3 (Tzivion et al., 1998). In this system, the role of $14-3-3$ dimers is twofold: it protects specific phosphorylated residues from phosphatases and structurally stabilizes the active conformation.

In addition to signalling, modulation of transcription factor activity has also been described. For example, the DNA binding activity of HNF1 $\alpha$ is dramatically enhanced upon 14-3-3 recruitment (Yu et al., 2013). Conversely, previous studies have elucidated roles for 14-3-3 in nuclear exclusion and translocation of the transcription factor Yorkie (Ren et al., 2010). Additionally, the experiments that led to an understanding of Yorkie 
regulation by $14-3-3$ were performed in the Drosophila eye. This suggests that $14-3-3 \mathrm{~s}$ are active in this context, including the direct regulation of transcription factor function.

Interest in the interaction between $14-3-3$ and $E(\mathrm{spl})$ repressors is derived from a yeast-two-hybrid $(\mathrm{Y} 2 \mathrm{H})$ screen that identified $14-3-3 \zeta$ as an interaction partner of the E(spl)M8-CtD (Kim and Bidwai, unpublished). Additional evidence for 14-3-3 and E(spl) repressor interaction can be found in the Drosophila Protein Interaction Map (DPiM), an S2-cell based interaction network assay (Guruharsha et al., 2011). In this highthroughput study, E(spl)My, Mס, M8, M3, M5 and M7 co-immunoprecipitated at least one 14-3-3 isoform as an interaction partner. Of the three $E(s p l)$ repressors expressed in the MF (M8, My and Mס), $\mathrm{E}(\mathrm{spl}) \mathrm{My}$ and $\mathrm{E}(\mathrm{spl}) \mathrm{M} 8$ both interacted with $14-3-3 \zeta$ and $\varepsilon$, whereas $\mathrm{E}(\mathrm{spl}) \mathrm{M} \delta$ interacted with only 14-3-3ろ. However, the DPiM database did not demonstrate whether these interactions depend on phosphorylation of $E(s p l)$ proteins. The possibility thus arises that distinct modes of regulation are imposed on $E(s p l)$ repressors by phosphorylation and different $14-3-3$ isoforms.

Based on these preliminary findings, we sought to further investigate the interaction between 14-3-3 and $\mathrm{E}(\mathrm{spl})$ repressors. This aspect of Notch signaling has not been studied to date. To this end, we identified 14-3-3 binding sites in $E(s p l)$ repressors by bioinformatics sequence analysis and performed genetic studies of $\mathrm{E}(\mathrm{spl}) \mathrm{M} \delta$ to infer the regulatory consequences of a possible physical interaction. 


\section{MATERIALS AND METHODS}

\section{Identification of 14-3-3 Binding Sites}

The Drosophila orthologs of $\mathrm{E}(\mathrm{spl})$ repressors expressed in the morphogenetic furrow and found to interact with 14-3-3 by the DPiM (Guruharsha et al., 2011; Guruharsha et al., 2012) were downloaded from flybase.org and aligned using standard settings on the MUSCLE online software. Multiple sequence alignments were visually inspected for motifs that correspond to the high affinity binding sites described previously by others (Yaffe et al., 1997). After resilient sequences were identified in the Drosophila $\mathrm{E}(\mathrm{spl})$ repressors, mammalian HES proteins were downloaded from the NCBI database and inspected for site conservation.

\section{Genetic Analysis of E(spl)M $\delta$}

Flies were raised on yeast-glucose medium at $24 \mathrm{C}$. Specific fly stocks were obtained from the Bloomington Stock Center at Indiana University. Stable balanced stocks were generated and maintained using standard protocols. These lines were crossed using virgin $q N^{s p l} / N^{s p l}$; leo $o^{12 B L} / C y O ;+/+$ and $\delta^{1+/+;}+/+; h H 10 G A L 4, U A S-E(s p l) M \delta / T M 6 B$. The recombinant stock was a generous gift from Adam T. Majot. 


\section{RESULTS AND DISCUSSION}

As mentioned above, $\mathrm{Y} 2 \mathrm{H}$ and $\mathrm{S} 2$-cell based studies indicate an interaction between 14-3-3 and $E(\mathrm{spl})$ proteins. However, it was unclear if these interactions are direct, or are mediated through accessory proteins. Consequently, the presence of well defined interaction motifs was investigated through bioinformatics analyses.

Of primary importance was investigating the existence of interaction sites within the $\mathrm{E}(\mathrm{spl})$ repressors. The most straightforward approach is to construct multiple sequence alignments and identify a motif that fits the strict consensus for 14-3-3 interaction, which have been described (Yaffe et al., 1997). While discovery of Mode-1 $(R-x-x-S-x-P)$ and Mode-2 (R-x-x-x-S-x-P) binding sites is straightforward, it is important to note that many sites are not readily inferred based solely on primary sequence analyses. The compiled and aligned sequences of the three morphogenetic furrow specific repressors, $\mathrm{E}(\mathrm{spl}) \mathrm{M} 8,-\mathrm{My}$ and $-\mathrm{M} \delta$ from the twelve Drosophila orthologs revealed motifs in distinct domains.

\section{4-3-3 binding motifs in E(spl)M8 and E(spl)My}

$\mathrm{E}(\mathrm{spl}) \mathrm{M} 8$ has a readily identifiable Mode- 2 consensus within the Orange domain

(Fig. 1, left). This site is well conserved among Drosophila orthologs, but does not exist consistently, even in closely related invertebrates (data not shown). E(spl)My also contains a conserved Mode- 2 binding site, but it is located in the C-terminal domain (Fig. 1, right). Interestingly, this site is proximal to the serine rich P-domain, a region of multiple phosphorylations as described for $\mathrm{E}(\mathrm{spl}) \mathrm{M} 8$ (see Introduction). This raises the possibility that direct or primed kinase targeting can form a high affinity 14-3-3 binding 
site. The position and conservation of 14-3-3 consensus sites in E(spl)M8 and E(spl)My starkly contrast the site in $\mathrm{E}(\mathrm{spl}) \mathrm{M} \delta$.

\section{4-3-3 binding motif in E(spl)Mo}

In E(spl)Mס, the sequence 'R-K-V-T-K-P' is located in the basic domain and closely meets the consensus for Mode-1 binding (Fig. 2A). Though residues in this region are conserved across paralogs, this specific motif is unique to $\mathrm{E}(\mathrm{spl}) \mathrm{M} \delta$ (compare paralogs, Fig. 3 Ch. 1). The importance of the identified site is reinforced when sequences are aligned with vertebrate members of the Hairy and Enhancer of Spilt homologs (HES). Specifically, HES1 and HES4 maintain a 14-3-3 site analogous to that of $\mathrm{E}(\mathrm{spl}) \mathrm{M} \delta$ in both sequence and position (Fig. 2B). Though the motif has changed slightly to 'R-K-S-S-K-P,' the spacing and chemistry of the residues have endured through approximately 800 myr of evolution.

\section{4-3-3 binding motifs in HES1 and HES4}

Interestingly, an in frame 'insertion' within the 14-3-3 binding motif of the HES4 gene generates two distinct isoforms. HES4 isoform 2 maintains the site analogous to HES1 and E(spl)Mס (Fig. 2C). On the other hand, HES4 isoform 1 has evolved a new site, 'R-K-V-G-S-R-P', which incorporates the first two basic residues of the Mode-1 site (Figure 2A and B). The motif in HES4 isoform 1 is Mode-2 binding; these sites exhibit similar binding affinity. Moreover, the residues near the serine are still basic, which may be important for kinase specificity. 


\section{4-3-3 and the $E(s p l) M \delta$ enhancement of $N^{\text {spl }}$}

The existence of a high affinity consensus that is evolutionarily resilient from $\mathrm{E}(\mathrm{spl}) \mathrm{M} \delta$ to the HES1 and HES4 repressors provided the impetus for further analysis. Previous observations had demonstrated that the $N^{s p l}$ allele is marked by neural hypotrophy in the Drosophila eye and that this phenotype is sensitive to hypermorphic $E(s p l)$ function, namely $E(s p l) D$ (Nagel et al., 1999). Similarly, expression of E(spl)Mס in the morphogenetic furrow using the driver $h^{H 10}$ GAL4 (stage 1, see Ch. 1, Fig. 4) results in dramatic reductions in eye size (Ligoxygakis et al., 1998) and overexpression using the driver 109.68GAL4 (stage $2 / 3$, see Ch. 1, Fig. 4) have been compared to the $N^{\text {spl }}$ phenotype (Li and Baker, 2001). Congruently, it has been observed that $\mathrm{E}(\mathrm{spl}) \mathrm{M} \delta$ expressed by $h^{H 10} G A L 4$ enhances the stereotyped $N^{\text {spl }}$ reduced eye phenotype (personal communication, Adam Majot). Therefore, modulation of this enhanced reduction of ommatidial facet counts served as a facile in vivo test for interaction between 14-3-3 and E(spl)Mס.

For these studies I employed the loss of function and recessive lethal allele $l e o^{12 B L}$. By themselves, $l e o^{12 B L} /+$ flies display normal eyes with no perturbation (data not shown), suggesting that half dosage of Leo is sufficient for normal eye development. In addition, the adult eye of male flies harboring the $l e o^{12 B L}$ allele in combination with $N^{\text {spl }}$ displayed a rough and reduced eye (Fig. $3 \mathrm{~A}$ and graph) whose severity was indistinguishable from $N^{\text {spl }} / Y$ males (data not shown). I next tested if the overexpression phenotype of UAS-E(spl)Mס is sensitive to this genetic background as shown in Fig. 3B,C and graph overexpression of $\mathrm{E}(\mathrm{spl}) \mathrm{M} \delta$ elicited a greater reduction in the eye field when tested in a 1 eo $12 B L /+$ background. To provide a quantitative analysis of adult eye 
phenotypes, the number of facets were counted in all relevant genotypes. As shown in the graph in Fig. $3, N^{s p l} / Y$ by themselves or in combination with $l e o^{12 B L} /+$ display $\sim 325$ facets. Overexpression of $\mathrm{E}(\mathrm{spl}) \mathrm{m} \delta$ in a leo+/+ background resulted in residual eye with $\sim 160$ facets whereas expression a $l e 0^{12 B L} /+$

resulted in a reduction to $\sim 40$ facets. Statistical analysis indicates that these differences are significant ( $p$-value $<<0.001)$. Thus $E(s p l) M \delta$ activity in its normal expression domain is sensitive to 14-3-3-Leo and the exacerbation of the reduced eye provides strong in vivo evidence that Leo normally functions to restrain $\mathrm{E}(\mathrm{spl}) \mathrm{M} \delta$ activity.

\section{SIGNIFICANCE}

The fact that six of the seven $\mathrm{E}(\mathrm{spl})$ repressors are indicated to interact with at least one isoform of 14-3-3 is initially a cause of concern regarding the reliability of the DPiM results. One could speculate that the interactions are spurious contamination, initiated by a motif common to all of the $\mathrm{E}(\mathrm{spl})$ proteins, or the basic domain of the repressors interacts non-specifically with the acidic 14-3-3s. These ideas are countered by the $\mathrm{Y} 2 \mathrm{H}$ screen, which isolated $14-3-3$ using only the $\mathrm{E}(\mathrm{spl}) \mathrm{M} 8-\mathrm{CtD}$. Inspection of the primary sequence of $\mathrm{E}(\mathrm{spl})$ repressors one can find 14-3-3 consensus motifs in most, albeit at disparate locations with respect to protein domains. Regardless of these complexities, the evidence presented here in describing $\mathrm{E}(\mathrm{spl}) \mathrm{M} \delta$ and its vertebrate homologs illuminate a conserved 14-3-3 motif that appears to be resilient to change through evolution and have functional significance during Drosophila development. 
Physical interaction between 14-3-3 and E(spl) or HES repressors would extend their regulation into a novel direction. Given the genetic interaction between leonardo, $E(s p l) m \delta$, and $N^{s p l}$, future investigation of this interaction is warranted. This would best be verified by in vitro assays using purified proteins and kinases that specifically target residues in the correspondent 14-3-3 motifs. It is important to note that the serines in the identified motif of HES are reportedly phosphorylated by PKC, thereby blocking its ability to bind DNA (Strom et al., 1997). These findings further extend the potential for 14-3-3, because the targeting of phosphoserine motifs underlies high affinity interaction.

Because phosphorylation of the 'R-K-S-S-K-P' decreases DNA binding in HES1, it would be reasonable to speculate that a similar regulation impinges upon $\mathrm{E}(\mathrm{spl}) \mathrm{M} \delta$. Mechanistically, the classical roles for 14-3-3 could be at play. For example, 14-3-3 binding could stabilize the inactive conformation of the repressor by preventing dephosphorylation. Because repression of target genes occurs within the nucleus, it is likely that subsequent consequences of $\mathrm{E}(\mathrm{spl}) \mathrm{M} \delta$ phosphorylation would involve nuclear export and protein degradation. This directly correlates with the $l e 0^{12 B L}$ mediated exacerbation of the $\mathrm{N}^{\text {spl }}$ phenotype seen in the genetic experiments (Figure 3).

Under specific signaling conditions or developmental contexts, it is also possible that other basophilic kinases target the residues in question. For example, PKA or PKB are also basophilic kinases that preferentially target sequences similar to that of PKC. This fits into the conception of Notch as having multiple and changing roles in a variety of tissues and would allow for further functional diversification. 
One important reason for extending research with respect to 14-3-3 and $\mathrm{E}(\mathrm{spl}) / \mathrm{HES}$ interaction can be found in emerging discussions which suggest the potential use of chemotherapeutic agents to modify 14-3-3 function (reviewed in (Zhao et al., 2011)). This is an extension of the observation that $14-3-3$ s are heavily involved in the regulation of signaling pathways like EGFR and also are involved in regulated cell proliferation and differentiation. To maximize the effective application of such therapeutics, it is critical to understand all aspects of $14-3-3$ functioning. This is especially true with respect to signaling pathways known to be involved in disease etiologies, like Notch and its terminal effectors.

Moreover, the role for $\mathrm{E}(\mathrm{spl}) / \mathrm{HES}$ in development is important, as improper function of these repressors is associated with congenital disorders. For example, spondylocostal dysostosis, a disease marked by skeletal malformations, is linked with missense mutations in HES7 that cause irregularities in its oscillatory expression. Interestingly, HES1 also exhibits an oscillatory characteristic (Hirata et al., 2002). Hypothetically, this may be associated with signal termination by $14-3-3$ dependent nuclear export prior to degradation.

In conclusion, a conserved high affinity $14-3-3$ binding site in the $\mathrm{E}(\mathrm{spl}) / \mathrm{HES}$ repressors has been described and genetic interaction now directly implicate this protein in Notch signaling. Though the details of this regulatory mechanism remains to be resolved, this analysis has revealed a previously unrealized example of $\mathrm{E}(\mathrm{spl}) / \mathrm{HES}$ regulation that is of clinical importance. Future experiments should be directed toward characterization of the physical complex between these proteins, identification of the relevant kinases, and investigate the relevant spatiotemporal context of the interaction. 
$E(s p l) M 8$

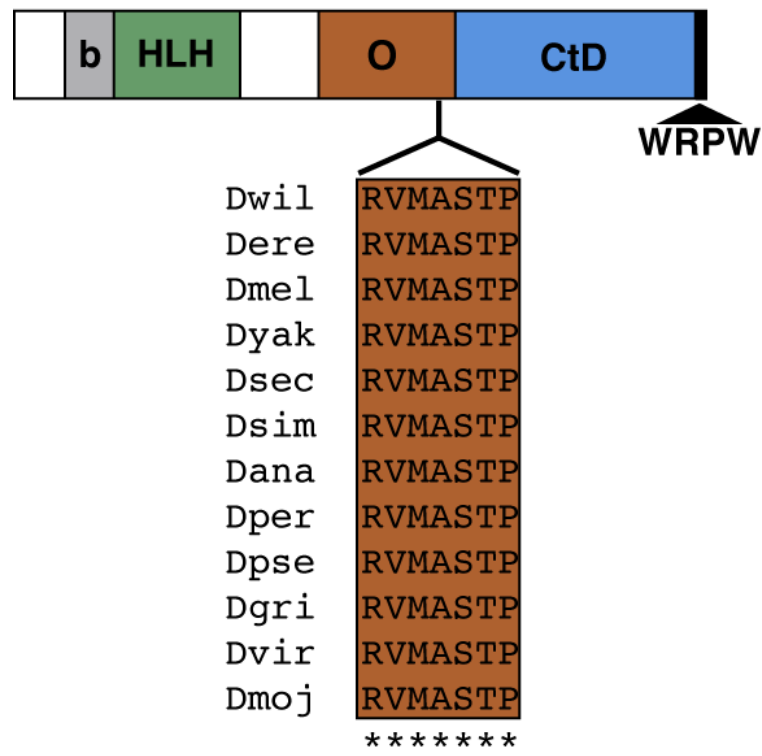

14-3-3
E(spl)My

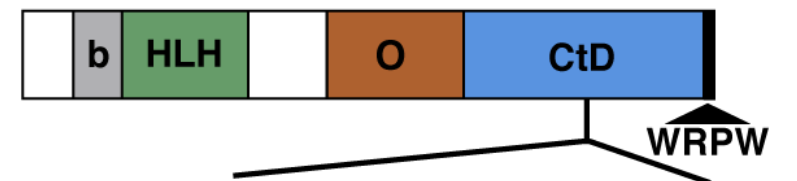

Dwil REAYSVPISPISSYAGSPNSS

Dper RDAYSVPISPVSSFAGSPNSS

Dpse RDAYSVPISPVSSFAGSPNSS

Dana RDAYSVPISPVSSFAGSPNSN

Dyak RDAYSVPISPISSYAGSPNSN

DSEC RDAYSVPISPISSYAGSPNSN

Dsim RDAYSVPISPISSYAGSPNSN

Dmel RDAYSVPISPISSYAGSPNSN

Dere RDAYSVPISPISSYAGSPNSN

Dgri RGGYSVPISPVSSFAGSPNSS

DMOj RDAYSVPISPISSYAGSPNSS

Dvir RDAYSVPISPISSYAGSPNSS

*. .*******:**:******.

14-3-3

Figure 1: Inspection of multiple sequence alignments for the orthologs of $\mathrm{E}(\mathrm{spl}) \mathrm{M} 8$ and $\mathrm{E}(\mathrm{spl}) \mathrm{My}$ reveal 14-3-3 consensus binding sites. Within the Orange domain of $E(s p l) M 8$ the sequence 'R-V-M-A-S-T-P' is a conserved Mode-2 binding site. Though previous experiments (see introduction) had indicated that 143-3 binding occurs in the CtD, no strict consensus could be identified in the region. Conversely, $\mathrm{E}(\mathrm{spl}) \mathrm{My}$ harbors the sequence 'R-D-A-Y-S-V-P' in the CtD. This Mode-2 binding site is likewise highly conserved in the melanogaster group. Interestingly, it is juxtaposed to the serine rich P-domain, previously shown to be phosphorylated at multiple positions. This raises the possibility that direct or primed kinase targeting drives 14-3-3 interaction at the relevant serine. Direct sequence similarities could not be identified in mammalian homologs of $\mathrm{E}(\mathrm{spl})$ repressors. Drosophila melanogaster (Dmel), D. willistoni (Dwil), $D$. pseudoobscura (Dpse), D. ananassae (Dana), D. yakuba (Dyak), D. sechellia (Dsec), D. simulans (Dsim), $D$. erecta (Dere), D. grimshawi (Dgri), D. mojavensis (Dmoj), D. virilis (Dvir). 
14-3-3 Binding Site in E(spl)Mo

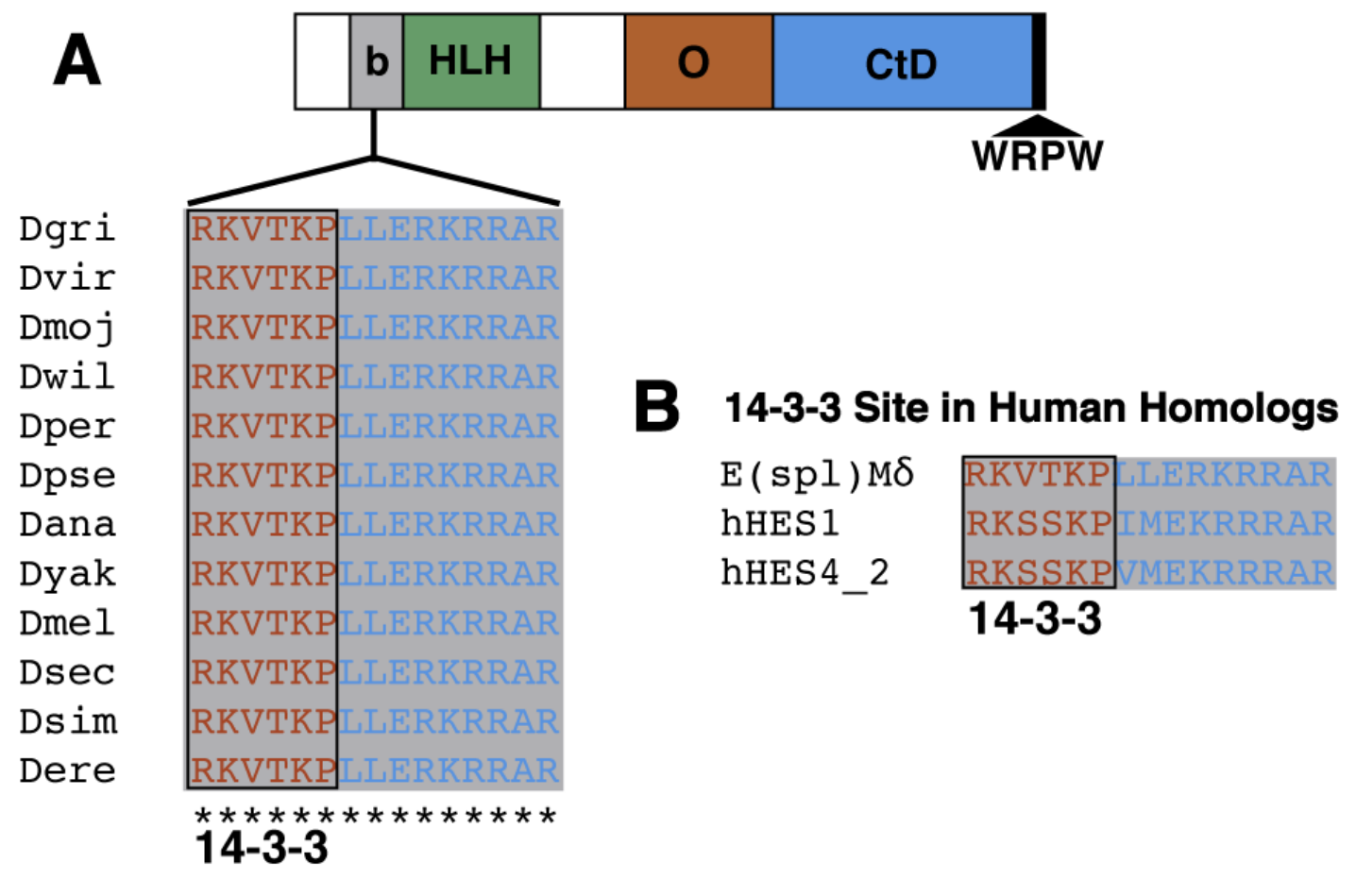

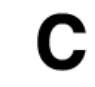

hHES 4 _ 1

hHES 4_2

\section{hHES4 Splice Variants}

\section{4-3-3}

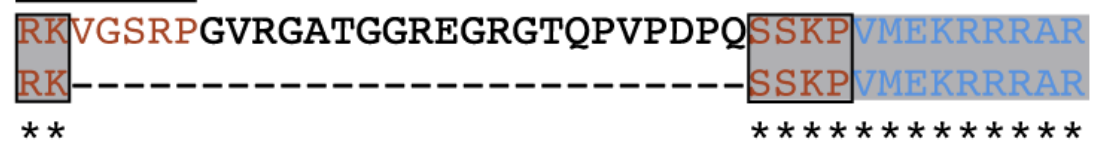

Figure 2: (A) The basic domain is a highly conserved region of the $E(\mathrm{spl})$ repressors (see Fig. 3, Ch. 1). However, within the basic domain of $\mathrm{E}(\mathrm{spl}) \mathrm{M} \delta$, a unique 14-3-3 binding motif is present. The sequence 'R-K-V-T-K-P' fits the Mode-1 binding consensus. This site is highly conserved not only among orthologs of the melanogaster group, but also higher vertebrates. (B) When comparing the sequences of $\mathrm{E}(\mathrm{spl}) \mathrm{M} \delta$ to the human homologs hHES1 and hHES4 isoform 2, it is striking that the 14-3-3 site has been conserved. (C) hHES4 isoform 1 contains an insertion located within the 14-3-3 binding site. Interestingly, this insertion maintains a 14-3-3 Mode-2 site of its own. Drosophila melanogaster (Dmel), $D$. willistoni (Dwil), D. pseudoobscura (Dpse), D. ananassae (Dana), D. yakuba (Dyak), D. sechellia (Dsec), D. simulans (Dsim), D. erecta (Dere), D. grimshawi (Dgri), D. mojavensis (Dmoj), D. virilis (Dvir). 


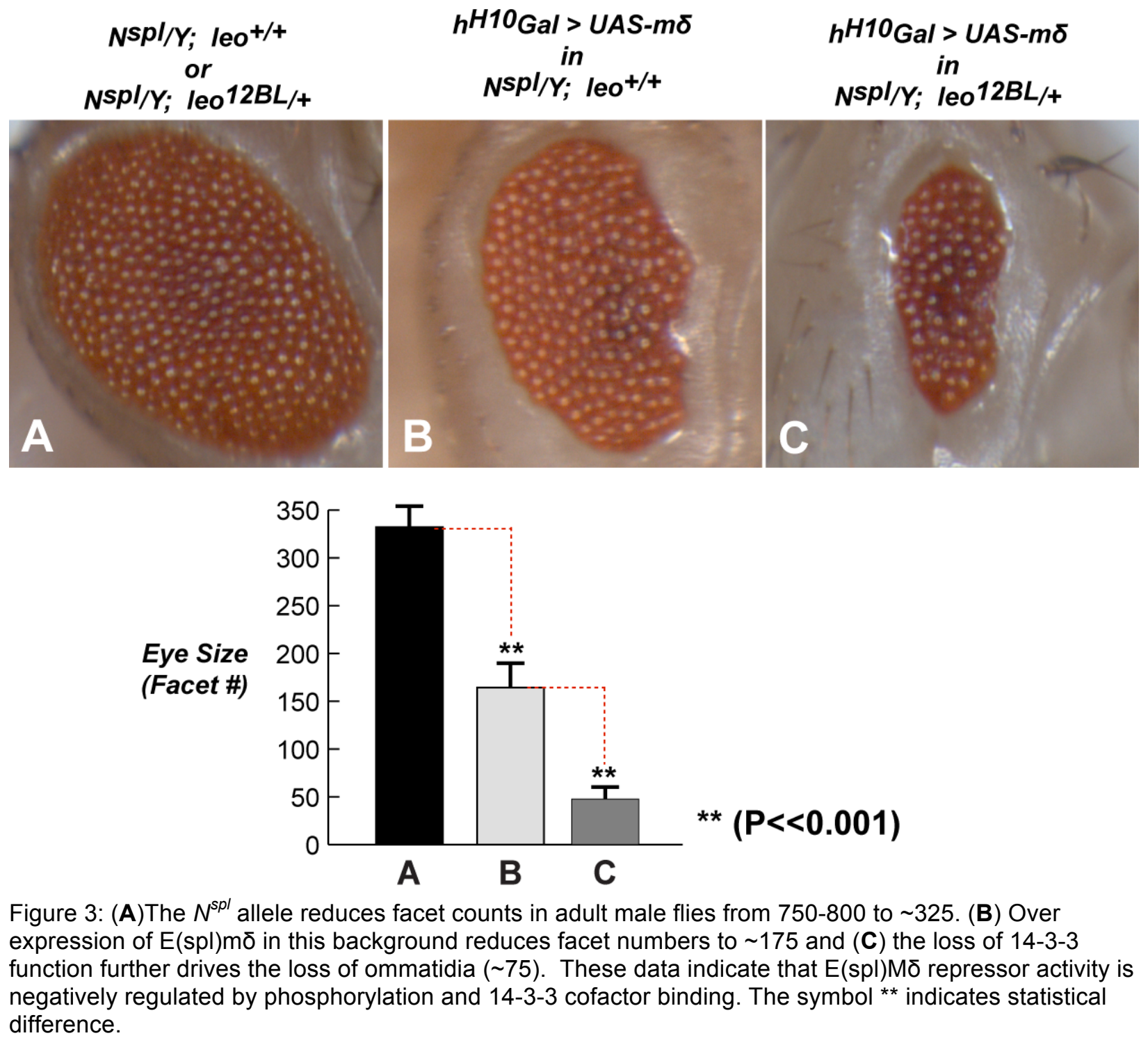




\section{REFERENCES CITED}

Aberle, H., Bauer, A., Stappert, J., Kispert, A. and Kemler, R. (1997) 'beta-catenin is a target for the ubiquitin-proteasome pathway', EMBO J 16(13): 3797-804.

Aitken, A. (1995) '14-3-3 proteins on the MAP', Trends Biochem Sci 20(3): 95-7.

Aitken, A. (2006) '14-3-3 proteins: a historic overview', Semin Cancer Biol 16(3): 16272.

Akten, B., Jauch, E., Genova, G. K., Kim, E. Y., Edery, I., Raabe, T. and Jackson, F. R. (2003) 'A role for CK2 in the Drosophila circadian oscillator', Nat Neurosci 6(3): 251-7.

Artavanis-Tsakonas, S. and Muskavitch, M. A. (2010) 'Notch: the past, the present, and the future', Curr Top Dev Biol 92: 1-29.

Artavanis-Tsakonas, S., Rand, M. D. and Lake, R. J. (1999) 'Notch signaling: cell fate control and signal integration in development', Science 284(5415): 770-6.

Bailey, A. M. and Posakony, J. W. (1995) 'Suppressor of hairless directly activates transcription of enhancer of split complex genes in response to Notch receptor activity', Genes Dev 9(21): 2609-22.

Baker, N. E., Yu, S. and Han, D. (1996) 'Evolution of proneural atonal expression during distinct regulatory phases in the developing Drosophila eye', Curr Biol 6(10): 1290-301.

Baonza, A. and Freeman, M. (2001) 'Notch signalling and the initiation of neural development in the Drosophila eye', Development 128(20): 3889-98.

Baonza, A. and Garcia-Bellido, A. (1999) 'Dual role of extramacrochaetae in cell proliferation and cell differentiation during wing morphogenesis in Drosophila', Mech Dev 80(2): 133-46.

Barolo, S., Stone, T., Bang, A. G. and Posakony, J. W. (2002) 'Default repression and Notch signaling: Hairless acts as an adaptor to recruit the corepressors Groucho and dCtBP to Suppressor of Hairless', Genes Dev 16(15): 1964-76.

Beals, C. R., Sheridan, C. M., Turck, C. W., Gardner, P. and Crabtree, G. R. (1997) 'Nuclear export of NF-ATc enhanced by glycogen synthase kinase-3', Science 275(5308): 1930-4.

Belanger-Jasmin, S., Llamosas, E., Tang, Y., Joachim, K., Osiceanu, A. M., Jhas, S. and Stifani, S. (2007) 'Inhibition of cortical astrocyte differentiation by Hes6 requires amino- and carboxy-terminal motifs important for dimerization and phosphorylation', $J$ Neurochem 103(5): 2022-34. 
Bhattacharya, A. and Baker, N. E. (2009) 'The HLH protein Extramacrochaetae is required for R7 cell and cone cell fates in the Drosophila eye', Dev Biol 327(2): 288-300.

Bidwai, A. P., Hanna, D. E. and Glover, C. V. C. (1992) 'The free catalytic subunit of casein kinase II is not toxic in vivo.', J Biol Chem 267: 18790-18796.

Bidwai, A. P., Reed, J. C. and Glover, C. V. C. (1994) 'Casein kinase II of Saccharomyces cerevisiae contains two distinct regulatory subunits, beta and beta'.', Arch Biochem Biophys 309(2): 348-355.

Bierhoff, H., Dundr, M., Michels, A. A. and Grummt, I. (2008) 'Phosphorylation by casein kinase 2 facilitates rRNA gene transcription by promoting dissociation of TIF-IA from elongating RNA polymerase I', Mol Cell Biol 28(16): 4988-98.

Blaydes, J. P. and Hupp, T. R. (1998) 'DNA damage triggers DRB-resistant phosphorylation of human p53 at the CK2 site', Oncogene 17(8): 1045-52.

Bose, A., Kahali, B., Zhang, S., Lin, J.-M., Allada, R., Karandikar, U. and Bidwai, A. (2006) 'Drosophila CK2 regulates lateral-inhibition during eye and bristle development', Mech Dev 123: 649-664.

Botas, J., Moscoso del Prado, J. and Garcia-Bellido, A. (1982) 'Gene-dose titration analysis in the search of trans-regulatory genes in Drosophila', EMBO J 1(3): 307-10.

Bray, S. (1998) 'A notch affair', Cell 93: 499-503.

Bray, S. and Bernard, F. (2010) 'Notch targets and their regulation', Curr Top Dev Biol 92: 253-75.

Bray, S. J. (2006) 'Notch signalling: a simple pathway becomes complex', Nat Rev Mol Cell Biol 7(9): 678-89.

Brown, N. L., Sattler, C. A., Paddock, S. W. and Carroll, S. B. (1995) 'Hairy and emc negatively regulate morphogenetic furrow progression in the Drosophila eye', Cell 80(6): 879-87.

Buchou, T., Vernet, M., Blond, O., Jensen, H. H., Pointu, H., Olsen, B. B., Cochet, C., Issinger, O. G. and Boldyreff, B. (2003) 'Disruption of the regulatory beta subunit of protein kinase CK2 in mice leads to a cell-autonomous defect and early embryonic lethality', Mol Cell Biol 23(3): 908-15.

Burnett, G. and Kennedy, E. P. (1954) 'The enzymatic phosphorylation of proteins', J Biol Chem 211(2): 969-80.

Bustos, D. M. and Iglesias, A. A. (2006) 'Intrinsic disorder is a key characteristic in partners that bind 14-3-3 proteins', Proteins 63(1): 35-42. 
Cagan, R. L. and Ready, D. F. (1989) 'The emergence of order in the Drosophila pupal retina', Dev Biol 136(2): 346-362.

Calleja, M., Renaud, O., Usui, K., Pistillo, D., Morata, G. and Simpson, P. (2002) 'How to pattern an epithelium: lessons from achaete-scute regulation on the notum of Drosophila', Gene 292(1-2): 1-12.

Canton, D. A. and Litchfield, D. W. (2006) 'The shape of things to come: an emerging role for protein kinase CK2 in the regulation of cell morphology and the cytoskeleton', Cell Signal 18(3): 267-75.

Cave, J. W., Loh, F., Surpris, J. W., Xia, L. and Caudy, M. A. (2005) 'A DNA transcription code for cell-specific gene activation by notch signaling', Curr Biol 15(2): 94-104.

Cheyette, B. N., Green, P. J., Martin, K., Garren, H., Hartenstein, V. and Zipursky, S. L. (1994) 'The Drosophila sine oculis locus encodes a homeodomain-containing protein required for the development of the entire visual system', Neuron 12(5): 977-96.

Chiu, J. C., Vanselow, J. T., Kramer, A. and Edery, I. (2008) 'The phospho-occupancy of an atypical SLIMB-binding site on PERIOD that is phosphorylated by DOUBLETIME controls the pace of the clock', Genes Dev 22(13): 1758-72.

Christensen, K. L., Patrick, A. N., McCoy, E. L. and Ford, H. L. (2008) 'The six family of homeobox genes in development and cancer', Adv Cancer Res 101: 93-126.

Cochet, C. and Chambaz, E. M. (1983) 'Oligomeric structure and catalytic activity of G type casein kinase. Isolation of the two subunits and renaturation experiments', J Biol Chem 258(3): 1403-6.

Coffman, C., Harris, W. and Kintner, C. (1990) 'Xotch, the Xenopus homolog of Drosophila notch', Science 249(4975): 1438-41.

Cohen, M., Georgiou, M., Stevenson, N. L., Miodownik, M. and Baum, B. (2010) 'Dynamic filopodia transmit intermittent $\Delta$-Notch signaling to drive pattern refinement during lateral inhibition', Dev Cell 19(1): 78-89.

Colombo, M., Mirandola, L., Platonova, N., Apicella, L., Basile, A., Figueroa, A. J., Cobos, E., Chiriva-Internati, M. and Chiaramonte, R. (2013) 'Notch-directed microenvironment reprogramming in myeloma: a single path to multiple outcomes', Leukemia 27(5): 1009-18.

Cooper, M. T., Tyler, D. M., Furriols, M., Chalkiadaki, A., Delidakis, C. and Bray, S. (2000) 'Spatially restricted factors cooperate with notch in the regulation of Enhancer of split genes', Dev Biol 221(2): 390-403.

Cox, M. L. and Meek, D. W. (2010) 'Phosphorylation of serine 392 in p53 is a common and integral event during p53 induction by diverse stimuli', Cell Signal 22(3): 564-71. 
Cross, D. A., Alessi, D. R., Cohen, P., Andjelkovich, M. and Hemmings, B. A. (1995) 'Inhibition of glycogen synthase kinase-3 by insulin mediated by protein kinase B', Nature 378(6559): 785-9.

Cubas, P., Modolell, J. and Ruiz-Gomez, M. (1994) 'The helix-loop-helix extramacrochaetae protein is required for proper specification of many cell types in the Drosophila embryo', Development 120(9): 2555-66.

Dahmus, G. K., Glover, C. V., Brutlag, D. L. and Dahmus, M. E. (1984) 'Similarities in structure and function of calf thymus and Drosophila casein kinase II', J Biol Chem 259(14): 9001-6.

Darling, D. L., Yingling, J. and Wynshaw-Boris, A. (2005) 'Role of 14-3-3 proteins in eukaryotic signaling and development', Curr Top Dev Biol 68: 281-315.

Dawson, S. R., Turner, D. L., Weintraub, H. and Parkhurst, S. M. (1995) 'Specificity for the hairy/enhancer of split basic helix-loop-helix (bHLH) proteins maps outside the bHLH domain and suggests two separable modes of transcriptional repression', Mol Cell Biol 15(12): 6923-31.

Delidakis, C. and Artavanis-Tsakonas, S. (1991) 'The enhancer of split [E(spl)] locus of Drosophila encodes seven independant helix-loop-helix proteins.', Proc Natl Acad Sci U S A 89: 8731-8735.

Delidakis, C., Preiss, A., Hartley, D. A. and Artavanis-Tsakonas, S. (1991) 'Two genetically and molecularly distinct functions involved in early neurogenesis reside within the Enhancer of split locus of Drosophila melanogaster', Genetics 129(3): 803-23.

Delprado, J. M. and Garciabellido, A. (1984) 'Genetic-Regulation of the Achaete-Scute Complex of Drosophila-Melanogaster', Wilhelm Rouxs Archives of Developmental Biology 193(4): 242-245.

DePaoli-Roach, A. A. (1984) 'Synergistic phosphorylation and activation of ATP-Mgdependent phosphoprotein phosphatase by FA/GSK-3 and casein kinase II.', J Biol Chem 259: 12144-12152.

Dominguez, I., Degano, I. R., Chea, K., Cha, J., Toselli, P. and Seldin, D. C. (2011) 'CK2alpha is essential for embryonic morphogenesis', Mol Cell Biochem 356(1-2): 20916.

Dotan, I., Ziv, E., Dafni, N., Beckman, J. S., McCann, R. O., Glover, C. V. and Canaani, D. (2001) 'Functional conservation between the human, nematode, and yeast CK2 cell cycle genes', Biochem Biophys Res Commun 288(3): 603-9.

Dougherty, M. K. and Morrison, D. K. (2004) 'Unlocking the code of 14-3-3', J Cell Sci 117(Pt 10): 1875-84. 
Duvall, L. B. and Taghert, P. H. (2011) 'Circadian rhythms: biological clocks work in phospho-time', Curr Biol 21(9): R305-7.

Ellis, H. M., Spann, D. R. and Posakony, J. W. (1990) 'extramacrochaetae, a negative regulator of sensory organ development in Drosophila, defines a new class of helixloop-helix proteins', Cell 61(1): 27-38.

Espinosa, L., Ingles-Esteve, J., Aguilera, C. and Bigas, A. (2003) 'Phosphorylation by glycogen synthase kinase-3 beta down-regulates Notch activity, a link for Notch and Wnt pathways', J Biol Chem 278(34): 32227-35.

Faust, R. A., Tawfic, S., Davis, A. T., Bubash, L. A. and Ahmed, K. (2000) 'Antisense oligonucleotides against protein kinase CK2-alpha inhibit growth of squamous cell carcinoma of the head and neck in vitro', Head Neck 22(4): 341-6.

Foltz, D. R., Santiago, M. C., Berechid, B. E. and Nye, J. S. (2002) 'Glycogen synthase kinase-3beta modulates notch signaling and stability', Curr Biol 12(12): 1006-11.

Ford, H. L., Landesman-Bollag, E., Dacwag, C. S., Stukenberg, P. T., Pardee, A. B. and Seldin, D. C. (2000) 'Cell cycle-regulated phosphorylation of the human SIX1 homeodomain protein', J Biol Chem 275(29): 22245-54.

Forrest, A. and Gabrielli, B. (2001) 'Cdc25B activity is regulated by 14-3-3', Oncogene 20(32): 4393-401.

Fu, H., Subramanian, R. R. and Masters, S. C. (2000) '14-3-3 proteins: structure, function, and regulation', Annu Rev Pharmacol Toxicol 40: 617-47.

Fu, H., Xia, K., Pallas, D. C., Cui, C., Conroy, K., Narsimhan, R. P., Mamon, H., Collier, R. J. and Roberts, T. M. (1994) 'Interaction of the protein kinase Raf-1 with 14-3-3 proteins', Science 266(5182): 126-9.

Garrell, J. and Campuzano, S. (1991) 'The helix-loop-helix domain; A common motif for bristles, muscles and sex.', Bioessays 13: 493-497.

Garrell, J. and Modolell, J. (1990) 'The Drosophila extramacrochaetae locus, an antagonist of proneural genes that, like these genes, encodes a helix-loop-helix protein', Cell 61(1): 39-48.

Garside, V. C., Chang, A. C., Karsan, A. and Hoodless, P. A. (2013) 'Co-ordinating Notch, BMP, and TGF-beta signaling during heart valve development', Cell Mol Life Sci 70(16): 2899-917.

Ghysen, A. and Richelle, J. (1979) 'Determination of sensory bristles and pattern formation in Drosophila. II. The achaete-scute locus', Dev Biol 70(2): 438-452. 
Giebel, B. and Campos-Ortega, J. A. (1997) 'Functional dissection of the Drosophila enhancer of split protein, a suppressor of neurogenesis', Proc Natl Acad Sci U S A 94(12): 6250-4.

Gigliani, F., Longo, F., Gaddini, L. and Battaglia, P. A. (1996) 'Interactions among the bHLH domains of the proteins encoded by the Enhancer of split and achaete-scute gene complexes of Drosophila', Mol Gen Genet 251(6): 628-34.

Giot, L., Bader, J. S., Brouwer, C., Chaudhuri, A., Kuang, B., Li, Y., Hao, Y. L., Ooi, C. E., Godwin, B., Vitols, E. et al. (2003) 'A protein interaction map of Drosophila melanogaster', Science 302(5651): 1727-1736.

Glover, C. V., 3rd (1998) 'On the physiological role of casein kinase II in Saccharomyces cerevisiae', Prog Nucleic Acid Res Mol Biol 59: 95-133.

Glover, C. V., Shelton, E. R. and Brutlag, D. L. (1983) 'Purification and characterization of a type II casein kinase from Drosophila melanogaster', J Biol Chem 258(5): 3258-65.

Glover, C. V. C., Bidwai, A. P. and Reed, J. C. (1994) 'Structure and function of Saccharomyces cerevisiae casein kinase II.', Cell Mol Biol Res 5/6: 481-488.

Gomez-Skarmeta, J. L., Campuzano, S. and Modolell, J. (2003) 'Half a century of neural prepatterning: the story of a few bristles and many genes', Nat Rev Neurosci 4(7): 58798.

Gratton, M.-O., Torban, E., Jasmin, S. B., Theriault, F. M., German, M. S. and Stifani, S. (2003) 'Hes6 Promotes Cortical Neurogenesis and Inhibits Hes1 Transcription Repression Activity by Multiple Mechanisms', Mol Cell Biol 23(19): 6922-6935.

Greenwald, I. and Rubin, G. M. (1992) 'Making a difference: the role of cell-cell interactions in establishing separate identities for equivalent cells', Cell 68(2): 271-81.

Greenwald, I. S., Sternberg, P. W. and Horvitz, H. R. (1983) 'The lin-12 locus specifies cell fates in Caenorhabditis elegans', Cell 34(2): 435-44.

Gridley, T. (2003) 'Notch signaling and inherited disease syndromes', Hum Mol Genet 12(1): R9-13.

Guindon, S., Dufayard, J. F., Lefort, V., Anisimova, M., Hordijk, W. and Gascuel, O. (2010) 'New algorithms and methods to estimate maximum-likelihood phylogenies: assessing the performance of PhyML 3.0', Syst Biol 59(3): 307-21.

Guruharsha, K. G., Obar, R. A., Mintseris, J., Aishwarya, K., Krishnan, R. T., Vijayraghavan, K. and Artavanis-Tsakonas, S. (2012) 'Drosophila Protein interaction Map (DPiM): A paradigm for metazoan protein complex interactions', Fly (Austin) 6(4): 246-53. 
Guruharsha, K. G., Rual, J. F., Zhai, B., Mintseris, J., Vaidya, P., Vaidya, N., Beekman, C., Wong, C., Rhee, D. Y., Cenaj, O. et al. (2011) 'A protein complex network of Drosophila melanogaster', Cell 147(3): 690-703.

Hanna, D. E., Rethinaswamy, A. and Glover, C. V. C. (1995) 'Casein kinase II is required for cell cycle progression during $\mathrm{G} 1$ and G2/M in Saccharomyces cerevisiae.', J Biol Chem 270: 25905-25914.

Hathaway, G. M. and Traugh, J. A. (1979) 'Cyclic Nucleotide-independant Protein Kinase from Rabbit Reticulocytes. Purification of Casein Kinases.', J Biol Chem 254(3): 762-768.

Hazbun, T. R., Stahura, F. L. and Mossing, M. C. (1997) 'Site-specific recognition by an isolated DNA-binding domain of the sine oculis protein', Biochemistry 36(12): 3680-6.

Healy, S., Khan, D. H. and Davie, J. R. (2011) 'Gene expression regulation through 143-3 interactions with histones and HDACs', Discov Med 11(59): 349-58.

Heberlein, U., Singh, C. M., Luk, A. Y. and Donohoe, T. J. (1995) 'Growth and differentiation in the Drosophila eye coordinated by hedgehog', Nature 373(6516): 70911.

Henriksson, M. L., Francis, M. S., Peden, A., Aili, M., Stefansson, K., Palmer, R., Aitken, A. and Hallberg, B. (2002) 'A nonphosphorylated 14-3-3 binding motif on exoenzyme $S$ that is functional in vivo', Eur J Biochem 269(20): 4921-9.

Hirata, H., Yoshiura, S., Ohtsuka, T., Bessho, Y., Harada, T., Yoshikawa, K. and Kageyama, R. (2002) 'Oscillatory expression of the bHLH factor Hes1 regulated by a negative feedback loop', Science 298(5594): 840-3.

Housden, B. E., Fu, A. Q., Krejci, A., Bernard, F., Fischer, B., Tavare, S., Russell, S. and Bray, S. J. (2013) 'Transcriptional dynamics elicited by a short pulse of notch activation involves feed-forward regulation by $\mathrm{E}(\mathrm{spl}) /$ Hes genes', PLoS Genet 9(1): e1003162.

Hu, S., Mamedova, A. and Hegde, R. S. (2008) 'DNA-binding and regulation mechanisms of the SIX family of retinal determination proteins', Biochemistry 47(11): 3586-94.

Huang, Z., Chattoraj, A., Li, X., Snyder, S. H. and Borjigin, J. (2009) 'The increased degradation of NAT-H28Y mutant protein is due to a reduced interaction with 14-3-3', $J$ Pineal Res 46(1): 119-20.

Hubaud, A. and Pourquie, O. (2013) 'Making the clock tick: right time, right pace', Dev Cell 24(2): 115-6.

Hur, E. M. and Zhou, F. Q. (2010) 'GSK3 signalling in neural development', Nat Rev Neurosci 11(8): 539-51. 
Jaffe, L., Ryoo, H. D. and Mann, R. S. (1997) 'A role for phosphorylation by casein kinase II in modulating Antennapedia activity in Drosophila', Genes Dev 11(10): 132740.

Jarman, A., Sun, Y., Jan, L. and Jan, Y. (1995) 'Role of the proneural gene, atonal, in formation of Drosophila chordotonal organs and photoreceptors', Develop 121(7): 20192030.

Jarman, A. P., Grell, E. H., Ackerman, L., Jan, L. Y. and Jan, Y. N. (1994) 'Atonal is the proneural gene for Drosophila photoreceptors', Nature 369(6479): 398-400.

Jimenez, G. and Ish-Horowicz, D. (1997) 'A chimeric enhancer-of-split transcriptional activator drives neural development and achaete-scute expression', Mol Cell Biol 17(8): 4355-62.

Jusiak, B., Abulimiti, A., Haelterman, N., Chen, R. and Mardon, G. (2012) 'MAPK target sites of eyes absent are not required for eye development or survival in Drosophila', PLoS One 7(12): e50776.

Kahali, B., Kim, J. E., Karandikar, U., Bishop, C. P. and Bidwai, A. P. (2010) 'Evidence that the C-terminal domain (CtD) autoinhibits neural repression by Drosophila E(spl)M8', Genesis 48(1): 44-55.

Karandikar, U. C., Trott, R. L., Yin, J., Bishop, C. P. and Bidwai, A. P. (2004) 'Drosophila CK2 regulates eye morphogenesis via phosphorylation of E(spl)M8', Mech Dev 121(3): 273-86.

Kenyon, K. L., Yang-Zhou, D., Cai, C. Q., Tran, S., Clouser, C., Decene, G., Ranade, S. and Pignoni, F. (2005) 'Partner specificity is essential for proper function of the SIX-type homeodomain proteins Sine oculis and Optix during fly eye development', Dev Biol 286(1): 158-68.

Klambt, C., Knust, E., Tietze, K. and Campos-Ortega, J. A. (1989) 'Closely related transcripts encoded by the neurogenic gene complex Enhancer of split of Drosophila melanogaster.', EMBO J 8: 203-210.

Knust, E., Bremer, K. A., Vassin, H., Ziemer, A., Tepass, U. and Campos-Ortega, J. A. (1987) 'The enhancer of split locus and neurogenesis in Drosophila melanogaster', Dev Biol 122(1): 262-73.

Knust, E., Schrons, H., Grawe, F. and Campos-Ortega, J. A. (1992) 'Seven genes of the Enhancer of split complex of Drosophila melanogaster encode helix-loop-helix proteins', Genetics 132(2): 505-18.

Kockel, L., Vorbruggen, G., Jackle, H., Mlodzik, M. and Bohmann, D. (1997) 'Requirement for Drosophila 14-3-3 zeta in Raf-dependent photoreceptor development', Genes Dev 11(9): 1140-7. 
Krejci, A. and Bray, S. (2007) 'Notch activation stimulates transient and selective binding of $\mathrm{Su}(\mathrm{H}) / \mathrm{CSL}$ to target enhancers', Genes Dev 21(11): 1322-7.

Kuenzel, E. A. and Krebs, E. G. (1985) 'A synthetic substrate specific for casein kinase II.', Proc Natl Acad Sci U S A 82: 737-741.

Kuenzel, E. A., Mulligan, J. A., Sommercorn, J. and Krebs, E. G. (1987) 'Substrate specificity determinants for casein kinase II as deduced from studies with synthetic peptides', J Biol Chem 262(19): 9136-40.

Kumar, J. P. (2009a) 'The molecular circuitry governing retinal determination', Biochim Biophys Acta 1789(4): 306-14.

Kumar, J. P. (2009b) 'The sine oculis homeobox (SIX) family of transcription factors as regulators of development and disease', Cell Mol Life Sci 66(4): 565-83.

Kunisch, M., Haenlin, M. and Campos-Ortega, J. A. (1994) 'Lateral inhibition mediated by the Drosophila neurogenic gene $\delta$ is enhanced by proneural proteins', Proc Natl Acad Sci U S A 91(21): 10139-43.

Kunttas-Tatli, E., Bose, A., Kahali, B., Bishop, C. P. and Bidwai, A. P. (2009) 'Functional dissection of Timekeeper (Tik) implicates opposite roles for CK2 and PP2A during Drosophila neurogenesis', Genesis 47(10): 647-58.

Lai, E. C. (2004) 'Notch signaling: control of cell communication and cell fate', Development 131(5): 965-73.

Levine, A. J. (1997) 'p53, the cellular gatekeeper for growth and division.', Cell 88: 323331.

Li, J. G., Chen, C., Huang, P., Wang, Y. and Liu-Chen, L. Y. (2012) '14-3-3zeta Protein regulates anterograde transport of the human kappa-opioid receptor (hKOPR)', J Biol Chem 287(45): 37778-92.

Li, Y. and Baker, N. E. (2001) 'Proneural enhancement by Notch overcomes Suppressor-of-Hairless repressor function in the developing Drosophila eye', Curr Biol 11(5): 330-8.

Lieber, T., Kidd, S., Alcamo, E., Corbin, V. and Young, M. W. (1993) 'Antineurogenic phenotypes induced by truncated Notch proteins indicate a role in signal transduction and may point to a novel function for Notch in nuclei', Genes Dev 7(10): 1949-65.

Ligoxygakis, P., Yu, S. Y., Delidakis, C. and Baker, N. E. (1998) 'A subset of Notch functions during Drosophila eye development require $\mathrm{Su}(\mathrm{H})$ and $\mathrm{E}(\mathrm{spl})$ gene complex.', Develop 125: 2893-2900. 
Lin, J. M., Kilman, V. L., Keegan, K., Paddock, B., Emery-Le, M., Rosbash, M. and Allada, R. (2002) 'A role for casein kinase 2alpha in the Drosophila circadian clock', Nature 420(6917): 816-20.

Liu, Y., Nandi, S., Martel, A., Antoun, A., loshikhes, I. and Blais, A. (2012) 'Discovery, optimization and validation of an optimal DNA-binding sequence for the Six1 homeodomain transcription factor', Nucleic Acids Res 40(17): 8227-39.

Lou, D. Y., Dominguez, I., Toselli, P., Landesman-Bollag, E., O'Brien, C. and Seldin, D. C. (2008) 'The alpha catalytic subunit of protein kinase CK2 is required for mouse embryonic development', Mol Cell Biol 28(1): 131-9.

Louvi, A. and Artavanis-Tsakonas, S. (2006) 'Notch signalling in vertebrate neural development', Nat Rev Neurosci 7(2): 93-102.

Lyden, D., Young, A. Z., Zagzag, D., Yan, W., Gerald, W., O'Reilly, R., Bader, B. L., Hynes, R. O., Zhuang, Y., Manova, K. et al. (1999) 'Id1 and Id3 are required for neurogenesis, angiogenesis and vascularization of tumour xenografts', Nature 401(6754): 670-7.

Maier, D., Marte, B. M., Schafer, W., Yu, Y. and Preiss, A. (1993) 'Drosophila evolution challenges postulated redundancy in the E(spl) gene complex', Proc Natl Acad Sci U S A 90(12): 5464-8.

Mayya, V., Lundgren, D. H., Hwang, S. I., Rezaul, K., Wu, L., Eng, J. K., Rodionov, V. and Han, D. K. (2009) 'Quantitative phosphoproteomic analysis of T cell receptor signaling reveals system-wide modulation of protein-protein interactions', Sci Signal 2(84): ra46.

McCright, B., Lozier, J. and Gridley, T. (2002) 'A mouse model of Alagille syndrome: Notch2 as a genetic modifier of Jag1 haploinsufficiency', Development 129(4): 1075-82.

Meek, D. W. and Cox, M. (2011) 'Induction and activation of the p53 pathway: a role for the protein kinase CK2?', Mol Cell Biochem 356(1-2): 133-8.

Meggio, F. and Pinna, L. A. (2003) 'One-thousand-and-one substrates of protein kinase CK2?', FASEB J 17(3): 349-68.

Meier, U. T. and Blobel, G. (1992) 'Nopp 140 shuttles on tracks between nucleolus and cytoplasm', Cell 70: 127-138.

Menet, J. S. and Rosbash, M. (2011) 'A new twist on clock protein phosphorylation: A conformational change leads to protein degradation', Mol Cell 43: 695-697.

Milan, M. and Cohen, S. M. (2010) 'Notch signaling: filopodia dynamics confer robustness', Curr Biol 20(18): R802-4. 
Miyata, Y. (2009) 'Protein kinase CK2 in health and disease: CK2: the kinase controlling the Hsp90 chaperone machinery', Cell Mol Life Sci 66(11-12): 1840-9.

Moore, B. W., Perez, V. J. and Penaramo.A (1967) 'Preparation of 3 New Soluble Acidic Proteins from Brain', Federation Proceedings 26(2): 675-\&.

Morgan, T. H. (1916) A Critique of the Theory of Evolution, Princeton, NJ: Princeton University Press.

Mumm, J. S. and Kopan, R. (2000) 'Notch signaling: from the outside in', Dev Biol 228(2): 151-65.

Muskavitch, M. A. (1994) ' $\Delta$-notch signaling and Drosophila cell fate choice', Dev Biol 166(2): 415-30.

Nagel, A. C. and Preiss, A. (1999) 'Notch spl is deficient for inductive processes in the eye, and $\mathrm{E}(\mathrm{spl}) \mathrm{D}$ enhances split by interfering with proneural activity.', Dev Biol 208: 406-415.

Nagel, A. C., Yu, Y. and Preiss, A. (1999) 'Enhancer of split [E(spl)(D)] is a groindependent, hypermorphic mutation in Drosophila', Dev Genet 25(2): 168-79.

Nakao, K. and Campos-Ortega, J. A. (1996) 'Persistent expression of genes of the enhancer of split complex suppresses neural development in Drosophila', Neuron 16(2): 275-86.

Neal, J. W. and Clipstone, N. A. (2001) 'Glycogen synthase kinase-3 inhibits the DNA binding activity of NFATc', J Biol Chem 276(5): 3666-73.

Niefind, K., Guerra, B., Ermakowa, I. and Issinger, O. G. (2001) 'Crystal structure of human protein kinase CK2: insights into basic properties of the CK2 holoenzyme', EMBO J 20(19): 5320-31.

Nuthall, H. N., Joachim, K. and Stifani, S. (2004) 'Phosphorylation of serine 239 of Groucho/TLE1 by protein kinase CK2 is important for inhibition of neuronal differentiation', Mol Cell Biol 24(19): 8395-407.

Oellers, N., Dehio, M. and Knust, E. (1994) 'bHLH proteins encoded by the Enhancer of split complex of Drosophila negatively interfere with transcriptional activation mediated by proneural genes', Mol Gen Genet 244(5): 465-73.

Okochi, M., Steiner, H., Fukumori, A., Tanii, H., Tomita, T., Tanaka, T., Iwatsubo, T., Kudo, T., Takeda, M. and Haass, C. (2002) 'Presenilins mediate a dual intramembranous gamma-secretase cleavage of Notch-1', EMBO J 21(20): 5408-16.

Padmanabha, R., Chen-Wu, J. L. P., Hanna, D. E. and Glover, C. V. C. (1990) 'Isolation, sequencing, and disruption of the yeast CKA2 gene: casein kinase II is essential for viability in Saccharomyces cerevisiae.', Mol Cell Biol 10: 4089-4099. 
Padmanabha, R. and Glover, C. V. C. (1987) 'Casein kinase II of yeast contains two distinct a polypeptides and an unusually large b subunit', J Biol Chem 262: 1829-1835.

Pan, D. and Rubin, G. M. (1997) 'Kuzbanian controls proteolytic processing of Notch and mediates lateral inhibition during Drosophila and vertebrate neurogenesis', Cell 90(2): 271-80.

Paroush, Z., Finley, R. L., Jr., Kidd, T., Wainwright, S. M., Ingham, P. W., Brent, R. and Ish-Horowicz, D. (1994) 'Groucho is required for Drosophila neurogenesis, segmentation, and sex determination and interacts directly with hairy-related bHLH proteins', Cell 79(5): 805-15.

Patrick, A. N., Cabrera, J. H., Smith, A. L., Chen, X. S., Ford, H. L. and Zhao, R. (2013) 'Structure-function analyses of the human SIX1-EYA2 complex reveal insights into metastasis and BOR syndrome', Nat Struct Mol Biol 20(4): 447-53.

Patrick, A. N., Schiemann, B. J., Yang, K., Zhao, R. and Ford, H. L. (2009) 'Biochemical and functional characterization of six SIX1 Branchio-oto-renal syndrome mutations', $J$ Biol Chem 284(31): 20781-90.

Pauli, T., Seimiya, M., Blanco, J. and Gehring, W. J. (2005) 'Identification of functional sine oculis motifs in the autoregulatory element of its own gene, in the eyeless enhancer and in the signalling gene hedgehog', Development 132(12): 2771-82.

Peng, C. Y., Graves, P. R., Thoma, R. S., Wu, Z., Shaw, A. S. and Piwnica-Worms, H. (1997) 'Mitotic and G2 checkpoint control: regulation of 14-3-3 protein binding by phosphorylation of Cdc25C on serine-216', Science 277(5331): 1501-5.

Petcherski, A. G. and Kimble, J. (2000) 'Mastermind is a putative activator for Notch', Curr Biol 10(13): R471-3.

Piao, S., Lee, S. H., Kim, H., Yum, S., Stamos, J. L., Xu, Y., Lee, S. J., Lee, J., Oh, S., Han, J. K. et al. (2008) 'Direct inhibition of GSK3beta by the phosphorylated cytoplasmic domain of LRP6 in Wnt/beta-catenin signaling', PLoS One 3(12): e4046.

Ponce, D. P., Maturana, J. L., Cabello, P., Yefi, R., Niechi, I., Silva, E., Armisen, R., Galindo, M., Antonelli, M. and Tapia, J. C. (2011) 'Phosphorylation of AKT/PKB by CK2 is necessary for the AKT-dependent up-regulation of beta-catenin transcriptional activity', J Cell Physiol 226(7): 1953-9.

Poulson, D. F. (1937) 'Chromosomal Deficiencies and the Embryonic Development of Drosophila Melanogaster', Proc Natl Acad Sci U S A 23(3): 133-7.

Poulson, D. F. (1940) 'The effect of certain X-chromosome deficiencies on the embryonic development of Drosophila melanogaster', J. Exp. Zool. 83: 271-325. 
Preiss, A., Hartley, D. A. and Artavanis-Tsakonas, S. (1988) 'The molecular genetics of Enhancer of split, a gene required for embryonic neural development in Drosophila', EMBO J 7(12): 3917-27.

Querfurth, C., Diemfellner, A. C. R., Gin, E., Malzahn, E., Hofer, T. and Brunner, M. (2011) 'Circadian conformational change of the Neurospora clock protein FREQUENCY triggered by clustered hyperphosphorylation of a basic domain', Mol Cell 43: 713-722.

Ready, D. F., Hanson, T. E. and Benzer, S. (1976) 'Development of the Drosophila retina, a neurocrystalline lattice', Dev Biol 53(2): 217-40.

Rebay, I., Fleming, R. J., Fehon, R. G., Cherbas, L., Cherbas, P. and ArtavanisTsakonas, S. (1991) 'Specific EGF repeats of Notch mediate interactions with $\Delta$ and Serrate: implications for Notch as a multifunctional receptor', Cell 67(4): 687-99.

Ren, F., Zhang, L. and Jiang, J. (2010) 'Hippo signaling regulates Yorkie nuclear localization and activity through 14-3-3 dependent and independent mechanisms', Dev Biol 337(2): 303-12.

Rethinaswamy, A., Birnbaum, M. J. and Glover, C. V. C. (1998) 'Temperature-sensitive mutations of the CKA1 gene reveal a role for casein kinase II in maintenance of cell polarity in Saccharomyces cerevisiae.', J Biol Chem 273: 5869-5877.

Roach, P. J. (1991) 'Multisite and hierarchal protein phosphorylation', J Biol Chem 266(22): 14139-42.

Roignant, J. Y. and Treisman, J. E. (2009) 'Pattern formation in the Drosophila eye disc', Int J Dev Biol 53(5-6): 795-804.

Romani, S., Campuzano, S. and Modolell, J. (1987) 'The achaete-scute complex is expressed in neurogenic regions of Drosophila embryos', EMBO J 6(7): 2085-92.

Roy, A., Kucukural, A. and Zhang, Y. (2010) 'I-TASSER: a unified platform for automated protein structure and function prediction', Nat Protoc 5(4): 725-38.

Scaglioni, P. P., Yung, T. M., Cai, L. F., Erdjument-Bromage, H., Kaufman, A. J., Singh, B., Teruya-Feldstein, J., Tempst, P. and Pandolfi, P. P. (2006) 'A CK2-dependent mechanism for degradation of the PML tumor suppressor', Cell 126(2): 269-83.

Schroeter, E. H., Kisslinger, J. A. and Kopan, R. (1998) 'Notch-1 signalling requires ligand-induced proteolytic release of intracellular domain', Nature 393(6683): 382-6.

Schrons, H., Knust, E. and Campos-Ortega, J. A. (1992) 'The enhancer of split complex and adjacent genes in the $96 \mathrm{~F}$ region of Drosophila melanogaster are required for segregation of neural and epidermal cells.', Genetics 132: 481-503. 
Schweisguth, F., Gho, M. and Lecourtois, M. (1996) 'Control of cell fate choices by lateral signaling in the adult peripheral nervous system of Drosophila melanogaster', Dev Genet 18(1): 28-39.

Serikaku, M. A. and O'Tousa, J. E. (1994) 'sine oculis is a homeobox gene required for Drosophila visual system development', Genetics 138(4): 1137-50.

Simpson, P. (1990) 'Lateral inhibition and the development of the sensory bristles of the adult peripheral nervous system of Drosophila', Development 109(3): 509-19.

Simpson, P. and Marcellini, S. (2006) 'The origin and evolution of stereotyped patterns of macrochaetes on the nota of cyclorraphous Diptera', Heredity 97(3): 148-56.

Simpson, P., Woehl, R. and Usui, K. (1999) 'The development and evolution of bristle patterns in Diptera', Develop 126(7): 1349-1364.

Snell, V. and Nurse, P. (1994) 'Genetic analysis of cell morphogenesis in fission yeast-a role for casein kinase II in the establishment of polarized growth.', EMBO J 13: 20662074.

Song, D. H., Dominguez, I., Mizuno, J., Kaut, M., Mohr, S. C. and Seldin, D. C. (2003) 'CK2 phosphorylation of the armadillo repeat region of beta-catenin potentiates Wnt signaling', J Biol Chem 278(26): 24018-25.

Sparrow, D. B., Sillence, D., Wouters, M. A., Turnpenny, P. D. and Dunwoodie, S. L. (2010) 'Two novel missense mutations in HAIRY-AND-ENHANCER-OF-SPLIT-7 in a family with spondylocostal dysostosis', Eur J Hum Genet 18(6): 674-9.

Spratford, C. M. and Kumar, J. P. (2013) 'Extramacrochaetae imposes order on the Drosophila eye by refining the activity of the Hedgehog signaling gradient', Development 140(9): 1994-2004.

Strom, A., Castella, P., Rockwood, J., Wagner, J. and Caudy, M. (1997) 'Mediation of NGF signaling by post-translational inhibition of HES-1, a basic helix-loop-helix repressor of neuronal differentiation', Genes Dev 11(23): 3168-81.

Sutherland, C. (2011) 'What Are the bona fide GSK3 Substrates?', Int J Alzheimers Dis 2011: 505607.

Taghli-Lamallem, O., Hsia, C., Ronshaugen, M. and McGinnis, W. (2008) 'Contextdependent regulation of Hox protein functions by CK2 phosphorylation sites', Dev Genes Evol 218(6): 321-32.

Tietze, K., Oellers, N. and Knust, E. (1992) 'Enhancer of splitD, a dominant mutation of Drosophila, and its use in the study of functional domains of a helix-loop-helix protein', Proc Natl Acad Sci U S A 89(13): 6152-6. 
Torres, J. and Pulido, R. (2001) 'The tumor suppressor PTEN is phosphorylated by the protein kinase CK2 at its $C$ terminus. Implications for PTEN stability to proteasomemediated degradation', J Biol Chem 276(2): 993-8.

Tran, I. T., Sandy, A. R., Carulli, A. J., Ebens, C., Chung, J., Shan, G. T., Radojcic, V., Friedman, A., Gridley, T., Shelton, A. et al. (2013) 'Blockade of individual Notch ligands and receptors controls graft-versus-host disease', J Clin Invest 123(4): 1590-604.

Trott, R. L., Kalive, M., Karandikar, U., Rummer, R., Bishop, C. P. and Bidwai, A. P. (2001a) 'Identification and characterization of proteins that interact with Drosophila melanogaster protein kinase CK2', Mol Cell Biochem 227(1-2): 91-8.

Trott, R. L., Kalive, M., Paroush, Z. and Bidwai, A. P. (2001b) 'Drosophila melanogaster casein kinase II interacts with and phosphorylates the basic-helix-loop-helix (bHLH) proteins $\mathrm{m} 5, \mathrm{~m} 7$, and $\mathrm{m} 8$ derived from the Enhancer of split complex.', J Biol Chem 276: 2159-2167.

Tuxworth, R. I., Vivancos, V., O'Hare, M. B. and Tear, G. (2009) 'Interactions between the juvenile Batten disease gene, CLN3, and the Notch and JNK signalling pathways', Hum Mol Genet 18(4): 667-78.

Tzivion, G., Luo, Z. and Avruch, J. (1998) 'A dimeric 14-3-3 protein is an essential cofactor for Raf kinase activity', Nature 394(6688): 88-92.

Uyttendaele, H., Marazzi, G., Wu, G., Yan, Q., Sassoon, D. and Kitajewski, J. (1996) 'Notch4/int-3, a mammary proto-oncogene, is an endothelial cell-specific mammalian Notch gene', Development 122(7): 2251-9.

Van Doren, M., Bailey, A. M., Esnayra, J., Ede, K. and Posakony, J. W. (1994) 'Negative regulation of proneural gene activity: hairy is a direct transcriptional repressor of achaete', Genes Dev 8(22): 2729-42.

Van Doren, M., Ellis, H. M. and Posakony, J. W. (1991) 'The Drosophila extramacrochaetae protein antagonizes sequence-specific DNA binding by daughterless/achaete-scute protein complexes', Development 113(1): 245-55.

Voas, M. G. and Rebay, I. (2004) 'Signal integration during development: insights from the Drosophila eye', Dev Dyn 229(1): 162-75.

Waterman, M. J., Stavridi, E. S., Waterman, J. L. and Halazonetis, T. D. (1998) 'ATMdependent activation of p53 involves dephosphorylation and association with 14-3-3 proteins', Nat Genet 19(2): 175-8.

Welshons, W. J. (1965) 'Analysis of a gene in drosophila', Science 150(3700): 1122-9.

White, N. and Jarman, A. (2000) 'Drosophila atonal controls photoreceptor R8-specific properties and modulates both receptor tyrosine kinase and Hedgehog signalling', Develop 127(8): 1681-1689. 
Wilker, E. W., Grant, R. A., Artim, S. C. and Yaffe, M. B. (2005) 'A structural basis for 14-3-3sigma functional specificity', J Biol Chem 280(19): 18891-8.

Wolff, T. and Ready, D. (1991a) 'The beginning of pattern formation in the Drosophila compound eye: the morphogenetic furrow and the second mitotic wave', Develop 113(3): 841-850.

Wolff, T. and Ready, D. (1991b) 'Cell death in normal and rough eye mutants of Drosophila', Develop 113(3): 825-839.

Woodgett, J. R. and Cohen, P. (1984) 'Multisite phosphorylation of glycogen synthase. Molecular basis for the substrate specificity of glycogen synthase kinase- 3 and casein kinase-Il (glycogen synthase kinase-5)', Biochim Biophys Acta 788(3): 339-47.

Xu, P. X. (2013) 'The EYA-SO/SIX complex in development and disease', Pediatr Nephrol 28(6): 843-54.

Yaffe, M. B. (2002) 'How do 14-3-3 proteins work?-- Gatekeeper phosphorylation and the molecular anvil hypothesis', FEBS Lett 513(1): 53-7.

Yaffe, M. B., Rittinger, K., Volinia, S., Caron, P. R., Aitken, A., Leffers, H., Gamblin, S. J., Smerdon, S. J. and Cantley, L. C. (1997) 'The structural basis for 14-33:phosphopeptide binding specificity', Cell 91(7): 961-71.

Younger-Shepherd, S., Vaessin, H., Bier, E., Jan, L. Y. and Jan, Y. N. (1992) 'deadpan, an essential pan-neural gene encoding an HLH protein, acts as a denominator in Drosophila sex determination', Cell 70(6): 911-22.

Yu, M., Guo, H. X., Hui, C., Wang, X. H., Li, C. Y., Zhan, Y. Q., Ge, C. H. and Yang, X. M. (2013) '14-3-3zeta interacts with hepatocyte nuclear factor 1 alpha and enhances its DNA binding and transcriptional activation', Biochim Biophys Acta.

Zha, J., Harada, H., Yang, E., Jockel, J. and Korsmeyer, S. J. (1996) 'Serine phosphorylation of death agonist $B A D$ in response to survival factor results in binding to 14-3-3 not BCL-X(L)', Cell 87(4): 619-28.

Zhang, T., Ranade, S., Cai, C. Q., Clouser, C. and Pignoni, F. (2006) 'Direct control of neurogenesis by selector factors in the fly eye: regulation of atonal by Ey and So', Development 133(24): 4881-9.

Zhang, Y. (2008) 'I-TASSER server for protein 3D structure prediction', BMC Bioinformatics 9: 40.

Zhao, J., Meyerkord, C. L., Du, Y., Khuri, F. R. and Fu, H. (2011) '14-3-3 proteins as potential therapeutic targets', Semin Cell Dev Biol 22(7): 705-12. 
Zheng, Y., Qin, H., Frank, S. J., Deng, L., Litchfield, D. W., Tefferi, A., Pardanani, A., Lin, F. T., Li, J., Sha, B. et al. (2011) 'A CK2-dependent mechanism for activation of the JAK-STAT signaling pathway', Blood 118(1): 156-66.

Ziemer, A., Tietze, K., Knust, E. and Campos-Ortega, J. A. (1988) 'Genetic analysis of enhancer of split, a locus involved in neurogenesis in Drosophila melanogaster', Genetics 119(1): 63-74. 